\title{
Experiences of continuity and discontinuity in student teachers' development
}

Martine Maria van Rijswijk 



\section{Experiences of continuity and discontinuity in student teachers' development}

Martine Maria van Rijswijk 
"With your feet on the air and your head on the ground

Try this trick and spin it, yeah

Your head will collapse if there's nothing in it

And you'll ask yourself

Where is my mind?"

Pixies/Black Francis - Where is my mind

ISBN 978-90-393-7266-1

Printing: Ridderkerk

Design: Leonie Sijtsma, Serendipity ontwerp, Utrecht

@2020 Martine Maria van Rijswijk

All rights reserved. No parts of the publication may be reproduced, stored in a retrieval system, or transmitted in any other form or by any other means, mechanically, by photocopy, by recording, or otherwise, without permission from the author. 


\section{Experiences of continuity and discontinuity in student teachers' development}

ERVARINGEN VAN CONTINUÏTEIT EN DISCONTINUÏTEIT IN DE ONTWIKKELING VAN STUDENTEN IN DE LERARENOPLEIDING

(met een samenvatting in het Nederlands)

\section{Proefschrift}

ter verkrijging van de graad van doctor aan de Universiteit Utrecht op gezag van derector magnificus, prof.dr. H.R.B.M. Kummeling,

ingevolge het besluit van het college voor promoties

in het openbaar te verdedigen op

vrijdag 17 april 2020 des middags te 2.30 uur

door

Martine Maria van Rijswijk

geboren op 4 juni 1972

te Utrecht 


\section{Promotoren:}

Prof. dr. J.W.F. Van Tartwijk

Prof. dr. S.F. Akkerman

\section{Copromotor:}

Dr. L.H. Bronkhorst 


\section{Table of Contents}

\section{Chapter 1}

Introduction

\section{Chapter 2}

Past Perceptions and Future Expectations: Sensed (Dis)Continuity at the Start of Teacher Education .

\section{Chapter 3}

Changes in Sensed (Dis)Continuity in the Development of Student Teachers throughout Teacher Education .

\section{Chapter 4}

Teacher Educators and Student Teachers Discussing Discontinuity in Development

\section{Chapter 5}

Teacher Educators Indicating that Change is Critical to Student Teachers

\section{Chapter 6}

Conclusion and Discussion

References

Nederlandse Samenvatting

Curriculum Vitae

Publications

Dankwoord

Appendix 1 Perceptions of the past and expectations of the future in student teachers' sense-making about development as a teacher 


\section{CHAPTER 1}

\section{Introduction}

To have to deal with 25 teenagers hour after hour... Well, with most of them I can manage. But there are those pupils who are really not enthusiastic and such. I can't get anywhere with them. I also just cannot imagine it; I was not like that myself. I was an annoyingly good pupil all the time. So, I felt less and less comfortable with teaching. And I thought, if I don't get anything in return even when they do enjoy it. Then I thought, no, I should stop doing this and try something else before I finish my studies.

Lionel, exit interview after quitting teacher education
You know, I have been a tutor and giving exam training since 2009. In my exam training classes, I had groups of nine pupils max. I stopped doing that some time ago, but I continued being a tutor. And I teach two of my friends French. [...] And they are really excited. And then I think: "well, I really have it in me, I can get the message across. People are really happy if I help them. A girl, she is in vmbo now, she has really low grades for all subjects except French. I am really proud of that. That is something I can do. [...]

But there is also a lot of frustration: why can't I just work my way through it? Finish it [teacher education]. Yeah, I don't know why, but I just couldn't do it. It was too much. The water was up to my lips as I mentioned earlier. [My teaching] seems to be fine. But sometimes the feeling isn't there at all. And for me, that is really frustrating.

Doris, exit interview after quitting teacher education

In student teachers' development, doubts seem to be unavoidable. The doubts that student teachers Lionel and Doris expressed during an exit interview after they decided to quit teacher education are not uncommon. They reflect why learning to become a teacher has been documented as a challenging and strenuous process for student teachers (Alsup, 2006; Beauchamp \& Thomas, 2009; Pillen, Beijaard, at den Brok, 2013). When student teachers experience their development as challenging and strenuous, this can have serious consequences, such as student teachers giving 
up on teacher education or deciding not to enter the teaching profession after successfully graduating (Beijaard, Meijer \& Verloop, 2004; Cole \& Knowles, 1993). This not only is problematic for the student teachers themselves, but also urgent because of the increasing quantitative and qualitative teacher shortages around the world (Ingersoll a Strong, 2011; Inspectie van het Onderwijs [Inspectorate of Education of the Netherlands], 2019; Wang, Hall It Rahimi, 2015). Consequently, research focusing on student teachers' reflections on themselves as teachers is gaining attention, in addition to research describing what student teachers should know and be able to do as teachers (Darling-Hammond it Bransford, 2007).

In the last decades, challenging experiences of student teachers in their development has been a topic of research (e.g., Akkerman a Meijer, 2011; Alsup, 2006; Rodgers a Scott, 2008). Yet, in order to be able to support individual student teachers, this line of research needs to be extended in terms of conceptualization and design (Beijaard i Meijer, 2017; Rodgers \& Scott, 2008). Current research is either biographical, portraying a few purposefully selected cases (Alsup, 2006), or overly generic in nature, providing insufficient information about differences among student teachers (Pillen et al., 2013). Also, research is predominantly based on retrospective reflections of student teachers who successfully graduated teacher education. This dissertation comprises four studies to analyze the developmental processes of individual student teachers, and support thereof, during teacher education - irrespective of whether they graduate or not. Findings of these studies can be used for supporting student teachers who have doubts about development as a teacher, ultimately aiming to prevent student teachers from quitting prematurely, misguidedly deciding not to enter the profession, and/or experiencing a demotivating practice shock in the first years of teaching (Koetsier at Wubbels, 1995; Stokking, Leenders, de Jong đt van Tartwijk, 2003).

\section{Student Teachers' Reflections on Themselves as Teachers}

Based on research on teacher education, teacher development, identity development and professional development in different domains (Akkerman \& Meier, 2011; Beauchamp it Thomas, 2009; Beijaard A Meijer, 2017; Ezzy, 1998; Hermans, 2002; Rodgers a Scott, 2008), we characterize the process of reflecting on one's development as a teacher as idiosyncratic: unique because of personal perceptions of the past and expectations of the future. It can also be characterized as dynamic and dialogical since new experiences in teacher education elicit new reflections, which shed a new light on one's self as a teacher. We also characterize the process of reflecting on one's development as a teacher as charged (not neutral): reflections have a genuine impact on what a person thought he/she knew about him/herself - a process that can be confrontational and disarming. Teacher educators are expected to support student teachers while they reflect on their development as teachers, even though it is not evident what this support entails (Beauchamp, 2015).

To do justice to the characteristics of the process of reflecting on development as a teacher and the context of the teacher education in which this process takes place, we use the following conceptual framework in this dissertation: 
- The reflections concern student teachers' perceptions and expectations about one's self as a teacher; these are conceptualized as self-attributes considered relevant for the profession. In line with Super and colleagues (1963), we refer to the idiosyncratic constellation of self-attributes as the vocational self-concept.

- The process of reflecting on development as a teacher is conceived as a process of sense-making in this thesis. Sense-making is narrative and dialogical in nature and can be triggered by experiences in teacher education (Ezzy, 1998; Hermans, 2002). Yet, sensemaking in relation to one's vocational self-concept already starts the moment a person

Lionel: "So I thought, if I don't get anything in return even when they enjoy it. Then I thought, no, ..." [sense-making] begins to consider a career as a teacher (Konstam, 2015; Savickas, 1997; Super, 1980), with student teachers actively and iteratively giving meaning to new experiences that provide information about the current and imagined self as teacher (Kelchtermans, 2005; Korthagen, 2005; Rodgers a Scott, 2008).

- The process of sense-making may result in an experience of continuity and/or discontinuity: a sense of consistency or inconsistency in the current or to-be-developed attributes that are relevant to the profession (cf. Akkerman $\mathrm{At}$ Meijer, 2011; Alsup, 2006; Beijaard a Meijer, 2017). In general, experiences of continuity contribute to well-being and the ability to persevere during development (Caspi $q$ Moffit, 1991; Ibarra \& Barbalescu, 2010). Experiences of discontinuity are often perceived negatively because of risks of decreasing self-confidence and frustration.

- Experiences of discontinuity seem inevitable in the process of sense-making as student teachers make first steps and have new experiences as professional teachers. Discontinuity can be desirable as a trigger for learning (Akkerman at

Doris: "People are really happy if I help them. (...) I am really proud of that. That is something I can do" [Experience of continuity]

Doris: "But there is also a lot of frustration: why can't I just work my way through it? Finish it. Yeah, I don't know why, but I just couldn't do it."

[Experience of discontinuity] Bakker, 2011), but also risky because of the potential negative results such as student teacher losing self-confidence and leaving the profession hastily and/or ill-advised.

- The process of sense-making is likely to be influenced by teacher educators since reflections, including student teachers' sense of self, their past and their future expectations, are discussed in supervision conversations. Also, the input of the students and the teacher educators in supervision conversations is not a one-way communication, isolated or independent of each other, but perceptions of the past and expectations of the future are discussed and changed in relation to the input of the other by anticipating and responding (Lyra, 1999). 
With this thesis we aim to characterize student teachers' development in terms of continuity and discontinuity in and over time and to understand how discontinuity can have a function in the developmental progress of student teachers throughout teacher education.

\section{Context}

The four studies in this dissertation were carried out in a one-year post-master's teacher education program in the Netherlands'. Earlier, Korthagen and colleagues (Brouwer a Korthagen, 2005; Korthagen et al., 2001) used "realistic teacher education" to characterize the curriculum of this particular teacher education program. This means that the curriculum of the program takes into account the concerns that student teachers generally have when learning from experiences in practice and aims to help them address these concerns by connecting the concerns to theory. The program is located at a research university in the Netherlands. At a national level, this and similar teacher education programs are stimulated to respond to increasing teacher shortages by adapting the curriculum in such a way that it is more suitable for lifelong learning and by creating flexible trajectories that cater to the needs of different types of student teachers.

In this teacher education program, teacher educators teach subject related and general pedagogical courses and stimulate student teachers to reflect on their (teaching) experiences, using theory. Teacher educators also supervise student teachers individually. Teacher educators organize, also on request of the student teachers, several supervision conversations during the teacher education program. At least twice a year there is a formal meeting about the so-called practice dossier, a portfolio in which student teachers show the level of their professional performance by including documents, videos, evaluations and reflections (Van Tartwijk, Van Rijswijk, Tuithof $\mathrm{at}$ Driessen, 2008).

Student teachers in this teacher education program have a bachelor's degree and most of them also have a master's degree, related to the subject in which they plan to teach (e.g., history, French). Student teachers will obtain a subject matter-specific teaching license, which allows them to teach at all levels of secondary education in the Netherlands.

To be able to characterize student teachers' development, also over time, we collected authentic data sources and additional instruments using a longitudinal design. Figure 1 presents a schematic overview of the data sources collected in the teacher education program. We collected:

Teacher profiles, i.e., reflections of student teachers about the question "Who do you think you are as a teacher?" written at the start of teacher education

\footnotetext{
1 Student teachers can also complete the program in two years when they study part-time, for instance because they combine studying with a paid job in teaching or when they participate in one of the Education and Communication Master programs, in which subject specific courses in the domain of teaching and learning of school subject (the domain of these master programs) are combined with courses with a focus on preparing students for teaching the subject as teachers.
} 
Audio-taped supervision conversations, i.e., authentic conversations between student teacher and teacher educator throughout the educational course

Interviews with six selected teacher educators about student teacher development and supervision approaches.

These data allowed us to focus on student teacher development, independent of whether, how and when student teachers completed teacher education (Leonard-Barton, 1992), amending for the effect of hindsight bias (Roese at Vohs, 2012).

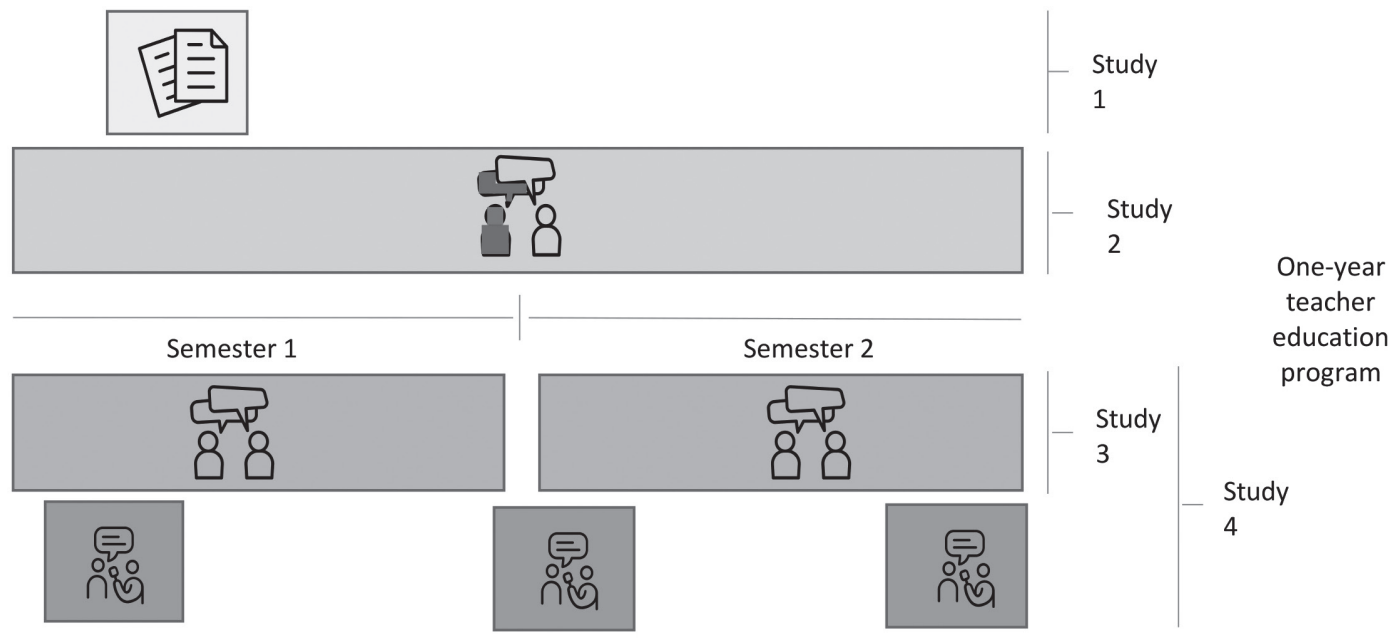

Figure 1. Schematic overview of the data ${ }^{2}$

\section{Structure of the Dissertation}

This dissertation includes four studies that build on each other. Table 1 provides an overview of the four studies.

In the first study, which we describe in Chapter 2, we investigated to what extent feelings of in/consistency in development as a teacher occur in different student teachers while they are in teacher education. Acknowledging the idiosyncrasy of student teachers, we explore differences in student teachers' expectations and perceptions as they enter teacher education. We analyze 35 narrated self-concepts of student teachers, so-called teacher profiles, to answer the research

2 Illustration credits: documents by Alice Design, conversation by Pauseo8 and interview by Yu luck, all from the Noun Project (https://thenounproject.com) 
question: How do reported self-concepts of student teachers at the start of teacher education differ between student teachers in terms of their expressed attributes, their perceptions of the past and the future and their sense of (dis)continuity?

In the second study, reported in Chapter 3, we describe if and how the initial identification with the profession changes throughout teacher education, and search for clues for (un)successful developmental progress throughout teacher education. We focus on changes in the extent to which student teachers perceive and expect (dis)continuity in their development during their program and study 25 authentic supervision conversations of six selected student teachers, enabling the analysis of development within and across six student teachers' developmental trajectories. The research question is: When and with what type of past perceptions and future expectations does the initial sensed (dis)continuity of student teachers change during teacher education?

In the next two chapters, we include the teacher educator explicitly as a significant contributor to the dialogical process of reflecting on him-/herself as a teacher during teacher education. In the third study, described in Chapter 4, we look into the paradox of addressing experiences of discontinuity: it seems productive to analyze problems in order to explore possibilities for development as a teacher, but this is also risky because of the potential negative consequences for the progress of the development (e.g., when doubts result in decreasing self-confidence). We focus on how student teachers and teacher educators discuss experiences of discontinuity in supervision conversations such that ongoing development is enabled. We analyze 110 sequences from 42 authentic supervision conversations evenly distributed over time and type: (1) meetings in the first and second semester of the study program and (2) both formal and informal (not related to a practice dossier) for answering the research question: How do student teachers and teacher educators introduce and explore discontinuity in development as a teacher during supervision conversations in a post-master teacher education program?

The third study showed that teacher educators, next to supporting student teachers in dealing with discontinuity, sometimes also indicate that change is critical to student teachers by raising questions in supervision conversations about student teachers' performance or development not mentioned by the student teacher themselves, potentially evoking experiences of discontinuity. As a follow up of this finding the fourth study, described in Chapter 5, explores teacher educators' considerations for doing so, despite the potential discomfort for both the student teachers and teacher educators involved. We analyze 42 audio-taped supervision conversations between six teacher educators and their 31 student teachers as well as eighteen interviews with these six teacher educators to answer the research question: Why and when, and how do teacher educators indicate that change is critical to student teachers in supervision conversations in a one-year, post-master teacher education program? 


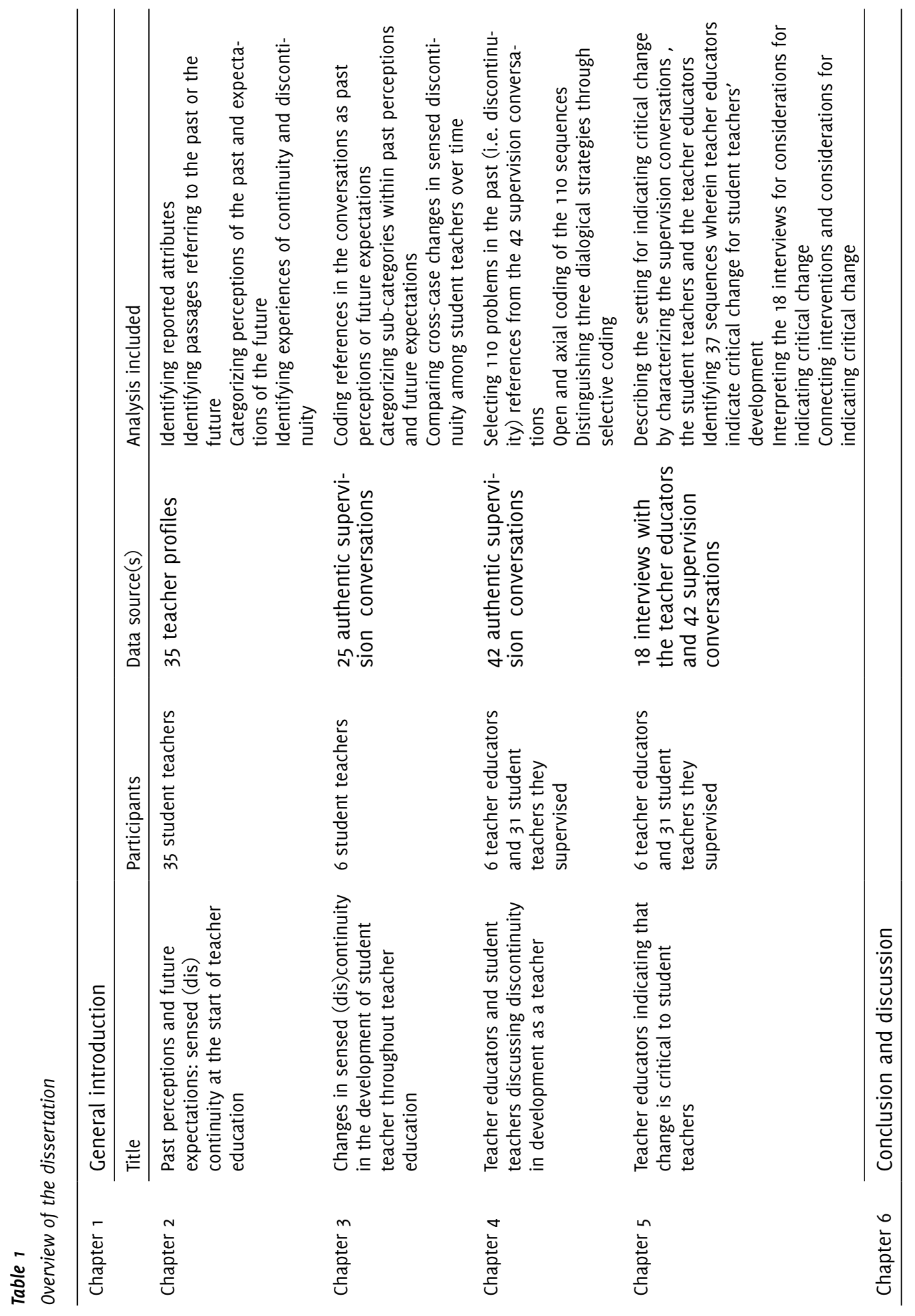




\title{
CHAPTER 2
}

\section{Past Perceptions and Future Expectations: Sensed (Dis)Continuity at the Start of Teacher Education 3,4}

\begin{abstract}
Because of pressing issues such as teacher attrition, we explored differences in student teachers' expectations and perceptions as they entered teacher education. Thirty-five narrated self-concepts of student teachers in a post-graduate teacher education program were studied. From these we identified four types of past perceptions and four types of future expectations. Combinations of perceptions and expectations were found to be illustrative of three types of sensed (dis)continuity in student teachers. The findings assemble into a framework that can be beneficial for researchers and teacher educators in diagnosing (dis)continuities in the self-concept and consequent expectations about further development as a teacher.
\end{abstract}

3 This chapter has been published as: van Rijswijk, M., Akkerman, S. F., Schaap, H., \& van Tartwijk, J. (2016). Past perceptions and future expectations: Sensed (dis)continuity at the start of teacher education. Teaching and Teacher Education, 58, 99-108.

4 Acknowledgement of author contributions: MR, SA, HS and JT designed the study, MR recruited participants and collected the data, MR and HS developed the instrument, MR analyzed the data, MR drafted the manuscript, all authors contributed to critical revisions of the paper, SA and JV supervised the study. 


\section{INTRODUCTION}

Learning to become a teacher is often reported as a challenging and strenuous process (e.g., Alsup, 2006; Akkerman a Meijer, 2011; Beauchamp it Thomas, 2009), amongst other things because it includes dealing with tensions or "competing demands within their teaching" (Freeman, 1993, p. 488). If student teachers fail to deal with such tensions, for instance when they have to be strict although they feel this does not match their personality, it has been found that they are more likely to leave teacher education or not enter the teaching profession (Beijaard, Meijer, a Verloop, 2004; Cole at Knowles, 1993; Pillen, Beijaard it den Brok, 2013). As qualitative and quantitative teacher shortages are a major problem in many countries around the world (Ingersoll a Strong, 2011; Unesco, 2013; Wang, Hall, at Rahimi, 2015), expanding the knowledge of how to support student teachers for entering and persisting in teaching is needed.

Research in this area so far has focused predominantly on typical tensions and coping strategies, common consequences for teachers and general suggestions for support in teacher education. Tensions have, for instance, been conceptualized as concerns (Fuller, 1969), dilemmas (Fransson A Grannäs, 2013), and professional identity tensions (Pillen et al., 2013). Others have found that tensions in teacher development pertain to both personal and professional aspects (cf. Akkerman it Meijer, 2011). From research on resilience in teachers, many researchers have concluded that teacher education should support student teachers in developing effective coping strategies needed to deal with challenges (Beltman, Mansfield, A Price, 2011; Johnson et al., 2014). Conway, and others, suggested that teacher education practice should include attention to anticipation, reflection, and learning opportunities that can arise from experiencing some form of crisis (Conway, 2001; Hammerness et al., 2005; Kelchtermans, 2009; Korthagen, Kessels, Koster, Lagerwerf, ct Wubbels, 2001; Meijer, 2011).

The extent to which labels such as "challenging" and "strenuous" apply to all student teachers alike is yet unclear. Pillen et al. (2013) suggested that not all student teachers come across, and suffer from, challenging experiences equally. In this study we will investigate how student teachers identify with the profession when they enter teacher education, including their perceptions of prior experiences and expectations of themselves as teachers. We will study student teachers who enter a one-year, post-graduate teacher education program, in which they start teaching in a school immediately after an introduction week at the university for about $50 \%$ of the available time in the program. Accordingly, student teachers experience what it means to be a teacher in practice already at the beginning of teacher education program and are potentially confronted with tensions right away. Our focus is on the start of the teacher education program, as research on transitions in education and career has shown that the transition into a professional role evokes heightened reflexivity in individuals, which is aimed at solving conflicting ideas about oneself in light of the transitional goal (Ecclestone, Biesta, at Hughes, 2009; Webb at Warren, 2009). In line with research on career development we acknowledge that each student teacher enters teacher education with at least some ideas about him/herself as a teacher, as one starts to identify with 
a profession the moment one starts to think about this career option (Konstam, 2015; Savickas, 1997; Super, 1980).

In the following sections, we turn to adjacent domains such as psychology, neuropsychology and sociology in order to clarify why and how the construction of a self-concept as a teacher is considered essential for teacher development. We also elaborate on the narrative nature of sense-making and address the concepts of continuity and discontinuity.

\section{THEORETICAL FRAMEWORK}

\section{The Self-Concept}

The unique way of being and acting of each individual is believed to be strongly influenced by his or her sense of self (Kira \& Balkin, 2014; Leary A Tangney, 2003). Researchers from domains varying from psychology and career development to neuroscience recognize the notion of self as an important topic. Klein and Gangi (2010) stated, "Each of us has the experience of a unitary self, an ' $\mathrm{l}$ ' that remembers, chooses, thinks, plans and feels" (p. 1). Mead (1934) introduced the notion of self as a mechanism that directs every individual's actions. Rodgers and Scott (2008), in the Handbook of research on teacher education, considered the self to subsume teacher identity. In line with this, Beauchamp and Thomas (2009) stressed that identity, although related to the personal dimension of the self, is also often viewed from the perspective of the profession.

The individuals' concept of his- or herself has been identified as one of the most significant regulators of behavior (Markus \& Wurf, 1987). Psychologists commonly define this self-concept as a sense of who one is, including personality characteristics (Markus \& Wurf, 1987; Slotter \& Gardner, 2014). Such attributes, or distinguishing qualities, can pertain to dispositional traits ("I am enthusiastic and creative") and to perceptions about oneself stemming from interactions and relationships with others ("I am a colleague one can depend on").

In the domain of career research, the Self-Concept Theory developed by Donald Super has been central in considering career development as a process of successively refining and applying one's self-concept to the domain of work (Super, Starishevsky, Matlin, at Jordaan, 1963). Super introduced the vocational self-concept and defined it as "[t]he constellation of self-attributes considered by the individual to be vocationally relevant" (Super et al., 1963, p. 20).

A person considers what is relevant to the self-concept by means of sense-making. Hermans (2002) referred to sense-making as an inner dialogue in which people negotiate what is characteristic for themselves. Ezzy (1998) conceptualized it as an ongoing internal and reflective narrative. In research on teacher development, several authors have argued that teachers make sense of who they are as teachers through actively and iteratively giving meaning to experiences that provide information about the self (Kelchtermans, 2005; Korthagen, 2005; Rodgers it Scott, 2008). The process of sense-making as a teacher starts the moment a person considers a career as a teacher 
(Konstam, 2015; Savickas, 1997; Super, 1980). Each student teacher thus enters teacher education with at least a tentative self-concept as a teacher.

\section{Perceptions of the Past and Expectations of the Future}

An exploration into the nature of sense-making should include development in and over time because perceptions of the past and expectations of the future determine the course of sensemaking (Bruner, 1990; Habermas at Bluck, 2000; Polkinghorne, 1996; Zittoun et al., 2013). Neurological research supports this, showing how memory and imagination are essential for decision making, behavior and one's sense of self (Buckner it Carroll, 2007).

By selecting appropriated past events people make sense of themselves in the present (Greenwald A Pratkanis, 1984; McAdams, 1993; McLean it Pasupathi, 2011). In other words, people consider what is relevant to the self-concept in a narrative process of continuous revision, relying on perceptions of past experiences and on past self-concepts (McLean, Pasupathi, at Pals, 2007).

Likewise, the forecast about what may happen in the future, realistically or hopefully, will influence an individual's sense-making process (Bruner, 1990; Polkinghorne, 1996). Making sense of oneself is always connected to what can eventually happen (Poli, 2010) or what is considered a possibility (d'Argembeau, Lardi, a Van der Linden, 2012). In the theory on Possible Selves, Markus and Nurius (1986) elaborated on this future-oriented aspect, accentuating the fact that ideas about the future, both positive (the self one would very much like to become) and negative (the self one fears to become), influence sense-making narratives in the present.

Researchers focusing on the attitudes of (beginning) teachers have recognized the influence of the past and the expected future on becoming a teacher (e.g., Cole a Knowles, 1993; Conway, 2001; Hamman et al., 2013). Studies on the "apprenticeship of observation" (Lortie, 1975), pre-conceptions (Wubbels, 1992) and beliefs (Mansfield at Volet, 2010; Pajares, 1992) have shown that past experiences significantly influence teachers' ideas and acts. Accordingly, several researchers have stressed the importance of reflection and anticipation in teacher education to reduce the practice shock often experienced when entering the teaching profession (Conway, 2001; Korthagen et al., 2001; Stokking, Leenders, De Jong, at Van Tartwijk, 2003). In this study, we aim to add to this body of knowledge on the attitudes of beginning teachers by exploring how student teachers differ in the way they perceive the past and expect the future while making sense of oneself as a teacher.

\section{Continuity and Discontinuity}

The main motive when making sense of oneself is to establish a sense of continuity: realizing coherence in the understanding of one's self over time (Caspi at Moffitt, 1991; Markus at Wurf, 1987; McAdams, 1993, Zittoun et al., 2013). A sense of continuity is central to a person's sense of well-being, as without a sense of permanence maintaining a coherent self-concept would be impossible. A sense of continuity is also functional, as it is "crucial for our ability to learn from 
past experience, to take moral responsibility for our behavior and choices, and to plan future action" (Sani, 2008, p. 3).

The sense of continuity can be disturbed, for instance when a "rapid succession of new experiences challenge existing schema, attitudes, and adaptation patterns and thus lead to change" (Caspi it Roberts, 2001, p. 51). Akkerman and Meijer (2011) conceptualized such a challenge as a sense of discontinuity: a perceived lack of rational connection or cohesion of the self over time. A sense of discontinuity can result in feelings of ambiguity or uncertainty, and Caspi and Moffitt (1991) argued that individuals will, accordingly, aim for re-establishing the continuity of the self. Such mechanisms as cognitive conservatism (preserving what is already registered about the self) and the associated confirmation bias (managing new information selectively so that existing opinions are confirmed), as Greenwald and Pratkanis (1984) described in socio-psychological research, illustrate this.

Several studies on the development of student teachers show how experiences can challenge the self-concept and, accordingly, trigger a sense of discontinuity (Akkerman C Meijer, 2011; Alsup, 2006; Beijaard et al., 2004). Pillen et al. (2013) presented 13 types of discrepancies between ideas, personality and values and the encountered social and cultural working condition that "can be very serious and may have a great influence on beginning teachers' learning and functioning" ( $p$. 6). The consequences of sensed discontinuity can be potentially severe: teachers can suffer feelings of uncertainty and low self-esteem (Hargreaves, 2005; Pillen et al., 2013, Zembylas, 2003) and/ or feelings of self-doubt and confusion about the profession (Akkerman A Meijer, 2011; Alsup, 2006).

\section{Research Question}

In this study we aim to explore differences in the extent to which the self-concept of student teachers is already challenged as they start the teacher education program. This will add to our understanding of the scope and applicability of labels such as "strenuous" and "challenging" on different student teachers at the start of teacher education. For this we will describe how student teachers, upon entering teacher education, perceive positive and negative attributes as well as past and expected experiences. The central question directing this study is as follows: How do reported self-concepts of student teachers at the start of teacher education differ between student teachers in terms of their expressed attributes, their perceptions of the past and the future and their sense of (dis)continuity? 


\section{METHOD}

\section{Participants and Context}

Thirty-five student teachers, who were enrolled in a post-graduate, one-year teacher education program of a Dutch research university, participated in this study. We based our selection of the student teachers on the availability of the assignment used in this study at the start of the study (see the section Data below). The teacher education program supports student teachers in obtaining a subject-matter specific teaching license at the master level, which allows them to teach at all levels of secondary education in the Netherlands. Among the 35 participants, student teachers represented all subject-matter tracks that the program offers (including history, geography, modern languages, mother tongue, music, and science subjects). The group of participants included twenty-four student teachers between 20 and 30 years old, seven student teachers between 31 and 45 years old, and four student teachers between 46 and 58 years old. Nine of these student teachers participated in an "alternative certification" version of the program (Tigchelaar, Brouwer, at Korthagen, 2008).

The teacher education program is characterized by a strong emphasis on learning from practice, using strategies to stimulate reflection with the aim to connect practice and theory. Scholars have referred to this as a realistic approach towards teacher education (Brouwer it Korthagen, 2005; Korthagen et al., 2001). As part of the supervision and assessment process, teacher-educators instruct student teachers to include several documents in their portfolios that address aspects of their self-concepts as teachers (Van Tartwijk, Van Rijswijk, Tuithof $\{$ Driessen, 2008).

\section{Data}

Data on the 35 student teachers' self-concepts were derived from narratives in the student teachers' portfolios: their teacher profiles. A teacher profile is a text written by a student teacher at the start of the teacher education program, in which he or she reflects on the central question: "Who do you think you are as a teacher?" In line with research on career autobiographies, we considered the personal narrative produced for the teacher profile assignment as an expressed self-concept of the student teacher as a teacher (Rehfuss, 2009).

An important design principle for the teacher profile instruction, which was included in the portfolio manual, was that the instruction in the assignment should stimulate student teachers to produce rich (i.e. diverse and illustrative) as well as authentic texts. To develop the instruction, six student teachers (not included in the data set of this study) participated in a pilot study in which three different types of instructions were evaluated. One instruction invited student teachers to describe themselves as teachers in terms of their attributes, norms, values, and ideals, and strong and weak points. The second instruction invited student teachers to reflect on an authentic situation, to elaborate on the significance of the situation for their sense-making as teachers and 
to take the perspective of others, such as mentors, on their attributes into account. The third instruction was very open, presenting only the central question of the teacher profile.

The first author interviewed all six student teachers about the pilot instruction and the strategy employed while completing the task. The first and third author analyzed the six texts produced in the pilot study concerning attributes and (dis)continuities mentioned in the texts and concerning the richness and sincerity of the texts. The researchers discussed the benefits of each instruction and the value of the texts produced in light of the underlying research questions. Consequently, the most promising elements of the three pilot instructions for answering our research questions were selected and combined into the final instruction.

The final instruction included prompts that invited student teachers to describe attributes, strong and weak points in their teacher conduct, values and norms, and the perspective of significant others. Two independent researchers, who also work as teacher educators, carefully studied the final instruction and agreed that it was clear and understandable. The instruction for the profile was included in the portfolio manual after ensuring that all teacher educators involved agreed that the instrument aligned with the tenor of other assignments in the teacher education program. The manual made clear that supervisors did not take the teacher profile into account for assessment purposes but served as input for supervision.

\section{Analysis}

All profiles were coded using the software program Atlas.ti. First, we coded all attributes: a qualification of the student teacher about him- or herself. Next, we divided all attributes into two categories: (1) general attributes pertaining to the person, not explicitly used in the context of becoming or being a teacher, and (2) profession specific attributes explicitly linked to that person becoming or being a teacher. In a quote such as "I am an enthusiast, social, serious, dedicated and focused person," we would code five general attributes. In a quote such as "I am a teacher who starts from high subject knowledge demands and a good cooperation with students" we would code two profession specific attributes. Some attributes looked similar, e.g., "enthusiastic" and "enthusiasm for", but we coded them as different attributes because the actual words differed and we wanted to capture the idiosyncratic self-characterization of student teachers. Finally, we added an evaluative code to each attribute. We coded an attribute as "Positive" whenever it was considered a strength. We coded an attribute "Ambiguous" whenever the student teacher considered it a strength and a weakness at the same time. An attribute was coded "Negative" whenever the student teacher considered it to be a weakness, and as "Neutral" whenever it did not seem to have an evaluative connotation.

After coding the attributes, we divided each profile into passages: units of meaning pertaining to one theme or subject. We coded the temporal dimension of each passage, distinguishing passages referring to the past, passages referring the present, passages referring to the future, and passages that had jumbled and/or connected references to the past, present and future. 
The first author then summarized all of the teacher profiles. For each profile, she clustered remarks referring to, respectively, the past, the present, and the future. After this, she categorized all references made to the past by means of purposefully comparing and contrasting the references (Boeije, 2002). This categorization resulted in a table containing four categories of perceptions of the past (see Table 2). The same was done for all expressed expectations of the future in the 35 profiles, which resulted in Table 3. Finally, for each of the 35 profiles, the first author determined the dominant perception of the past and the dominant expectation of the future. The dominance was determined by considering the emphasis throughout the entire profile, establishing which reference was most elaborated on and represented the final conclusion of the profile (see Table 4).

We followed an audit procedure to ascertain transparency and reliability with regard to all aspects of the analysis of the data set (Akkerman, Admiraal, Brekelmans, it 0ost, 2008). For this, the first author made an audit trail, that is, a detailed account of the data and of all steps and procedures followed in the analysis (Poortman a Schildkamp, 2012). An independent researcher, not involved in this study, performed the audit. She was given access to the raw data ( 35 teacher profiles), the processed data (files in Atlas.ti), and all data summaries that were the basis for the result section in this article. After familiarizing herself with the analysis and the processed data, the auditor checked all steps of the analysis by randomly selecting examples of the raw and processed data. She assured that the several stages of the processed data could be reliably related to the original data set and concluded that the reported results are transparently and reliably grounded in the data.

\section{RESULTS}

The average length of the 35 teacher profiles was 1,014 words. Five teacher profiles contained fewer than 500 words (minimum 424 words) and six profiles contained more than 1,500 words (maximum 2,075 words). Below, we describe (1) the attributes in the 35 profiles, (2) the perceptions of the past found in the profiles, (3) the expectations of the future, and (4) how these perceptions and expectations combine in sensed (dis)continuity. We illustrate our findings with quotes from the profiles.

\section{Attributes in the Teacher Profiles}

In the 35 profiles, student teachers mentioned a total of 346 different attributes. The total number of general attributes mentioned in the teacher profiles was 167 . The total number of profession specific attributes was 179. Except for the attribute "strict," which was used nine times in the total of 35 profiles, no attribute was used more than five times.

In seven profiles, student teachers mentioned more than ten general attributes (the highest number being 21 ), while in six profiles, student teachers did not mention any general attributes. 
In three profiles, student teachers mentioned more than 10 different profession specific attributes (the highest number being 18), while in two profiles, the student teachers did not mention any profession specific attributes. Table 1 provides an overview of the evaluations connected to the attributes mentioned in the profiles.

\section{Table 1}

Evaluation of the General and Profession specific Attributes in the 35 Teacher Profiles

\begin{tabular}{llllll}
\hline Attributes & $\begin{array}{l}\text { Total } \\
(346)\end{array}$ & $\begin{array}{l}\text { Strength } \\
(247)\end{array}$ & $\begin{array}{l}\text { Weakness } \\
(52)\end{array}$ & $\begin{array}{l}\text { Ambiguous } \\
(44)\end{array}$ & $\begin{array}{l}\text { Neutral } \\
(3)\end{array}$ \\
\hline Ceneral attributes & 167 & 101 & 36 & 27 & 2 \\
$\begin{array}{l}\text { Profession specific } \\
\text { attributes }\end{array}$ & 179 & 146 & 16 & 17 & 1 \\
\hline
\end{tabular}

\section{Perceptions of the Past}

In the summaries of the 35 teacher profiles, we identified four different perceptions of the past. Table 2 shows in how many of the 35 profiles we found each type of perception. A profile can contain more than one type of reference to the past.

\section{Table 2}

Perceptions of the Past in the 35 Teacher Profiles

\begin{tabular}{|c|c|c|c|}
\hline Occurrence* & $\begin{array}{l}\text { Reported about the } \\
\text { past }\end{array}$ & Description & $\begin{array}{l}\text { Expressing a } \\
\text { sense of }\end{array}$ \\
\hline 13 & $\begin{array}{l}\text { Consistency related } \\
\text { to attributes }\end{array}$ & $\begin{array}{l}\text { References that reflect certainty and } \\
\text { confidence about specific attributes and } \\
\text { abilities as they became known prior to } \\
\text { teacher education. }\end{array}$ & continuity \\
\hline 27 & $\begin{array}{l}\text { Consistency related } \\
\text { to experiences }\end{array}$ & $\begin{array}{l}\text { References to specific experiences with } \\
\text { teaching, with other professional } \\
\text { experiences and/or as a student. }\end{array}$ & continuity \\
\hline 5 & No past & No description of the past & discontinuity \\
\hline 7 & Problems in the past & $\begin{array}{l}\text { References about negative attributes and } \\
\text { problems that reflect weak teacher } \\
\text { conduct. }\end{array}$ & discontinuity \\
\hline
\end{tabular}

* Number of profiles in which this way of addressing the past occurred 
Consistency related to attributes. In these references, student teachers describe their development as a teacher, leading up to the position they are in now. The references include remarks on their personality, presented and illustrated through general attributes. For example, one student teacher wrote:

The role of a university-trained teacher fits me because I am . . . very interested in theory, especially concerning pedagogical subject knowledge and general linguistic theories. This involves analytical and abstract thinking.

In consistency-related-to-attributes-type references, we found student teachers elaborating on a dominant thread throughout their lives, for instance:

I am a historian in the sense that I want to know everything about background and history of development. In the end, I put everything in the context of fundamental life questions about being: what is the meaning of life, what does it mean to live a good life, what are just actions, how do we deal with suffering, sadness, pain, what is happiness, what gives meaning to (my) life. I have carried these questions with me since high school. I am fascinated by the answers my studies and personal introspection provided me with.

Specific personal attributes were explicitly considered relevant to take into account when starting teacher education, in these references.

Consistency related to experiences. In consistency-related-to-experiences-type references, student teachers expressed a sense of who they are as teachers in the present because of specific experiences in the past. Thirteen times these experiences pertained to experiences in the field of education. For example, one student teacher wrote:

In 2010, I followed an introductory course for teaching at the teacher education institute. Because of this, I was able to get briefly acquainted with education. Now I have been at a practice school for a number of weeks... where I have given about ten complete lessons. I notice that because of this I [now] have a fairly extensive image of me being a teacher.

This quote indicates that the teaching experience that the student teachers referred to does not necessarily need to be extensive (in this case not more than about sixteen lessons in total) in order for them to understand themselves as teachers.

Student teachers also referred to specific experiences in other jobs and/or professional settings (five times) to illustrate what is important in one's work or to illustrate professional abilities. For instance:

When I worked as a travel guide, teachers often participated in my groups. The feedback

I regularly received was that they could imagine me working as a teacher.

In this quote, the student teacher describes her attributes as a professional while working in a non-educational setting. She considers being a teacher suitable because experienced teachers predicted a fit between her and the profession.

Nine times student teachers addressed specific experiences they encountered as students. 
One student teacher wrote:

I often feel disturbed when other teachers are being inconsistent. I want to be consistent in my behavior so students will know what they can expect. I also conclude this because of what I liked as a student myself.

No past. In five teacher profiles, student teachers did not address the past when expressing their thoughts about who they are as teachers. A possible explanation for this lies in the following quote:

It is still too early to discuss with my school mentor how she sees me as a teacher because I have not taught a lesson yet and therefore I have not called up an impression.

The author does not seem to regard non-educational experiences in the past as necessary to mention when writing about being a teacher in the present or future. This suggests a lack of connection between the past and the present with regard to the aim to become a teacher.

Problems in the past. In seven profiles, student teachers included experiences from the past that made their professional conduct as a teacher questionable and potentially problematic. By elaborating on weak points, the student teachers openly acknowledged personal issues that could hinder their success as a teacher. One student teacher wrote:

The outside world thinks of me as a tough and confident young woman who is not afraid to speak up. To some extent, this is true because of what I went through, but as soon as it gets really difficult and I have to control myself in a professional setting, I often take on a role. Despite the fact that this is not visible to anyone but a psychologist, I sometimes wonder if I am a genuine person.

For student teachers who addressed weak points and problems in the past, starting the teacher education program seemed to be connected to avoiding certain behavior, as one student teacher wrote:

I think people say about me that I am easy to approach, but hard to fathom. Sometimes a crisis is needed to "really" get to know me. Starting my educational program, I will do whatever it takes to prevent this from happening and be open and absorb all new knowledge.

In problems-in-the-past-type references, student teachers reported a need to undergo profound changes in order to become a teacher.

In summary, the student teachers who expressed consistency-related-to-attributes type references and consistency-related-to-experiences-type references demonstrated perceived continuity in development from the past to the present. Student teachers who did not refer to the past or who expressed problems-in-the-past type references demonstrated perceived discontinuity in development from the past to the present, in, respectively, an implicit (no-past) or an explicit (problems-in-the-past) form. Before looking more closely at how perceptions of the past are related to the way these student teachers look upon the future, we will present four different expectations of the future as found in the teacher profiles. 


\section{Expectations of the Future}

We identified four different expectations of the future in the 35 teacher profiles. Table 3 shows these four types of expectations, including a description of the nature of the reference pertaining to both development as a teacher (becoming) in the future as well as the state as a teacher (being) in the future. Table 3 also indicates in how many of the 35 profiles student teachers used each reference. Again, please note that some profiles contained more than one type of expectation of the future.

\section{Table 3}

Expectations of the Future in the 35 Teacher Profiles

\begin{tabular}{|c|c|c|c|}
\hline Occurrence* & $\begin{array}{l}\text { Reported with } \\
\text { respect to the } \\
\text { future }\end{array}$ & Description & $\begin{array}{l}\text { Expressing a } \\
\text { sense of }\end{array}$ \\
\hline 5 & Confidence & $\begin{array}{l}\text { References indicating clarity and certainty of } \\
\text { expected attributes and professional conduct } \\
\text { as a teacher and indicating confidence in a } \\
\text { continuous development. }\end{array}$ & continuity \\
\hline 15 & Development & $\begin{array}{l}\text { References indicating probability of antici- } \\
\text { pated attributes and professional conduct as } \\
\text { a teacher and indicating a phased nature of } \\
\text { the developmental trajectory. }\end{array}$ & continuity \\
\hline 14 & Coals & $\begin{array}{l}\text { References indicating pursued attributes and } \\
\text { professional conduct, without specific } \\
\text { information about what it will take to reach } \\
\text { these goals. }\end{array}$ & discontinuity \\
\hline 10 & Challenges & $\begin{array}{l}\text { References problematizing the feasibility of } \\
\text { required attributes and professional conduct } \\
\text { and the developmental trajectory towards } \\
\text { this. }\end{array}$ & discontinuity \\
\hline
\end{tabular}

* Number of profiles in which this way of addressing the future occurred

Confidence. The confidence-type references included comments about trust in becoming and being a teacher. Student teachers emphasized what they wanted and would do in order to develop as a teacher. The references imply that being a teacher means focusing on improvement and expanding abilities that are part of who one is already. For example, one student teacher wrote:

I do not want to become the best and nicest teacher, but only the best teacher I can be, given my possibilities. A teacher who is involved with his students, who can adapt to them and at the same time monitor the learning process of the group as well as the individual students. 
The confidence-type references included remarks about the continuous nature of development as a teacher.

Development. Expectations indicating development included comments about the probability of being a teacher in the future and having a clear image of the nature of the developmental trajectory towards this. One student teacher wrote:

As a teacher I want to be someone who can motivate students by showing them the relevance of the subject. This can be different for every student and I suspect this will demand something of my creativity.

Student teachers expected the developmental trajectory to be an intensive process that needs attention and experience:

I am curious to know how you can create an atmosphere during a lesson in which you can transfer this sense of trust and safety without having to make this explicit. . . I think this is something that has to happen naturally and that has to do with a personal connection.

In these references, student teachers expressed the feeling that being a teacher would happen although they acknowledged that this development would take time.

Goals. Expectations that were categorized as goals, concerned remarks about what the student teachers want as teachers, what is important, and/or what one must do or not do as a teacher. The focus of the expectation was on the future professional conduct as a teacher. In the words of one student teacher:

I close my eyes and let my thoughts run wild... Before me I see three of my former students talking to each other, 15 years after graduating. They are a success in society as well as personally. Thinking aloud about their high school years, reminiscing about former teachers, one of them mentions my name: - Do you still know Ms. vD? No matter how tired and obnoxious we were at the end of the day, she always knew how to motivate us. I always visited her lessons with great pleasure and was always disappointed when the hour ended. All the thought-experiences we did and the dilemmas we discussed were very interesting for me.

In the goal-type references, the student teachers specified the objective but included hardly any information about what it will take to reach specific goals. The goal-type references suggest that obtaining new skills and qualities is necessary, but they did not comment on the developmental trajectory towards these attributes.

Challenges. In challenges-type references the student teachers addressed the future as uncertain or even problematic, as one student teacher illustrated:

I will find it hard to give all students equal attention and to treat them all the same

without a noticeable judgment. I am strong-minded and I often give my opinion.

In this quote, the student teacher suggests that certain attributes of the present self may impede becoming a teacher. In challenges-type expectations, student teachers noted how fundamental change is necessary for them to become a teacher. 
In summary, in the first two types of expectations presented in Table 3 (confidence and development), student teachers expected continuity in development from the present towards the future. In the third and fourth types (goals and challenges), the student teachers suggested discontinuity in development.

\section{Combinations of Perceptions of the Past and Expectations of the Future}

For each profile, we determined the most dominant perception of the past and expectation of the future, as we described in the analysis part of the method section. Table 4 presents the combinations of perceptions of the past and expectations of the future that were found in the profiles.

\section{Table 4}

Overview of the Dominant Perceptions of the Past and the Dominant Expectations of the Future

\begin{tabular}{|c|c|c|c|c|}
\hline \multirow[b]{2}{*}{ Reference to the past } & \multicolumn{4}{|c|}{ Expectation of the future } \\
\hline & Confidence & Development & Goals & Challen \\
\hline & \multicolumn{2}{|c|}{ A } & \multicolumn{2}{|c|}{ C } \\
\hline $\begin{array}{l}\text { Consistency related to } \\
\text { attributes }\end{array}$ & 31 & 2 II & 31 & o II \\
\hline \multirow{2}{*}{$\begin{array}{l}\text { Consistency related to } \\
\text { experiences }\end{array}$} & o III & $9 \mathrm{IV}$ & $5 \mathrm{III}$ & $5 \mathrm{IV}$ \\
\hline & \multicolumn{2}{|c|}{ B } & \multicolumn{2}{|c|}{$\mathrm{D}$} \\
\hline No past & 01 & o II & 31 & 2 II \\
\hline Problems in the past & O III & O IV & O III & $3 \mathrm{IV}$ \\
\hline
\end{tabular}

The combinations of perceptions of the past and expectations of the future in $A^{\prime}, A^{\mathrm{IV}}, D^{\prime}$, and $D^{\mathrm{IV}}$ illustrate four intuitively logical self-concepts as teachers at the start of teacher education: (1) In the three profiles in $A^{\prime}$, we noted a combination of dominant perceptions of consistency-related-toattributes and confidence, suggesting that for these student teachers entering teacher education is a logical step in finalizing their development as a teacher; (2) In nine profiles, categorized in $A^{\mathrm{IV}}$, we noted a combination of dominant perceptions of consistency-related-to-experiences and expectations of development in the future, suggesting that for these student teachers development during teacher education means lengthening the development they started before; (3) In three profiles, categorized as $D^{\prime}$, the student teachers included no references to the past and focused mainly on the goals that they needed to meet in order to become a teacher; and (4) In three profiles, categorized in $D^{\mathrm{IV}}$, we noted a combination of dominant perceptions of the past as 
problematic for becoming a teacher and the expectation that in the future challenges would also occur. Student teachers showing this combination felt fundamental, personal changes were needed in order to become a teacher. These four types of self-concepts made up $51 \%$ of the total combinations found in the teacher profiles, meaning that $49 \%$ of the combinations expressed a variant of these combinations.

Nineteen profiles contained a dominant perception of consistency-related-to-experiences ( $A^{\text {IV }}$, $C^{I I I}$, and $\left.C^{I V}\right)$. Ten profiles combined this perception of the past with the expectation that becoming a teacher means starting something new. For five of these ten profiles, $\mathrm{C}^{\mathrm{III}}$, this seems to mean that they must meet specific goals in order to become a teacher, and for five others, $C^{\mathrm{IV}}$, this seems to imply that they must solve some problems.

\section{The Expressed Sense of Discontinuity in the Teacher Profiles}

Following the combinations of perceptions of the past and expectations of the future, the profiles are distinctive in expressing a sense of (dis)continuity. Table 4 illustrates how in 14 profiles (A) student teachers expressed a general sense of continuity. This indicates that those student teachers perceived their entry into teacher education as fitting with their perceived past and future development. In contrast, in eight profiles (D), student teachers expressed a general sense of discontinuity, suggesting that the teacher education program marked the start of a new and challenging development. In the remaining 13 profiles (B), student teachers expressed an ambiguous sense of perceived continuity and expected discontinuity. As one might expect, in no profiles did student teachers express an ambiguous sense of perceived discontinuity and expected continuity (C).

\section{DISCUSSION}

This study aimed at exploring student teachers' attributes, perceptions of the past and of the future, and issues of (dis)continuity in the expressed sense of self as a teacher. Teacher profiles of 35 student teachers were considered and analyzed as expressed self-concepts at the start of the teacher education program.

The reported self-concepts revealed a large variety of general and profession specific attributes. This variety is consistent with the idiosyncratic nature of students teachers' self-concepts described in earlier research (Alsup, 2006). A substantial number of student teachers openly mentioned precarious attributes. In literature about reflection and its role in teacher learning, Kelchtermans (2009) considered such a critical stance beneficial for achieving a realistic outtake on one's abilities as a teacher.

We identified four types of perceptions of the past and four types of expectations of the future throughout the 35 profiles and found that the majority of the 35 student teachers already 
understood themselves at least partly as teachers at the start of the teacher education program. Contrary to what we conceptually expected based on people's inner needs to create continuity of self over time in narrative processing (e.g., Habermas a Bluck, 2000; Zittoun et al., 2013), we found that some student teachers did not refer to the past at all in their teacher profiles, but only to expectations of their future.

Nine different combinations between dominant perceptions of the past and expectations of the future were found in the teacher profiles, illustrative of three types of sensed (dis)continuity: 1) a general sense of continuity, 2) a general sense of discontinuity and 3) an ambiguous sense of perceived continuity and expected discontinuity. This framework of sensed (dis)continuity shows how student teachers' differ in identifying with the profession at the start of teacher education. This is relevant because an individual perceives (new) experiences selectively and in relationship to (past) self-concepts (e.g., McLean a Pasupathi, 2011). Taking into account the human tendency to strive for continuity of self, we believe that student teachers will likely try to maintain their current self-concept during teacher education, even if the self-concept contains unrealistic beliefs and expectations about themselves as teachers (Greenwald \& Pratkanis, 1984; Habermas \& Bluck, 2000; Zittoun et al., 2013).

Profiles that contained a general sense of continuity suggested a positive attitude towards coming to identify with the profession. Researchers have found that such a positive attitude is preferable when student teachers move into subsequent professional development (Judge, 2009; Onafowora, 2005). It could, however, also hamper these student teachers in realistically considering adjustments that they might need to successfully function as a teacher (Caspi a Roberts, 2001; Greenwald a Pratkanis, 1984). When self-confidence is very strong, student teachers could fall under the spell of a false sense of infallibility, which is associated with chalking away negative experiences as "just part of the progress" (Greenwald a Pratkanis, 1984). Some might need to experience a major crisis to disrupt this sense of continuity, which could lead to harmful effects, such as leaving teacher education (Alsup, 2006; Beijaard et al., 2004; Meijer, 2011).

In the student teachers' profiles that showed an ambiguous sense of perceived continuity and expected discontinuity, becoming a teacher is perceived as a changeable process, containing specific points of improvement. For these student teachers, experiences in the past seemed to make the tensions that can be encountered in practice more tangible. Reflecting on the past for these student teachers could make possible future difficulties more concrete. These findings add a note of caution to the literature that calls for the use of reflection on autobiographic experiences during teacher education (Hammerness et al., 2005). Notably, reconsidering former experiences when developing as a teacher can add to a sense of discontinuity for some student teachers and consequently can trigger feelings of uncertainty (Zembylas, 2003).

Student teachers who expressed a general sense of discontinuity in their profiles confirmed the belief that becoming a teacher is perceived as a new and challenging process. For these student teachers, the past seemed to contain no grounds or even impediments for a self-concept as a teacher and the future seemed uncertain and challenging. Whether this might be a realistic 
expectation or an expectation that will prove to be overly pessimistic, it can also function as a self-fulfilling prophecy. This can hamper further development as expected failure is likely to influence the way new experiences are encountered and interpreted (Conway, 2001; Greenwald it Pratkanis, 1984). Then again, it can be argued that it is beneficial that these student teachers are aware of the possible challenges that are part of becoming a teacher. They seem to recognize that they will need to put forth a thorough effort to deal with these obstacles and that they must be open to change (Hargreaves, 2005).

To summarize, this study of the self-concepts of student teachers, focusing on perceptions and expectations of becoming a teacher, provided a framework that supports the understanding of differences between student teachers at the start of teacher education. Various perceptions of the past and expectations of the future were found to determine differences in sensed (dis)continuity, illustrating how student teachers differ in identifying with the profession at the threshold of developing as a teacher.

\section{Implications for Teacher Education}

We feel the framework of sensed (dis)continuity can enrich the awareness of teacher educators about differences between student teachers in terms of self-concepts and expectations, already at the start of teacher education. Teacher educators could examine if the student teachers' expressed sense of (dis)continuity is realistic and, together with them, explore goals and future actions. Consequently, the results can be useful for adaptive supervision (Beauchamp a Thomas, 2009; Beijaard et al., 2004; Meijer, 2011). For student teachers who expect discontinuity, organizing experiences that contribute to a sense of success and accomplishment could be helpful (Korthagen et al., 2001; Korthagen, 2004). Assisting them with guided reflection that explicitly calls to mind experiences and abilities that testify to the feasibility of becoming a teacher could also be helpful. For student teachers who perceive and expect continuity, exploring and discussing tensions reported by their peers could be helpful and might even prevent more severe "practice shocks" later on (Pillen et al., 2013; Stokking, Leenders, De Jong, at Van Tartwijk, 2003).

\section{Limitations and future research}

Questions about whether sensed (dis)continuity is indeed realistic and how it relates to further development during teacher education deserve further exploration. More specifically, researchers could focus on the predictive qualities of the types of sensed (dis)continuity and on their applicability in analyzing self-concepts in later stages of the teacher education program and/or in other settings, such as the practice environment. Researchers could then also focus on how supervisors, in and beyond the teacher education program, consider the types of sensed (dis)continuity presented in this article instrumental for supporting the development of student teachers (Beltman et al., 2011; Pillen et al., 2013). 
We argue, based on the findings of this study, that there are several layers researchers should explore and question when promoting the notion of anticipatory reflection and its effects on retaining a healthy optimism about the future as a teacher (Conway, 2001). Besides a primary questioning of how student teachers anticipate and what expectations they have, a second question should be to what extent these expectations are realistic. We suggest specific attention should be paid to student teachers who enter teacher education with previous professional or life experiences and the relationship between these specific experiences and their perceptions and expectations. Third, it is important to question and examine the impact of expectations on subsequent development. We know that people tend to selectively perceive and make sense of their experiences, partly based on their specific expectations. This can lead for example to self-fulfilling prophecies or a disregarding of information and feedback from situations that could be relevant for reflection and development.

As one's self-concept is dynamic, contextual, and temporal (Leary a Tangney, 2003), we want to stress that researchers and teacher educators should take caution when typifying student teachers' expressed self-concepts. Although a self-concept pertains partly to a relatively stable core of dispositional attributes, it also changes continuously as student teachers have new experiences and interactions with others in and outside the context of teacher education (Rodgers at Scott, 2008). The results articulated in this article thus reflect these student teachers' self-concepts as explicated in written form at a specific moment and in a specific context. Profiles written a week, or maybe even a day, later could display (slightly) different results, influenced by a renewed way of making sense of these experiences. The types of sensed (dis)continuity presented in this article, however, illustrate how the self-concepts of student teachers can differ on a more abstract level at the start of teacher education and can serve as an analytical lens for further exploring the process of making sense of oneself as a teacher. 
䓂宁

일

$\vec{\nabla}$.

芩

홍 공

콩 응.

高

空

苋

혹

을 穴

용

옥

을 


\title{
CHAPTER 3
}

\section{Changes in Sensed (Dis)Continuity in the Development of Student Teachers throughout Teacher Education 5, 6}

\begin{abstract}
Initiatives aimed at supporting student teachers for entering and staying in the teaching profession require a better understanding of the nature of student teachers' development as it unfolds during teacher education. Accordingly, we focused on changes in the extent to which student teachers perceive and expect (dis)continuity in their development during the program. The design of the study included 25 authentic supervision dialogues/conversations, enabling the analysis of development within and across six student teachers' developmental trajectories. Findings showed that student teachers' initial sense of (dis)continuity is not necessarily predictive of progress and (un)successful completion of teacher education. Furthermore, sensed (dis)continuity varies differently over time in student teachers, both in terms of when it changes as well as in terms of with what types of past perceptions and future expectations these changes occur.
\end{abstract}

\footnotetext{
5 This Chapter has been published as: van Rijswijk, M. M., Bronkhorst, L. H., Akkerman, S. F., at van Tartwijk, J. (2018). Changes in sensed (dis)continuity in the development of student teachers throughout teacher education. European Journal of Teacher Education, 41(3), 282-300.

6 Acknowledgement of author contributions: MR, SA and JT designed the study, MR recruited participants and collected the data, MR analyzed the data, MR drafted the manuscript, all authors contributed to critical revisions of the paper, LB, SA and JV supervised the study.
} 


\section{INTRODUCTION}

Development as a teacher has been conceptualized as a complex internal process that includes "struggling" with questions such as "who am I as a teacher?" and "what kind of teacher do I want to become?" (Beijaard It Meijer, 2017, p.177). Exploring the answers to these questions can prompt tensions in student teachers, that is conflicting beliefs about themselves and the profession, which can lead to a loss of self-confidence (Alsup, 2006; Beltman, Mansfield, at Price, 2011, Pillen, Beijaard A den Brok, 2013). Moreover, research has shown that teachers, because of tensions between their personality and the demands of the profession, decided to leave the profession (Beijaard et al., 2004, Hong, 2010, Flores, 2014, Hong, Greene a Lowery, 2017). Attrition is not only problematic because of the personal frustration of (student) teachers, but also because of growing teacher shortages in many countries (e.g., Ingersoll a Strong, 2011; Johnson et al., 2014). A better understanding of when and how student teachers experience tensions can help prevent dropout from teacher education and later attrition from the profession.

Up to now, knowledge about the nature of student teachers' tensions is often based upon studies analyzing the reflections of graduates, after finishing teacher education (cf. Alsup, 2006; Meijer, 2011; Pillen, Beijaard a den Brok, 2013). More recently, researchers have also started to focus on teacher development as it unfolds, and the role of tensions therein. For instance, Flores (2014) reported on tensions in the development of beginning teachers in different school contexts and Hong, Green and Lowery (2017) studied development over time in student- and beginning teachers, analyzing interviews about feelings of change and stability, and assimilation and disequilibrium (Hong, Green $A$ Lowery, 2017). In line with such a longitudinal approach and aiming to study student teachers' tensions as they occur, we designed a study that included analyzing successive authentic supervision conversations during a teacher education program. This design allowed us to focus on student teacher development, independent of whether, how, and when student teachers completed teacher education (Leonard-Barton, 1990). Moreover, the design helped to avoid effects of hindsight bias (Roese it Vohs, 2012) and allowed analysis of student teachers' development as it unfolds in teacher education. We report on how student teachers describe themselves, their experiences and their development as teachers throughout these conversations. Besides contributing to more theoretical insight in the dynamics of ongoing teacher development and the role of tensions therein, our findings can support university supervisors in addressing tensions and contribute to avoiding drop out.

\section{THEORETICAL FRAMEWORK}

\section{The Vocational Self-Concept and Sensed (Dis)Continuity}

To study student teachers' development we turn to Super, Starishevsky, Matlin and Jordaan (1963), who defined the vocational self-concept as "the constellation of self-attributes considered by the 
individual to be vocationally relevant" (Super et al., 1963, p.20). A vocational self-concept consists of self-attributes that are considered traits by the individual (e.g., "I am friendly"), including attributes that are known because of interaction with others (e.g., "students consider me to be reasonable"). New experiences can trigger the renegotiation of vocational relevance and/or accuracy of self-attributes (Super et al., 1963) and thus influence further development. Recurring renegotiation of self-attributes can be conceptualized as narrative sense-making (Ezzy, 1998; Hermans, 2002). Past perceptions, an individual's selection of appropriate past events, and future expectations (i.e., one's forecast about what may happen in the future), determine the process of sense-making (Britzman, 2007; Bruner, 1990; Polkinghorne, 1996; Zittoun et al., 2013).

The main motive of sense-making is the human need for sensed continuity: the urge to experience coherence in the understanding of one's self over time (Akkerman 2 Meijer, 2011; Zittoun et al., 2013). A sense of continuity is central to well-being, as without a sense of permanence maintaining a coherent self-concept would be impossible. Moreover, a sense of continuity is functional as it enables people to learn from past experiences, "to take moral responsibility for our behavior and choices, and to plan future action" (Sani, 2008, p. 3). However, teaching experiences have been shown to elicit reflections about the relevance and/or accuracy of self-attributes for the vocation. Discrepancies among these reflections have been referred to as professional identity tensions: "internal struggles between aspects relevant to the teacher as a person and the teacher as professional" (Beijaard a Meijer, 2017, p.186, see also Pillen et al., 2013). These tensions are related to sensed discontinuity in student teachers: experiencing a lack of coherence over time, which can lead to anxiety (Hong, Green a Lowery, 2017). It has been shown that people who experience a sense of discontinuity will typically try to reinstall a sense of coherence over time (Caspi it Moffit, 1991). Research shows that sensed discontinuity in teachers can lead to a decrease in self-confidence (Akkerman \& Meijer, 2011), negatively influence motivation (Sutton it Wheatly, 2003) and may result in attrition (Beijaard et al., 2004, Hong, 2010, Flores, 2014).

The vocational self-concept of student teachers can differ in terms of a general sense of (dis) continuity because of the combination of past perceptions and future expectations at the beginning of teacher education. In previous empirical research on 35 so-called profiles of student teachers, four types of past perceptions and four types of future expectations were identified (Chapter 2). Student teachers were found to express a general sense of continuity, with both past perceptions and future expectations reflecting a sense of continuity. For instance: "I always knew I wanted to be a teacher. I played school with my younger sister at an early age and I feel my enthusiasm for instruction will benefit my growth as a teacher" (Chapter 2). A general sense of continuity suggests that student teachers are confident about their further development as a teacher, based on their positive way of looking back on the past (cf. Sani, 2008). Student teachers were also found to express a general sense of discontinuity, with both past perceptions and future expectations reflecting a sense of discontinuity. For instance: "I know I can be very impatient and I will have to change that in order to be a teacher. I feel this will be a struggle and I do not know if I will like it" (Chapter 2). A sense of discontinuity suggests that becoming a teacher is a new 
and challenging process (cf. Beijaard et al., 2004). Finally, student teachers were found to express an ambiguous sense of (dis)continuity at the start of teacher education. For instance: "Because of my work as a travel guide, I know I can explain things quite well; but doing this in a group of 30 fifteen-year-olds will be tricky for me" (Chapter 2). An ambiguous sense of (dis)continuity suggests that development as a teacher for those student teachers is a variable process.

To summarize, the vocational self-concepts of student teachers at the start of teacher education differ because of individual perceptions of the past and expectations of the future. Accordingly, student teachers differ whether and how they experience tensions when they enter teacher education. In this current study, we set out to study how this initial experience of (dis)continuity changes throughout teacher education. Amongst others, this will inform us about the stability of perceiving the past and expecting the future within individuals and if and how new experiences impact student teachers' experience of (dis)continuity throughout teacher education. The question we aim to answer is: When and with what type of past perceptions and future expectations does the initial sensed (dis)continuity of student teachers change during teacher education?

\section{METHOD}

\section{Context}

The one-year, post-master, teacher education program from which the participants in this study were selected, is located at a research university in the Netherlands and supports student teachers in obtaining a subject-matter specific teaching license. This license allows them to teach at all levels of secondary education in the Netherlands. About $80 \%$ of the student teachers of this program graduate after one year of teacher education, $11 \%$ graduate after two, three or four years, and about $9 \%$ of the student teachers quit the teacher education program (COLUU, 2013). The teacher education program is characterized by a strong emphasis on learning from practice, using supervision strategies to stimulate reflection and connecting practice and theory. Scholars have referred to this as a realistic approach towards teacher education (Korthagen et al., 2001).

The one-year program consists of a so-called university-based part and, parallel to this, two consecutive practice periods. During the two practice periods, student teachers teach at least 20 lessons in the presence of a mentoring teacher, that is a cooperating teacher who agreed to host and mentor the student teacher (cf. Cuenca, 2013) and at least 100 lessons without a mentoring teacher being present in the classroom. Student teachers finalize each practice period by composing a portfolio to show the level of their professional performance by including documents, videos and evaluations illustrating their abilities (cf. van Tartwijk, van Rijswijk, Tuithof at Driessen, 2008). Student teachers are also supervised by university supervisors, who, amongst others, visit the student teacher periodically at their placement school, provide them with feedback on methods and theory and monitor developmental progress throughout teacher education. 
Throughout the program, university supervisors autonomously schedule different types of supervision meetings: (1) introductory conversations, up to three weeks after the start of teacher education; (2) reflection conversations held after the university supervisor visits a lesson of a student teacher during the practice periods; (3) discussions about the portfolio at the end of the first and second semester; and (4) conversations to discuss the progress of the student teachers. With the exception of the supervision conversations about the portfolio, the university supervisors decide if and when the conversations take place, leading to a varying amount of supervision conversations during the one-year program per student teacher.

\section{Participants and Data collection}

For this study we selected six student teachers from the teacher education program described above. For the purpose of exploring changes in past perceptions and future expectations within different developmental trajectories, we applied a "typical case sampling" approach (Patton, 1990). Because of their responsibilities in monitoring development within student teachers throughout teacher education, we interviewed university supervisors as "key informants" (Patton, 1990) about their student teachers after about six weeks of teacher education. By then, the university supervisors had experienced the student teachers in group meetings (about six to eight meetings of three hours in the first six weeks) and in individual supervision conversations (generally one meeting in the first month of teacher education per student teacher). The group meetings included student teachers' micro-teaching, exchanging stories about their first experiences in school practice, and discussing different professional roles. All supervisors had a background in teaching in secondary education, but also had at least two years of experience as a university supervisor. Each one supervised at least five student teachers.

In the interview we asked the university supervisors to describe their student teachers and prompted them to estimate for each student teacher (1) the extent to which he/she experienced a match with the profession (i.e., (dis)continuity because of the past) and (2) the extent to which he/she was confident about their development as a teacher (i.e., (dis)continuity in terms of the future). From the estimates at start, we purposefully selected six student teachers: two student teachers were estimated by their university supervisors to experience a match because of their past and to expect some challenges for the future (an ambiguous sense of (dis)continuity); two student teachers were estimated to experience a problematic match and who doubted their successful development as teachers (a general sense of discontinuity); and two student teachers were estimated to experience a match and to feel confident about their development as teachers (a general sense of continuity). In this study, half of the included student teachers decided to leave the teacher education program before graduation, which does not match the average completion rate of $80 \%$ described in the subsection Context. When asked about this in an interview at the end of the academic year, conducted for another study about university supervisors' perceptions of student teacher development, the university supervisors of the student teachers that quit 
the teacher education program declared that they viewed the higher drop out percentage to be a coincidence.

\section{Table 1}

Overview of the data collection

\begin{tabular}{lcclcc}
\hline Name & $\begin{array}{l}\text { Age at the } \\
\text { start of } \\
\text { teacher } \\
\text { education }\end{array}$ & Subject & $\begin{array}{l}\text { Sense of (dis)continuity estimated } \\
\text { by the university supervisor }\end{array}$ & $\begin{array}{l}\text { Number of } \\
\text { recorded } \\
\text { supervision } \\
\text { meetings }\end{array}$ & $\begin{array}{c}\text { Average } \\
\text { length of a } \\
\text { supervision } \\
\text { meetings in } \\
\text { minutes }\end{array}$ \\
\hline Lionel & 23 & Biology & Ceneral sense of continuity & 3 & 29 \\
Rebecca & 26 & Dutch & Ambiguous sense of (dis)continuity & 6 & 39 \\
Tina & 22 & English & Ambiguous sense of (dis)continuity & 4 & 32 \\
Samuel & 27 & Music & Ceneral sense of discontinuity & 5 & 27 \\
Mike & 26 & Religion & Ceneral sense of discontinuity & 4 & 27 \\
Doris & 49 & French & Ceneral sense of continuity & 3 & \\
\hline
\end{tabular}

Table 1 provides an overview of the selected student teachers, including their age, subject, the estimated sense of (dis)continuity by the university supervisor and information about the supervision meetings that were recorded during the teacher education program. Please note that all names are pseudonyms. The length of the audio-recorded supervision dialogues used in this study varied from about ten minutes up to sixty minutes (mean: thirty-four minutes) and all types of supervision conversations explained above were included in the data collection. Because we wanted the data collection to be as little disruptive as possible, we asked the university supervisors to audio-record all supervision conversations themselves and provided them with recorders. Common to all supervision conversations was the focus on discussing the development of the individual student teacher in view of their performance as a teacher and the demands held by the profession. Accordingly, past perceptions, future expectations and consequent sensed (dis)continuity were likely to feature in the supervision conversations. Informed consent was collected from all participants, both university supervisors and student teachers, and the study was approved by the Ethics Committee. 


\section{Analysis}

As this study focused on intra-individual development (Zittoun et al., 2013), we first applied a within-case strategy (Yin, 2009). All recorded supervision conversations of the six students were written out in detail by the first author while listening to the recordings, excluding a limited number of remarks about practical issues-such as assignments or technical specifics of the portfolio. First, all remarks about being (past reference) or becoming (future reference) a teacher were identified and listed chronologically. Second, all references were coded as past perceptions or future expectations. For this the first author used an existing coding scheme that was developed in a prior study to gather data on the vocational self-concepts of student teachers at the start of teacher education (Chapter 2). This coding scheme includes four types of past perceptions and four types of future expectations and is integrated in Table 2. Third, in order to be able to identify in detail with what type of past perceptions and future expectations the initial sensed (dis)continuity changed, sub-categories were iteratively determined by comparing and contrasting items in the four past perceptions and future expectations (Miles i Huberman, 1994). For instance, the general type of past perception expressing "consistency related to attributes" was refined by adding the sub-categories: self-description, appreciation of the profession, current status as teacher and role model. The general type of future expectation "challenge" was refined by adding the sub-categories: pitfalls, difficulties of the profession, and insecurity. For an overview, including examples of student teachers' references for all codes, see Appendix 1. To ensure consistency of the coding, the third author, who was not part of the research team that performed the analysis, checked the elaborated coding scheme with 29 categories. The independent double coding of the 48 references resulted in a satisfactory overall agreement (Cohen's Kappa of 0.89 ). The six references that were coded differently by the first and third author, were discussed and altered in full agreement.

For comparing changes in sensed (dis)continuity between student teachers, we then made a systematic cross-case comparison (Yin, 2009). First, a time-ordered matrix (Miles it Huberman, 1994) was made for each student teacher with the sub-categories of perceptions and expectations in the rows and the supervision meetings in the columns. Next, a summary of the dominant expressed sense of (dis)continuity of each student teacher at different moments was deduced from this matrix. The type of references that were most strongly emphasized during the conversation and/or represented the final conclusion were considered "dominant".

\section{RESULTS}

In this section, we will first present the results of the within-case analysis. We will successively describe changes of past perceptions and future expectations within student teachers who expressed (1) a general sense of continuity (2) a general sense of discontinuity, and (3) an 
ambiguous sense of (dis)continuity in their first supervision conversation. For each student, dominant past perceptions and future expectations are presented in a table and elaborated on in a description of their development. In this description, the type of references will be mentioned in italics, illustrating the dominating sub-category applicable in the specific conversation. Finally, we will present the results of the cross-case analysis, using a graphical representation of the different developmental trajectories of the six student teachers.

\section{Changes of Past Perceptions and Future Expectations Following an Initial General Sense of Continuity}

The dominant past perceptions and future expectations of Lionel in his first supervision conversations expressed a general sense of continuity. Table 3 provides an overview of his past perceptions and future expectations during subsequent supervision conversations.

Table 3

Past perceptions and future expectations following an initial sense of continuity

\begin{tabular}{|c|c|c|c|c|c|}
\hline \multirow[b]{3}{*}{ Lionel } & & \multicolumn{2}{|c|}{ References to the past } & \multicolumn{2}{|c|}{ References to the future } \\
\hline & & Discontinuity & Continuity & Discontinuity & Continuity \\
\hline & \multicolumn{5}{|l|}{ Aug/Sept } \\
\hline & Oct/Nov & & $\begin{array}{l}\text { Consistency } \\
\text { attributes }\end{array}$ & & Development \\
\hline & Dec/Jan & & $\begin{array}{l}\text { Consistency } \\
\text { experiences }\end{array}$ & & Confidence \\
\hline & Feb/Mar & & $\begin{array}{l}\text { Consistency } \\
\text { attributes }\end{array}$ & Challenges & \\
\hline & \multicolumn{5}{|l|}{ Apr/May } \\
\hline & \multicolumn{5}{|l|}{ Jun/Jul } \\
\hline & Lior & el left the teach & ucation progr & he beginning $\mathrm{c}$ & \\
\hline
\end{tabular}

Lionel. In his first supervision conversation, Lionel emphasized what he appreciated about the profession and elaborated about his current status as a teacher. He mentioned how much he liked the fact that being a teacher enabled him to be creative when designing lessons. In terms of the future, he stressed the importance of development as an objective in itself; he wanted to be a teacher in a way that was a good fit for him. Although he could think of role models, he emphasized the importance of finding his own voice. In the second supervision conversation, Lionel elaborated 
on his experiences with teaching by talking about specific teacher behavior, which was mostly about what he did to ensure a good classroom atmosphere. With regard to the future, he predominantly demonstrated enthusiasm; he felt things would be all right and he trusted his future experiences in practice would help him to extend his skills. In the third supervision conversation, Lionel emphasized his current status as a teacher when talking about the past and reflected on finding it easier to relate to older students. With regard to the future, he explicitly mentioned the difficulties of the profession he expected to encounter during his second practice period. He feared he might feel disappointed: "Maybe it will never be this good again". Lionel left the teacher education program about half way through the program, two weeks into the second practice period.

\section{Changes of Past Perceptions and Future Expectations Following an Initial General Sense of Discontinuity}

The dominant past perceptions and future expectations of Doris and Mike in their first supervision conversation expressed a general sense of discontinuity. Table 4 provides an overview their subsequent past perceptions and future expectations.

\section{Table 4}

Past perceptions and future expectations following an initial general sense of discontinuity

\begin{tabular}{|c|c|c|c|c|c|}
\hline \multirow[b]{3}{*}{ Doris } & \multirow[b]{3}{*}{ Aug/Sept } & \multicolumn{2}{|c|}{ References to the past } & \multicolumn{2}{|c|}{ References to the future } \\
\hline & & Discontinuity & Continuity & Discontinuity & Continuity \\
\hline & & & & & \\
\hline & Oct/Nov & $\begin{array}{l}\text { Problems in the } \\
\text { past }\end{array}$ & & \multicolumn{2}{|l|}{ Challenges } \\
\hline & Dec/Jan & & $\begin{array}{l}\text { Consistency } \\
\text { attributes }\end{array}$ & \multicolumn{2}{|l|}{ Goals } \\
\hline & Feb/Mar & $\begin{array}{l}\text { Problems in the } \\
\text { past }\end{array}$ & & \multicolumn{2}{|l|}{ Challenges } \\
\hline & \multicolumn{5}{|l|}{ Apr/May } \\
\hline & \multicolumn{5}{|l|}{ Jun/Jul } \\
\hline \multicolumn{6}{|c|}{ Doris left the teacher education program in the beginning of March } \\
\hline
\end{tabular}




\begin{tabular}{|c|c|c|c|c|c|}
\hline \multirow[b]{3}{*}{ Mike } & \multirow[b]{3}{*}{ Aug/Sept } & \multicolumn{2}{|c|}{ References to the past } & \multicolumn{2}{|c|}{ References to the future } \\
\hline & & Discontinuity & Continuity & Discontinuity & Continuity \\
\hline & & $\begin{array}{l}\text { Lack of } \\
\text { experience }\end{array}$ & & Goals & \\
\hline & Oct/Nov & & $\begin{array}{l}\text { Consistency } \\
\text { attributes }\end{array}$ & & Development \\
\hline & Dec/Jan & & $\begin{array}{l}\text { Consistency } \\
\text { experiences }\end{array}$ & & Development \\
\hline & Feb/Mar & & $\begin{array}{l}\text { Consistency } \\
\text { attributes }\end{array}$ & & Development \\
\hline & Apr/May & & & & \\
\hline
\end{tabular}

Mike graduated from the teacher education program in the beginning of July

Mike. In the first supervision conversation, Mike emphasized his lack of experience with teaching in general and formulated goals in general terms-for instance, "I want to learn to become a real teacher", without elaborating on what this means precisely. In his second supervision conversation, Mike stated that teaching turned out better than he first expected. He found that relating to students was easier than he feared and he thus commented on his current status as a teacher. Looking at the future, he focused on further development; for instance, in concretizing what he wanted to do to discover his own "style". In the next supervision conversation, Mike predominantly talked about teaching experiences in general terms: "Having an affiliation with students is really one of the best parts of teaching". In terms of the future, he continued to stress focused development, stating that he regards development as an objective in itself and emphasizing how much he values personal growth. Mike graduated from teacher education at the end of the oneyear teacher education program.

Doris. In the first supervision conversation, Doris predominantly emphasized confusion about the teacher education program and teaching itself, and she stressed impeding patterns such as her tendency always to focus on the negative in her behavior and performance. In terms of the future, she only mentioned goals and challenges. She elaborated on her own insecurity and she stated that: "Things will really have to change if I want to persevere in teacher education". During the third supervision conversation, Doris emphasized her current status as a teacher when she looked to the past; when looking at the future, she mainly focused on goals in terms of specific teacher behavior, without discussing what it would take to reach these goals. In the fourth supervision conversation, Doris referred mainly to impeding patterns and expected pitfalls for the future, explicitly mentioning that she would have to work hard to avoid them. Doris left the teacher education program after two weeks into the second practice period. 


\section{Changes in Past Perceptions and Future Expectations Following an Initial Ambiguous Sense of (Dis)Continuity}

The dominant past perceptions and future expectations of Rebecca, Tina, and Samuel in their first supervision conversation expressed an ambiguous sense of (dis)continuity. Table 5 provides an overview of their past perceptions and future expectations during successive supervision conversations.

\section{Table 5}

Past perceptions and future expectations following an initial ambiguous sense of (dis)continuity

\begin{tabular}{|c|c|c|c|c|c|}
\hline \multirow{9}{*}{ Rebecca } & & \multicolumn{2}{|c|}{ References to the past } & \multicolumn{2}{|c|}{ References to the future } \\
\hline & & Discontinuity & Continuity & Discontinuity & Continuity \\
\hline & Aug/Sept & & $\begin{array}{l}\text { Consistency } \\
\text { attributes }\end{array}$ & Challenges & \\
\hline & Oct/Nov & & $\begin{array}{l}\text { Consistency } \\
\text { experiences }\end{array}$ & & Development \\
\hline & Dec/Jan & & $\begin{array}{l}\text { Consistency } \\
\text { attributes }\end{array}$ & & Development \\
\hline & Feb/Mar & $\begin{array}{l}\text { Problems in the } \\
\text { past }\end{array}$ & & Challenges & \\
\hline & Apr/May & $\begin{array}{l}\text { Problems in the } \\
\text { past }\end{array}$ & & & Development \\
\hline & Jun/Jul & & $\begin{array}{l}\text { Consistency } \\
\text { attributes }\end{array}$ & & Development \\
\hline & \multicolumn{5}{|c|}{ Rebecca graduated from the teacher education program in the beginning of July } \\
\hline & & References to th & ast & References to & uture \\
\hline & & Discontinuity & Continuity & Discontinuity & Continuity \\
\hline \multirow[t]{6}{*}{ Tina } & Aug/Sept & & $\begin{array}{l}\text { Consistency } \\
\text { attributes }\end{array}$ & Challenges & \\
\hline & Oct/Nov & & & & \\
\hline & Dec/Jan & & & & \\
\hline & Feb/Mar & & $\begin{array}{l}\text { Consistency } \\
\text { experiences }\end{array}$ & & Development \\
\hline & Apr/May & & $\begin{array}{l}\text { Consistency } \\
\text { experiences }\end{array}$ & & Development \\
\hline & Jun/Jul & & $\begin{array}{l}\text { Consistency } \\
\text { attributes }\end{array}$ & & Development \\
\hline
\end{tabular}




\begin{tabular}{|c|c|c|c|c|c|}
\hline \multirow[b]{3}{*}{ Samuel } & \multirow[b]{3}{*}{ Aug/Sept } & \multicolumn{2}{|c|}{ References to the past } & \multicolumn{2}{|c|}{ References to the future } \\
\hline & & Discontinuity & Continuity & Discontinuity & Continuity \\
\hline & & $\begin{array}{l}\text { Problems in the } \\
\text { past }\end{array}$ & & & Development \\
\hline & Oct/Nov & $\begin{array}{l}\text { Problems in the } \\
\text { past }\end{array}$ & & Challenges & \\
\hline & Dec/Jan & $\begin{array}{l}\text { Problems in the } \\
\text { past }\end{array}$ & & & Development \\
\hline & $\mathrm{Feb} / \mathrm{Mar}$ & $\begin{array}{l}\text { Problems in the } \\
\text { past }\end{array}$ & & & Development \\
\hline & Apr/May & $\begin{array}{l}\text { Problems in the } \\
\text { past }\end{array}$ & & & Development \\
\hline
\end{tabular}

Samuel left the teacher education program at the end of May

Rebecca. At the start of teacher education, Rebecca emphasized consistency related to attributes by giving self-descriptions. She elaborated on why she felt the profession suited her: "Becoming a teacher is a positive choice. I felt really at home at school when I was a student". She expected challenges for the future related to classroom management because she doubted if she could be strict. She considered this to be her pitfall. During the second supervision conversation, Rebecca stressed specific teacher behavior; for instance, being able to use creative teaching methods. For the future, she focused on concrete developmental issues, elaborating on what she would do in order to improve her lessons in terms of efficiency. Halfway through the program, Rebecca reflected positively on her current status as a teacher by making comments such as "I am content with the steps I have taken so far", but she acknowledged that the relationship with students could be improved. She thought this would happen if she could: "really take the role of a teacher". She emphasized the importance of personal growth for her development as a teacher. During the fourth supervision conversation, halfway through the second practice period, Rebecca spoke about her problems with classroom management and referred to impeding patterns: she started off on the wrong foot and now could not escape the behavioral pattern she has developed with her students. She formulated goals and challenges and she focused on how her teaching in general should be changed in order to be a successful teacher. During the fifth conversation, Rebecca again described the impeding patterns she noticed because of the problems she faced in school. In terms of the future, she stressed focused development. She was determined to engage in personal conversations with her students at the start and end of each lesson. In the final supervision conversation, Rebecca mostly referred to her current status as a teacher and references to the future were scant. She evaluated the steps she made as a teacher. Although she professed to know that she was not yet the teacher she could be, she felt she was growing into the teacher 
she wanted to be. Rebecca graduated at the end of the program.

Tina. In the first supervision conversation, Tina described herself as friendly and compliant; self-descriptions indicative for consistency related to attributes. At the same time, she claimed to expect challenges for the future: she was insecure about whether she would succeed in classroom management. During her second supervision conversation, Tina again gave self-descriptions, but also commented on her status as a teacher when she expressed her pride about the successes she had during the first practice period. With regard to the future, she focused on further development; for instance, when she elaborated on the strategies she wanted to apply in order to improve in classroom management. In consequent supervision conversations, Tina elaborated on her experiences in school practice by emphasizing specific teacher behavior and her current status as a teacher, concretizing her conduct as a teacher. She stressed that she expected focused development, indicating that she wanted to improve as a classroom manager. In addition, she emphasized how much she valued development as an objective in itself. Tina graduated from teacher education at the end of program.

Samuel. In his first supervision conversation, Samuel predominantly perceived problems when referring to the past, emphasizing that teaching to him was unnatural: "My personal problems can possibly threaten my functioning as a teacher". However, when he looked at the future, Samuel predominantly focused on his development, especially on growth as a teacher. Samuel repeatedly mentioned that for him teacher education represented the possibility to change as a person. For instance, he said that he found it very difficult to relate to other people and that teacher education is a context that would force him to do this with students. In his second supervision conversation, Samuel continued to highlight problems in the past, especially focusing on impeding patterns. When looking at the future, he mostly expected challenges, revealing that he was insecure about his ability to change his teaching conduct. In the third supervision conversation, Samuel again focused on problems in his past, stressing both difficult professional conduct as well as unnaturalness. He returned to quite an optimistic outlook on the future as he mostly talked about focused development; for instance, when he reflected on what he wanted to do to stimulate students to perform music in his lessons. During the fourth supervision conversation, Samuel persevered in elaborating about difficult professional conduct and unnaturalness. For instance, he remarked that he often did not know himself why certain lessons could be useful. However, he again focused on development in terms of the future, this time mostly looking forward to growth as a teacher. In the fifth supervision conversation, Samuel elaborated on impeding patterns and on specific personal attributes that were, in his own words, "incompatible" with working in education. With regard to the future, he speculated about the difficulty potentially involved in trying to change or reapply these attributes and was insecure about the feasibility of these efforts. Samuel left teacher education in the latter half of the second practice period. 


\section{Changes of Sensed (Dis)Continuity Throughout Teacher Education}

The cross-case analyses allowed us to compare changes over time in terms of sensed (dis)continuity for different student teachers. In Figure 1, the changes of sensed (dis)continuity are summarized for each student teacher. The first three columns present the student teachers who graduated, the last three columns present the student teachers that left teacher education.

\begin{tabular}{|c|c|c|c|c|c|c|c|c|c|c|c|c|c|c|c|c|c|c|}
\hline & \multicolumn{3}{|c|}{ Rebecca } & \multicolumn{3}{|c|}{ Tina } & \multicolumn{3}{|c|}{ Mike } & \multicolumn{3}{|c|}{ Doris } & \multicolumn{3}{|c|}{ Samuel } & \multicolumn{3}{|c|}{ Lionel } \\
\hline & D & A & C & D & A & C & D & A & C & D & A & C & D & A & C & D & A & C \\
\hline Aug/Sept & & & & & $x$ & & & & & & & & & & & & & \\
\hline Oct/Nov & & & & & & & & & & & & & & & & & & \\
\hline Dec/Jan & & & & & & & & & & & & & & & & & & \\
\hline Feb/Mar & & & & & & & & & & & & & & & & & & \\
\hline Apr/May & & & & & & & & & & & & & & & & & & \\
\hline Jun/Jul & & & & & & $t$ & & & & & & & & & & & & \\
\hline
\end{tabular}

$D=$ general sense of discontinuity $A=$ ambiguous sense of (dis)continuity $C=$ general sense of continuity

Figure 1 Changes in the general sense of (dis)continuity of the six student teachers

The perceptions and expectations of Rebecca, Tina, and Mike, who all graduated from teacher education at the end of the teacher education program, did change towards a general sense of continuity after the first supervision conversation. The conversations following their first supervision conversation, included future expectations that predominantly focused on development, emphasizing continuous growth, and demonstrating knowledge about what it would take to reach these goals. The past perceptions of Rebecca, Tina, and Mike were similar halfway through the year, when they predominantly reflected on their current status as teachers after the first practice period. For Mike and Tina, the general sense of continuity was consistent throughout the supervision conversations from that moment on. Rebecca, however, reported about difficult professional conduct and impeding patterns during the second practice period, expressing a sense of discontinuity. At first, she expected challenges in the future, but in the course of the second practice period, she returned to expectations of focused development.

Doris and Samuel, who both left teacher education before graduation, perceived the past in terms of discontinuity almost consistently throughout the teacher education program (Doris once referred to past perceptions consistency related to attributes). In terms of future expectations, Samuel alternately expected development and challenges. The alignment of past perceptions and future expectations in terms of (dis)continuity for Samuel varied quite strongly throughout teacher education and, consequently, he repeatedly expressed an ambiguous sense of (dis)continuity. 
Doris predominantly stressed impeding patterns and reoccurring challenges throughout teacher education. The past perceptions and future expectations of Doris aligned quite consistently throughout teacher education in terms of sensed discontinuity.

Lionel, who also left teacher education before graduation, started teacher education showing a lot of certainty and positivity towards the future. Lionel, however, had a counterintuitive change towards ambiguous (dis)continuity. In the third conversation, Lionel presented a nonalignment between sensed (dis)continuity in past perceptions and future expectations: he perceived continuity because of the past and he predominantly expected challenges for the future.

\section{DISCUSSION}

The focus of this study was to explore if and how the experience of tensions changes in student teachers during teacher education. Tensions were defined as conflicting beliefs about the person and the profession, that can induce a loss of self-confidence and propel teacher attrition. We conceptualized tensions in relation to sensed discontinuity in development as a teacher. By conducting this study, we aimed to increase our understanding of when and how initially sensed (dis) continuity of student teachers changes throughout teacher education. Analyses of 25 audio-taped supervision conversations of six student teachers showed how perceptions of the past, expectations of the future, and the expression of sensed (dis)continuity vary for each student teacher throughout the course of teacher education. Furthermore, results showed that sensed (dis)continuity varies differently over time within student teachers, both in terms of when sensed (dis) continuity changes as well as in terms of with what types of past perceptions and future expectations. An initial sense of (dis)continuity could not be related to a specific developmental trajectory and/or successful completion of teacher education. The cross-case analysis of the developmental trajectories did show that the three students who graduated from the teacher education program expressed a dominant sense of continuity in their final conversation. Therefore, it appears that finalizing a developmental trajectory within the context of teacher education tends to coincide with perceiving coherence in past development as well as expressing confidence in future professional development.

The developmental pattern of overcoming disillusionment, described as typical student teacher development in retrospective research (e.g., Meijer et al., 2011), could be related to the past perceptions and future expectations of just one of the six developmental trajectories described in this study. Rebecca described her frustration about recurring inefficient teacher conduct at the midst of teacher education. Although she knew what was wrong, she found it very hard to change because of personal impeding patterns. Sensed continuity reoccurred when she turned her attention more strongly towards further development, instead of concentrating on repeated challenges.

The other five trajectories showed a dissimilar pattern. The perceptions and expectations of Mike and Tina showed hesitance at the beginning of teacher education about the prospects of 
becoming a teacher. During the course of teacher education, concrete experiences in practice were talked about in the supervision conversations, which seemed to reflect the human need to reinstate continuity in times of challenge in order to feel secure and confident (cf. Caspi at Moffit, 1991). Both Mike and Tina strongly valued development as a goal in itself. Their cautious expectations at the start of teacher education may have contributed to a sense of accomplishment because of their development progresses. Doris, Samuel and Lionel did not overcome the struggle that is often associated with becoming a teacher (cf. Beijaard et al., 2004). Doris and Samuel, who quit teacher education after about four weeks into the second practice period, repeatedly presented a sense of discontinuity. For them, development as a teacher seemed to become more challenging over time. Their attempts to change in order to become a teacher failed, which seemed to fuel their original misgivings about their suitability to the profession. Lionel, who started off very confident and enthusiastic, expressing continuity, gained a more detailed image of the profession over time. Halfway through the year he expressed expected challenges in much more detail, maybe because his experiences in the first practice period helped to specify the demands of the profession. We propose that the developmental trajectories of the six student teachers described in this study are illustrative for the necessity in teacher education to direct attention towards idiosyncratic development and take personal challenges into account during supervision (cf. Korthagen et al., 2001).

A developmental trajectory that changes towards sensed discontinuity during teacher education can be considered problematic, since teacher inflow and retention is increasingly identified as one of the major priorities for professional teaching, in research, policy, and practice (Ingersoll a Strong, 2011). However, it could be considered to be a blessing in disguise that Doris, Samuel and Lionel presented sensed discontinuity during the supervision conversations that otherwise would typically be introduced in the induction phase of teaching. Research has shown how tensions are related to attrition (cf. Pillen et al., 2013, Hong, Green a Lowery, 2017). Addressing challenging issues prior to entering the profession may help to avoid a costly and complex induction trajectory that can lead to burnout. Consequently, further research that will delve deeper into the support of sense-making processes provided by university supervisors, is needed. We recommend that this future research will take into account both what is needed to adapt to the idiosyncratic nature of student teachers' development as well as how university supervisors can deal with challenges connected to attending to experiences of (dis)continuity in student teachers throughout teacher education.

The real-time, longitudinal approach applied in this study resulted in a description of the development of student teachers, independent of whether, when, and if they complete teacher education. This approach enabled us to explore the developmental trajectories of three student teachers who happened to quit teacher education; a group omitted in studies on development in teacher education in which graduates are asked to look back on teacher education. Although the approach is both time-consuming as well as labor intensive (Leonard-Barton, 1990), this specific design, that is, studying real-time cases at consecutive moments, allowed us to describe development as it unfolds over time, yielding complementary insights. 


\section{Limitations and Implications}

As this study focused on intra-individual development (Zittoun et al., 2013), we excluded the context of the supervision conversations in our analysis. In order to explore how interactions between student teachers and university supervisors affect student teachers' development we recommend that future research also tries to incorporate analyses that include interactions surrounding past perceptions and future expectations and consequent expressions of sensed (dis)continuity.

Our results imply that supervising university supervisors should be aware of the relatively unpredictable and idiosyncratic nature of the development of student teachers. The expanded framework for identifying perceptions and expectations (see Table 2 and Appendix 1) can assist supervisors in constructing a more detailed understanding of changes in the vocational selfconcept of individual student teachers during teacher education. The framework enables university supervisors to be sensitive toward changes in the appraisal and interpretation of experiences and, consequentially, discuss changing perceptions and expectations of (dis)continuity of student teachers. Future research is then needed to explore the implications of this approach for university supervisors' supervision behavior and the supervision relationship between student teachers and university supervisors. 
옹

은.

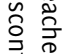

言. 誉

ज.

ㅁ

蛋

응 은

寻 蒿

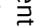

苋

品

모․

䨐 


\title{
CHAPTER 4
}

\section{Teacher Educators and Student Teachers Discussing Discontinuity in Development 7,8}

\begin{abstract}
During teacher education student teachers regularly experience challenges. This can result in an experience of discontinuity: a sense of inconsistency about current or future attributes as a teacher. Discontinuity can be a trigger for development but can also lead to stagnation and even drop-out.

In this study we explored how student teachers and university supervisors introduce and explore experiences of discontinuity in such a way that ongoing development is enabled. Content analysis of 110 sequences from authentic supervision conversations showed that predominantly the students themselves $(81 / 110)$ introduced an experience of discontinuity in the supervision conversation. We identified three strategies for further elaborating on the experience: trusting on development over time, compensating with other aspects of the vocational self and re-evaluating the relevance of the sense of discontinuity. The strategies were used by both student teacher and teacher educator, typically combined and created the possibility of experiencing continuity as well. The results illustrate how student teachers and teacher educators together can create a perspective on ongoing development when discussing an experience of discontinuity.
\end{abstract}

7 This chapter is a translation of the article that is published in Dutch as: Van Rijswijk, M.M., Bronkhorst, L.H., van Tartwijk, J. đt Akkerman, S. F. (2019). Lerarenopleiders en studenten in gesprek over discontinuïteit in de ontwikkeling als leraar. Pedagogische Studiën, 96 (6), pp. 423-440. The translation has been proofread.

8 Acknowledgement of author contributions: MR, LB, SA and JT designed the study, MR recruited participants and collected the data, MR analyzed the data, MR drafted the manuscript, all authors contributed to critical revisions of the paper, LB, SA and JV supervised the study. 


\section{INTRODUCTION}

The development of teachers not only pertains to learning skills and knowledge, but also to reflecting on one's identity as a teacher (e.g., Beijaard at Meijer, 2017; Beijaard, Meijer, at Verloop, 2004). Consequently, teacher educators are expected to reflect with student teachers on new experiences in light of their personal attributes and expectations (Conway, 2001; Korthagen, Kessels, Koster, Lagerwerf, at Wubbels, 2001, Rodgers at Scott, 2008). This helps student teachers to prepare to begin - and remain - in the teaching profession.

When reflecting on experiences as a teacher, student teachers may feel that their personal attributes conflict with the profession (for example, "I am conflict-avoidant and that does not work well as a teacher"). Student teachers can also perceive that they are still missing certain attributes, which they therefore need to develop (for example, "As a teacher you have to be patient and keep repeating. That is a challenge for me because I always want to move on quickly"). In teacher education, it is relevant to discuss such reflections on teacher identity in supervision conversations, for example to explore possible graduation concerns, to prevent a practice shock after teacher education or to increase the likelihood of continuing within the profession during the induction phase (Johnson et al., 2014; Stokking, Leenders, de Jong, a van Tartwijk, 2003).

Experiencing that one possesses conflicting attributes or lacks attributes that teachers require can lead to frustration, diminished self-confidence and stagnation in student teachers' development. Consequently, reflecting on new experiences in supervision conversations can be complicated (Alsup, 2006; Gipe a Richards, 1992). Whether this is the case, appears to depend on the perceptions and expectations of the individual student, the perceived severity and extent of the situation and whether the student teacher feels that their development as a teacher is still possible (Sani, 2008; Tang, 2003; Chapter 2).

Addressing conflicting or missing attributes in supervision conversations is thus characterized by a paradox: it is useful to analyze problems in order to explore the possibilities available for development, but this is also risky due to the potential negative implications for developmental progress. Previous studies have offered clues for teacher educators who want to support student teachers who are experiencing conflicting or missing attributes (Pillen, den Brok, a Beijaard, 2013), but they primarily focus on interventions with regard to a single aspect of the paradox. On the one hand, research focuses on solving problems, for example by allowing students to deliberately undertake challenges (Bronkhorst, Meijer, Koster, a Vermunt, 2014) in order to explore opportunities for development. On the other hand, research seeks to strengthen self-confidence, for instance by emphasizing personal qualities (Korthagen et al., 2001) in order to avoid hampering development.

In this study, we do not focus on specific interventions, but rather explore authentic supervision conversations to determine how students and teacher educators discuss contradictory or missing attributes with regard to the continuous development of the student teacher as a teacher. We study sequences from supervision conversations to provide insights into how conflicting or 
missing attributes are introduced and discussed in conversations between students and teacher educators.

\section{THEORETICAL FRAMEWORK}

In this section we first describe what is known about sense-making as a teacher and the unique way in which each student teacher reflects on himself or herself as a teacher. We then discuss our understanding of the process of reflecting on attributes in interaction and describe our views on supervision conversations as dialogical processes.

\section{Student Teachers' Sense-Making}

In teacher education, experiences with teaching can raise questions such as: "Who am I as a person and as a teacher?", "How am I inclined to act in practice and do I want that?" or "Is the way I function in line with what is expected of me as a teacher?" (cf. Akkerman ct Meijer, 2011; Alsup, 2006; Beijaard, Meijer, a Verloop, 2004). We understand these types of questions as manifestations of a process of intrapersonal sense-making as a teacher, as continuous reflections that are narrative and dialogical in nature (Ezzy, 1998; Ferreira, Salgado, Cunha, Meira, C Konopka, 2005), related to the vocational self-concept of student teachers. Specifically, they are the constellation of personal attributes that the individual considers relevant for the profession (Super, Strahishevsky, Matlin, it Jordaan, 1963).

The continued reflections of student teachers about themselves as teachers as well as their associated feelings of confidence and/or uncertainty for further development are determined by past experiences and future expectations (Polkinghorne, 1996; Zittoun et al., 2013). If student teachers believe that their attributes contradict or are insufficient for the profession, they experience so-called discontinuity with regard to the vocational self-concept: a sense of inconsistency in the current or to-be-developed attributes that are relevant to the profession (Akkerman a Meijer, 2011; Sani, 2008; Zittoun et al., 2013).

In general, people tend to avoid experiences of discontinuity owing to the potential damage they may cause to their confidence and certainty in development (Caspi \& Moffit, 1991; Sani, 2008). Previous research has demonstrated that people pursue experiences of continuity as they develop, as the feeling of consistency among attributes contributes to their overall well-being (Ibarra at Barbalescu, 2010; Sani, 2008). Moreover, student teachers and teacher educators benefit from exploring experiences of continuity because a positive, confident attitude is related to self-confidence in professional practice and resilience during further professional development (Zembylas, 2003).

Experiences of discontinuity are inevitable during teacher education as confronting and challenging experiences are inextricably linked to the first steps in the profession (Ahonen, Pyhältö, 
Pietarinen, It Soini, 2015; Alsup, 2006). Experiences of discontinuity are therefore an actual and because they make the need for change tangible - desirable part of student teachers' development. During teacher education, these potential obstacles to further development as a teacher can be explored and solved (Meijer, 2013). Teacher educators may choose to explore experiences of discontinuity owing to their responsibility for monitoring student development in light of graduation (Byrd a Fogelman, 2013) and preparing students for further professional development after teacher education (Cuenca, 2013). Student teachers may want to explore experiences of discontinuity in order to solve problems in practice and/or to confirm whether the profession is a valid career option (Rots, Aelterman, a Devos, 2014).

However, if experiences of discontinuity last too long and/or are experienced by the student teacher as disproportionate, they can engender uncertainty, reducing motivation and stagnating development (Gipe a Richards, 1992; Tang, 2003). Whether and how this occurs is dependent on the individual student teacher: his or her individual perceptions and expectations as well as the extent to which there are experiences of continuity seem to determine whether experiences of discontinuity are too long or disproportionate (Chapter 3). Furthermore, previous research has shown that experiences of discontinuity do not necessarily have to be burdensome or negative, even if they continue for a long time, because they can evoke an impression of continued learning (Bronkhorst, van Rijswijk, Meijer, Koster, at Vermunt, 2013).

\section{Idiosyncratic Perceptions and Expectations of Student Teachers}

Previous empirical research has offered insights into differences between students in terms of sense-making as a teacher. An analysis of 35 narrative reflections of students in teacher education on the question "Who do you think you are as a teacher?" has demonstrated that different types of perceptions of the past and the future play a role in experiencing (dis)continuity with regard to one's development as a teacher (Chapter 2). These perceptions of the past and expectations of the future - as well as associated experiences of (dis)continuity - alter within and between students during their development as teachers and are difficult to predict (Chapter 3 ). The perceptions and expectations found in these studies are described and illustrated in Appendix 1.

Experiences of continuity and discontinuity occur simultaneously in students. For example, in the words of one student: "Through my work as a travel guide, I know that I can explain things very well (experience of continuity), but doing this in a group of thirty fifteen-year-olds will be difficult for me (experience of discontinuity)" (Chapter 2). Possessing sufficient experiences of continuity in addition to experiences of discontinuity seems to be necessary for the successful completion of teacher education and continuous development as a teacher (Chapter 3). 


\section{Discussing Discontinuity in a Supervision Conversation}

When discontinuity is discussed in a supervision conversation, student teachers and teacher educators discuss themes that are often sensitive and complex, which may lead to potentially serious consequences such as frustration and faltering development (Alsup, 2006; Gipe at Richards, 1992; Meijer, 2011). Such supervision conversations are dialogical in nature: the input of the students and the teacher educators is not one-way communication, isolated or independent; rather, perceptions of the past and expectations of the future are discussed and altered in relation to the input of the other by anticipating and responding (Lyra, 1999). For example, if a student discusses his or her uncertainty, the teacher educators' response - be it encouraging, confirming or evasive has an effect. It can affect the perceived severity of the uncertainty, opportunities for further development, the confidence that the student teacher has in the support of the teacher educator and more. The student teacher's response will also affect how the teacher educator subsequently offers support.

In previous literature, supervision approaches have often been understood in a more straightforward manner: teacher educators are advised to stimulate student teachers to reflect on alternative, effective behaviors that can be used for the problems they encounter in educational practice (Korthagen et al., 2001; Meijer, 2011). In addition, a common recommendation is to emphasize skills and personal qualities, as this can contribute to the self-confidence of student teachers (Korthagen et al., 2001). A typical characteristic of these approaches is that they are mainly aimed at strengthening student teachers' repertoire of teacher behavior and their overall feelings of resilience and self-confidence by means of the conscious intervention of the teacher educator. However, discussing discontinuity is not only guided by a predetermined intervention of the teacher educator, as student teachers can also (unexpectedly) introduce experiences of discontinuity. Moreover, the course of the reflections in an interpersonal setting is difficult to predict because of the dialogical nature of the supervision conversations.

In this study, we explore what happens during supervision conversations when teacher educators and student teachers discuss discontinuity with regard to one's development as a teacher. This will provide us with insights into how teacher educators and student teachers introduce and discuss conflicting or still missing qualities as teachers, within a setting that focuses on the progress of development in teacher education. The research can provide support to teacher educators who, confronted with the paradox of addressing experiences of discontinuity, seek a substantiated way of working. We describe how the inconsistencies are attended to in such a way that diminished self-confidence or stagnation in development is avoided, thereby facilitating student teachers' continued development in both the short and long term. The research question is: How do student teachers and teacher educators introduce and explore discontinuity in development as a teacher during supervision conversations in a teacher education program? As described earlier, we conceptualize discontinuity as a sense of inconsistency in the current or to-be-developed attributes of the student teacher that are regarded as relevant to the profession. 


\section{METHOD}

\section{Context}

This study was conducted in a one-year post-master teacher education program at a Dutch university, where students obtain a license for teaching a school subject at the master's level. Half of the program consists of practical internships, in which the student teachers design and teach lessons with an increasing amount of independence. The other half of the program takes place at the university, where theory is presented and discussed in the context of the student teachers' experiences in practice. This particular teacher education program was suitable for this study because it uses the so-called realistic approach to teacher education (Korthagen et al., 2001). This means that the structure of the program is tailored to meet the concerns of the student teachers and significant attention is also paid to reflections on experiences in the university-based part of the program.

Teacher educators at the institute supervise the development of student teachers by scheduling supervision conversations, attending classes at the internship school and providing feedback on assignments related to didactics and pedagogy. Student teachers conclude every internship period by making a "practice dossier", comparable to a portfolio (Van Tartwijk, van Rijswijk, Tuithof, at Driessen, 2008). In these practice dossiers, student teachers demonstrate the level of their functioning as a teacher with the help of illustrations such as reflection reports, designed lessons, videos and evaluations. The practice dossiers are discussed with the teacher educators, who try to adapt to the concerns of the students, keeping in mind the graduation level of the program.

\section{Participants}

For this study, we selected six teacher educators and their student teachers, varying in school subject and age (from recently graduated in a subject study to student teachers in a so-called alternative certification track). The six teacher educators (three men and three women) each possessed at least two years of experience in this teacher education program as a supervisor. The teacher educators were all qualified teachers and trained in the so-called realistic approach in teacher education (Korthagen et al., 2001). The number of student teachers supervised by a teacher educator varied from five to nine student teachers. Both the student teachers and the teacher educators were informed in advance about the nature and structure of the study and they all gave informed consent. The study was approved by the ethics committee of the university involved.

\section{Data sources}

We asked the six trainers to audio-record all of the supervision conversations they held with their student teachers. These supervision conversations were planned by the trainers themselves. The 
lengths of the supervision conversations varied from about ten minutes to seventy minutes, the average length being thirty minutes. In order to analyze a wide variety of types of supervision meetings, we studied 42 conversations, evenly distributed over time and type, that is, meetings in the first and second semester of the study program and both formal and informal (not related to a practical file).

\section{Analysis}

In order to identify passages in which discontinuities were discussed, the lead author of this article first wrote out all 42 conversations in detail while listening to the recordings. This resulted in a report with sequences (units of meaning) that were related to one theme or topic and in which perceptions of the past and/or expectations of the future were identified. To code the perceptions of the past and the expectations of the future, we used a detailed scheme that was developed in an earlier study (Chapter 3, see also Appendix 1).

We then selected sequences related to discontinuity, namely problems in the past references $(n=110)$. We opted for these sequences because they included inconsistencies linked to specific experiences that logically occur during teacher education and therefore in all selected conversations. The 110 sequences were derived from 34 different conversations. They concerned all teacher educators and at least four different student teachers per teacher educator.

The lead author studied the 110 sequences iteratively and recorded the following for each sequence: 1) how and by whom (the student teacher or the teacher educators) the discontinuity was introduced; 2) how the subject was subsequently discussed by the teacher educator and the student teacher; and 3) whether a perspective was provided on developmental progress. The numbers recorded for 1 ) and 3 ) were added and described in the results. Following the step-bystep analysis described by Boeije (2002), the responses in 2) were first coded open, to subsequently arrive at overarching codes in the axial phase by comparing and contrasting. In the final phase of selective coding, three processes that were regarded as distinctive but similar dialogical strategies were identified. These strategies were identified in each sequence and the second author of this article verified this by independently coding 36 sequences, reaching similar results.

\section{REsUlts}

Analysis of the 110 sequences showed that both student teachers and teacher educators introduce discontinuity. There were no striking differences in formal and informal supervision meetings and in meetings in the first or second half of the course with regard to discussing discontinuities. We saw that after introducing discontinuity, teacher educators and student teachers jointly reflected on the significance of the discontinuity. This reflection seemed to be aimed at ensuring that, despite the discontinuity, continued development would be possible. We therefore refer here to 
this discussion as a strategy that was used by teacher educators and student teachers alike. We have distinguished three strategies, which usually occurred in combination: (1) trusting in development, (2) compensating from the professional self and (3) re-evaluating the relevance of the sense of discontinuity. Exploring the meaning of discontinuity led to a change in the experience of inconsistency and created space for the experience of continuity in addition to the experience of discontinuity, or for the experience of discontinuity to be deepened or strengthened.

In this section, we describe in detail the introduction of discontinuity, the strategies that were used in the discussion and the two different outcomes of the discussion of discontinuity. All names are pseudonyms.

\section{Introducing Discontinuity}

In the majority of the sequences (81/110), a discontinuity was first mentioned by the student teacher. This often followed a question from a teacher educator concerning a difficulty (for example, "Are there things you bump into that you really don't like?"). Sometimes it concerned a student's input about a personal weakness (for example, "I set very high standards for myself"). Introducing discontinuity by the student also occurred in sequences, where the teacher educator or the student teacher initiated the conversation in a neutral or positive way. Often these were questions (for example, "And how is [the role] manager of the work atmosphere?" or "What have you done that you're happy with?"), but sometimes also compliments (for example, "I like the interaction that you have in class").

In the sequences in which the discontinuity was first mentioned by the teacher educator (29/110), this was by mentioning observations (for example, "Structure is your biggest challenge, order is not the problem"), by addressing previously established difficulties (for example, "You write [in the case file]: I am too fast, and I know you too"), by asking a question that makes clear that there is a difficulty (for example, "What do you think is heavy?") or by asking for details about the difficulties the student faces (for example, "Do you know when you do not have enough presence?").

\section{Exploring the Meaning of Discontinuity}

After introducing discontinuity, student teachers and teacher educators reflected on the meaning of the inconsistency. The following conversation between trainer Bianca and student Iris about making contact with pupils represents an example:

Bianca
(teacher educator)

Iris And does that work out well?

(student teacher) I find it difficult, approaching them if you don't know them well. But they Bianca are also interested in me and that makes it easier. Well, that all sounds good. 
In this short example, Iris indicates that she finds it difficult to make contact with pupils. She immediately adds other information to this observation, namely that it is easier to make contact when the pupils show an interest. Bianca then asks a question and indicates that she does not hear disturbing issues: "Well, that all sounds good". In this supervision conversation, the student teacher and teacher educator explore whether the issue that was identified as an obstacle (making contact with students) will hamper further development or not (given that students are interested, it is easier).

We have identified three ways of exploring the meaning of discontinuity: (1) trusting in development, (2) compensating from the professional self and (3) re-evaluating the relevance of the sense of discontinuity. The three dialogical strategies usually occurred in combination. An example of this is detailed in Table 1. In the following section, we will discuss these strategies in greater detail and use examples from the sequences.

\section{Table 1}

Dialogical strategies for exploring the meaning of discontinuity in a supervision conversation of teacher educator Wilma and student teacher Shirley

\begin{tabular}{|c|c|c|}
\hline Participant & Conversation & Dialogical strategies \\
\hline Shirley & $\begin{array}{l}\text { My main concern is setting limits and knowing } \\
\text { what I want to allow in the classroom. }\end{array}$ & $\begin{array}{l}\text { [introducing an experience of } \\
\text { discontinuity] }\end{array}$ \\
\hline Wilma & Yes, knowing your boundaries. & \\
\hline Shirley & $\begin{array}{l}\text { In theory I thought about it, but then other } \\
\text { things happen. And every situation is different. } \\
\text { And then you start to doubt, and you tend to } \\
\text { react too soft, instead of strict. }\end{array}$ & \\
\hline Wilma & $\begin{array}{l}\text { Yes, and then it goes further then you want. } \\
\text { Yeah, I get it. }\end{array}$ & \\
\hline \multirow[t]{3}{*}{ Shirley } & $\begin{array}{l}\text { I have to take some steps, but I notice it is } \\
\text { becoming easier. }\end{array}$ & Trusting in development \\
\hline & Also preparing lessons & Compensating from the \\
\hline & So, I still like doing it & $\begin{array}{l}\text { professional self } \\
\text { Re-evaluating the relevance of } \\
\text { the sense of discontinuity }\end{array}$ \\
\hline Wilma & $\begin{array}{l}\text { That is how you come across, relaxed, natural. } \\
\text { Pupils notice that, it is really important. Also for } \\
\text { support, pupils want to be liked. }\end{array}$ & $\begin{array}{l}\text { Compensating from the } \\
\text { professional self } \\
\text { Re-evaluating the relevance of } \\
\text { the sense of discontinuity }\end{array}$ \\
\hline
\end{tabular}

Below, we elaborate on the characteristics of the three strategies by using examples from the sequences. 


\section{Trusting in development}

Trusting in development includes accepting that something has to change and trusting that this can happen because of what was already there and/or what is to come. For example, in the supervision conversation between teacher educator Anna and student teacher Michael:

Anna I especially like the interaction you have with the students when you (teacher educator) teach.

Michael That is usually the case in my lessons. When we talk about new informa(student teacher) tion, I mainly let the class work, I just facilitate. But that is also dangerous; it is possible that not all students cooperate. I should improve.

Anna Yes, but you can also apply it in smaller groups. What you do is very good, just expand it a little.

In this example, the student teacher introduces discontinuity in response to the teacher educator's compliment, with the student indicating that further development is required. The teacher educator responds by emphasizing that he is already doing very well and that his development as a teacher is simply a matter of continuing in this regard.

The trusting in development strategy relates to trust that change is possible, for example by emphasizing that gaining experience will help, that the situation is now better than it was before or by indicating that the situation will improve. In a conversation between teacher educator Anna and student teacher Liv, gaining experience is discussed:

Anna Do you feel confident in your subject? It appears so...

(teacher educator)

Liv

Sometimes I doubt it, with grammar.

(student teacher)

Anna

Whether you know it yourself or whether you can teach it?

Liv Whether I can teach it, knowing it myself is no problem. But I have to look at my paper and use that.

Anna

OK, you need some examples you can use.

Liv

I have them, that's not the problem, but I have to be able to come up with them on the spot. That is a matter of practicing and doing.

In this sequence, in response to the question about confidence with regard to the subject, the student teacher mentions her doubts. Anna seeks greater clarity to ascertain the nature of the inconsistency. In response to the teacher educator's paraphrasing ("OK, you need some examples you can use"), Liv states that she has examples but also feels she should be able to use them instinctively. This requires greater experience, in her own words: "That is a matter of practicing and doing".

\section{Compensating from the professional self}

Compensating from the professional self includes acknowledging that there is a problem or weakness as well as that additional qualities and skills exist. For example, in the supervision 
conversation between teacher educator Bianca and student teacher Zoë about teaching in the second practical period:

Zoë

(student teacher)

Bianca

(teacher educator)

Zoë
I have to give lessons of seventy minutes: that will be a challenge. However, the pedagogical concept of the school [Montessori] ensures that the students are used to organizing their work themselves. I hope that's fine. That is scary? Do you see yourself doing it?

Yes, it will be fine. I am someone who likes to be well prepared and now I will ensure that I have a good relationship with the students in my class.

In this example, the student teacher and the teacher educator acknowledge that it can be difficult to teach at a new practice school. The teacher educator asks about the possibility of success, to which the student teacher responds in terms of what she knows about herself and what she can use to overcome the anticipated problem.

Compensating from the professional self pertains to relevant attributes that outweigh discontinuity, for example by emphasizing that there are compensating skills or traits available, or that effective alternative behaviors can be used. In a supervision conversation between teacher educator Anna and student teacher Hiske, the discussion centers on what the student teacher can do about the lack of time pupils spent on tasks:

Anna

(teacher educator)

Hiske

(student teacher)

Anna

Hiske

Anna

Hiske

Anna

Hiske

Anna
I want to look at [the teacher role] classroom manager. The pupils were working hard, but at some point, they stopped. Do you have any idea why? Well, we switched from working independently to working together. That contributed to that. And some were already done.

So, yes...?

So, I do not know?

They didn't have enough to do. And if you help students you are quite loud.

Me?

Yes, you talk loud and so do the students.

OK, so I have to make sure there is more silence.

Correct. Then you give a good signal.

In this sequence, Anna identifies a problem in class: the pupils stopped working diligently. She asks Hiske to reflect on the reasons, a task at which she originally struggles. The teacher educator then indicates that she can see two causes: the pupils did not have enough to do, and the student teacher speaks too loudly. Hiske addresses this by mentioning an alternative approach to the lesson: ensuring that there is more silence. The student teacher does not opt for a solution that relates to the aforementioned inconsistency (softer talking) but thinks about what she can do differently so that there will be less commotion. 


\section{Re-evaluating the relevance of the sense of discontinuity}

Re-evaluating the relevance of the sense of discontinuity includes reconsidering the sense discontinuity itself in terms of its threats to further development. For example, in the supervision conversation between teacher educator Jeff and student teacher Jessica:

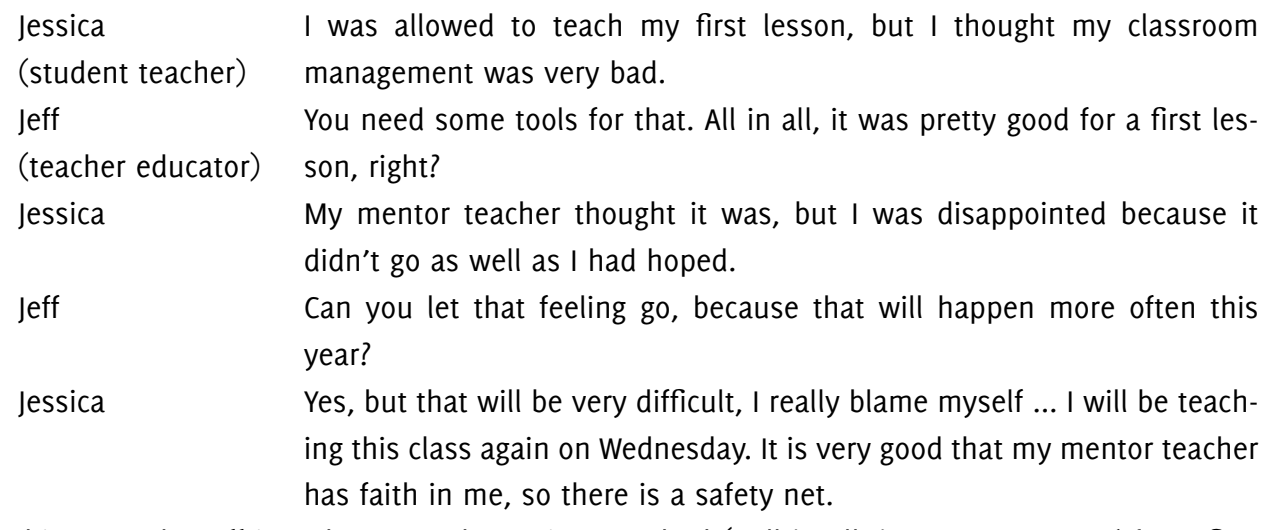
In this example, Jeff introduces an alternative standard ("all in all, it was pretty good for a first lesson") to put the experience of discontinuity introduced by the student ("I thought classroom management was very bad") into perspective.

Re-evaluating the relevance of the sense of discontinuity is related to the experience of discontinuity and the exploration of an alternative standard, for example by discussing the severity of the situation or by discussing the standards required for good teaching. In a supervision conversation between teacher educator Anna and student teacher Rebecca, this means:

Anna

What kind of teacher do you want to become?

(teacher educator)

Rebecca

Hard to say, I don't know if I have enough experience for that. In the

(student teacher) fourth grade it was easy, but ...

Anna

Deep sigh?

Rebecca

Difficult question. I have not yet taught the fifth and sixth grade. I hope I can become more certain. At least [to become] someone who pupils like to be with in class.

Anna Yes. You're not the type to have a class that is not nice, are you?

Rebecca But, also not the type to be in control. But I don't know if that is bad?

Anna Well, it sounds great already, right?

Rebecca Yes, I mostly want to make sure that they learn something.

In this sequence, Anna addresses the doubts that Rebecca has about herself as a teacher, initially by emphasizing her non-verbal signal ("Deep sigh?"). Rebecca then explains that she mainly hopes that she can become more certain and at the very least as someone with whom it is nice to be in class with. Anna says that in her opinion that will not be a problem, whereupon Rebecca indicates that she can still see an inconsistency: she is not the person who is in control. She then 
questions whether this is genuinely a problem, to which the teacher educator indicates her satisfaction with the way Rebecca is teaching.

\section{Perspective on Developmental Progress}

We found that by introducing discontinuity, inconsistency became part of the student teachers' processes of sense-making. By exploring this discontinuity by means of the three dialogical strategies, the experience of inconsistency changed.

In the vast majority of the sequences (96/110), emphasizing developmental progress (i.e. an experience of continuity) constituted an aspect of discussing discontinuity. An example of this can be seen in a conversation between teacher educator Ken and student Mariska:

Mariska I notice that I now have more time for it. Last year I was just working, and

(student teacher) development stopped, and then you quickly fall back on what you already have.

Ken Yes, and if you initiate that yourself, you have more control and it is

(teacher educator) easier. The challenge is to give responsibility to the pupils, certainly in the upper classes.

Mariska Yes, and what you say, you can control that, I have to learn that because I think that is scary, in principle.

Ken Yes, and what is it that is scary?

Mariska That you don't know what is coming.

Ken But what I saw in your lesson...

Mariska Yes, I dare to, eventually. I am getting better at it, but my first tendency is to control it myself. But I also see the benefits, it is much more effective that they are working. Otherwise you are completely exhausted yourself. I also think it is different at VMBO than at Vwo.

Ken Yes, yes, you could say that you need to be more in shape at VMB0, but during the last lesson you asked if there were questions ... and then a lot of questions came up.

Mariska Yes, that is funny because with this in mind, I thought I am going to put that method into practice and then there were no questions.

Ken oh really!? [Laughing]

Mariska It was too long before the test, so they didn't panic. So, you see that it is always different from what you expect.

In this example, the student teacher states that she struggles when she cannot control the situation in the classroom ("I think that is scary"). She then indicates that she is better at giving the students space (trusting in development) and that she also recognizes its value (re-evaluating the relevance). Ultimately, she relativizes the intimidating aspect of letting things go by referring to a specific incident in the classroom, interjecting that things simply always work differently than 
expected (trusting in development). Such confirmation of the interlocutor, who puts the experience of inconsistency into perspective, was provided in 76 of the 96 sequences, mostly by the students $(62 / 76)$.

In 14 of the 110 interview fragments, the experience of discontinuity was deepened or expanded by exploring the discontinuity. The majority of these cases (11/14) concerned experiences of discontinuity in which the student teacher initially seemed to place the origin of the discontinuity beyond himself or herself. For example, one student teacher mentioned that he found it difficult to take a test "because I don't understand that the test is being made at school during the period". In this case, the student teacher felt that he had been confronted with a difficult situation that was created by the circumstances, causing him to feel frustrated.

In three cases, the teacher educator presented the student teacher with a norm with which they did not agree. For example, in a conversation between trainer Anna and student Michael:

Michael $\mathrm{OK}$, I was thinking of a mini-flipping the classroom.

(student teacher)

Anna

Yes, you can search the Internet, there are probably several films about (teacher educator) that.

Michael I then experience a barrier, in that I really do not see myself in that compelling role.

Anna Yes, I understand that, but you have to teach yourself: that is your role.

Michael But my motivation to become a teacher was because of hating that compelling teacher, to do it differently.

Anna Yes, but to be able to avoid that, you must be able to do it. Bob [fellow student], for example, is not coercive, but he could be, and the pupils know that.

In this example, Anna states that the student will have to demonstrate a specific teacher behavior, but Michael is reluctant. He elaborates on why he does not see himself in that role by mentioning that his motivation to become a teacher was the opposite. The teacher educator tries to convince him of the value of being coercive. In this sequence, the disjuncture between the student teacher's attributes and what is considered relevant to the profession in the eyes of the teacher educator appears to expand.

\section{CONCLUSION}

Student teachers are inevitably confronted with experiences of discontinuity during teacher education: feelings of inconsistency in their present or to-be-developed attributes as a teacher. An experience of discontinuity can lead to change and learning as a teacher, but it can also compromise their development if it is perceived as threatening or overwhelming and/or they have no experience of continuity. In this study, we explored what happens during supervision conversa- 
tions when teacher educators and student teachers discuss discontinuity with regard to their development as teachers. We examined how inconsistencies are addressed in order to protect student teachers' self-confidence and to prevent their development from stagnating, so that they can develop in both the short and long term. We selected 110 sequences in which discontinuity was discussed from authentic supervision conversations in a one-year university teacher education program.

We found that discontinuity was most often mentioned first by students, often in response to a compliment as to their strengths. By introducing discontinuity, the inconsistency became part of student teachers' sense-making, with teacher educators and student teachers then discussing the meaning of the discontinuity together. Such reflection appeared to be aimed at ensuring that in spite of the discontinuity, ongoing development would be possible, hence we regard such a discussion as a strategy that can be used by trainer and student alike. We were able to distinguish three dialogical strategies, which usually occurred in combination: (1) trusting in development (accepting that something has to change and trusting that this can happen because of what was already there and/or what will be), (2) compensating from the professional self (acknowledging that there is a problem or weakness and that there are other, additional qualities and skills available) and (3) re-evaluating the relevance of the sense of discontinuity (reconsidering the sense of discontinuity itself in terms of its threat to further development).

Exploring experiences of discontinuity resulted in an amended experience of inconsistency in all sequences. In most instances, the perspective on inconsistency changed, presenting a greater opportunity for an experience of continuity in addition to that of discontinuity. Moreover, by exploring the experience, the inconsistency was deepened or strengthened, potentially jeopardizing further development.

\section{DISCUSSION AND IMPLICATIONS}

This study was designed to gain insight into the paradox underlying the development of students that have problems because they experience conflicting or (still) missing attributes for the profession. Although it may appear to make sense to explore problems so that one can investigate the options available for development in the short and long terms, this can also be risky owing to its potentially negative consequences for development. Given that supervision conversations are difficult to predict, complex and to a certain extent unique, we elaborate here on how the empirical findings of this study may inform the design of a curriculum aimed at assisting student teachers in making sense of themselves as teachers. We do not provide generally applicable recommendations for interventions, but rather outline a framework that could serve to consciously enable feelings about conflicting or missing attributes to play a role in the process of making sense as a teacher.

A limitation of this study is that by choosing a specific, narrow focus, no room was available to 
describe the whole supervision conversations and (for instance) introducing positive attributes. We recommend that follow-up research examine the sequences about discontinuities within the larger context of the supervision setting, for example with the help of discourse analysis or a narrative, autobiographical approach.

Discussing discontinuity appeared to be commonplace in the supervision conversations we analyzed. We found that student teachers and teacher educators alike would introduce discontinuity in every type of supervision meeting (formal and informal) and in every phase of the study program (first half and second half). It seems that in a teacher education program in which teacher educators regularly schedule supervision conversations, discontinuity in development can and will constitute a topic of discussion. It is important to note that the nature of the teacher education program, which focuses on adapting supervision to the concerns of the student teachers and places strong emphasis on reflecting on one's experiences, is likely to contribute in this regard (Korthagen et al., 2001). Although supervision conversations have a role in monitoring a student's progress (i.e. assessment), not least with a view to graduation (Byrd a Fogelman, 2013), this function does not appear to represent an obstacle for students in terms of introducing discontinuity. We recommend that follow-up research explore when students feel willing to discuss discontinuity in a supervision conversation. Such research might also include other types of teacher education program.

Given that discontinuity seems to be addressed naturally in supervision conversations, discussing occasionally complex and personal themes may become an explicit and unexpected aspect of supervision. As a result, teacher educators participate, both solicited and unsolicited, in personal reflections that can have a major influence on the self-confidence of their students (cf. Zembylas, 2003). This can lead to feelings of uncertainty and doubts about behavior among teacher educators (Cuenca, 2013) and necessitates exploration of their role and expertise. We recommend paying attention to the parallel process among teacher educators: the professional development of teacher educators also largely relates to the ongoing process of reflecting on who you are as a professional and what is expected of you in the profession (cf. Loughran, 2014; Swennen, Jones, a Volman, 2010). Especially given that supervising students with experiences of discontinuity can be characterized as complicated and difficult, we deem it necessary to gain greater insights into the challenges that teacher educators experience. Aside from the fact that such supervision is unpredictable and dialogical, it is difficult to adapt to the needs of student teachers as they manifest considerable differences (Chapter 2) and develop in different ways during the teacher education program (Chapter 3). Standard examples of supervision approaches that might provide support are therefore difficult to identify. Follow-up research may offer insights into the ways in which trainers understand and approach such complex supervision.

Discussing discontinuity in supervision conversations to facilitate development in teacher education implies that there should be room for peer consultation among teacher educators. Sharing doubts about supervision and discussing possible approaches for complex issues will support teacher educators in dealing with professional uncertainty. The three dialogical strategies identified 
in this study may provide a framework for analysis because they offer support in ensuring that an experience of discontinuity does not automatically lead to a downward spiral of diminished professional motivation. In the case of experiences of discontinuity, teacher educators can make sense of their supervision by using three questions: How was it before and/or will it improve? What qualities and skills matter? To what extent is this actually an obstacle to further development?

This study has provided new insights into the dialogical nature of reflecting on discontinuity in supervision conversations (c.f. Ezzy, 1998; Hermans, 2003). It has illustrated how sense-making is influenced by both discussion partners (Lyra, 1999): teacher educators and student teachers alike ask questions in response to one another and emphasize consistency alongside the discontinuity. Therefore, we believe that the three questions about discontinuity suggested in the previous section can also play a role in the interaction between teacher and student. This study has shown that it is possible to address discontinuity without providing a concrete solution to the problem: making room for continuity assists student teachers in their development. Discussing discontinuity is not only about what needs to be changed in a student teacher's functioning or thinking, but also about placing the experience of discontinuity within the student teacher's development as a whole. By means of reflection after or during the conversation, student teachers and teacher educators can also gain more insights into recurring patterns in development. Making these patterns explicit can contribute to the regulation of sense-making by student teachers in teacher education and subsequently during further professionalization. 


\title{
CHAPTER 5
}

\section{Teacher Educators Indicating that Change is Critical to Student Teachers ${ }^{9}$}

\begin{abstract}
Support for student teachers' development is generally expected to be concern-based and adaptive in teacher education. In contrast, sometimes teacher educators indicate that change is critical to student teachers, a finding for which the literature offers limited, and diverging rationales. In this study, we explore why and when, and how teacher educators indicate that change is critical to student teachers. We analyzed 42 audio-taped supervision conversations between six teacher educators and their 31 student teachers as well as eighteen interviews with these six teacher educators. Findings show that teacher educators indicated that change is critical when they considered student teachers' attributes inadequate and change doable, depending on their valuation of professional standards, essential attributes of student teachers and the timing of developmental interventions. Teacher educators indicated change in a directive way or a more considerate way, simultaneously expressing little to no doubt or additional considerations about whether the student teachers' attributes are inadequate and/or change is doable. Implications for teacher education are discussed.
\end{abstract}

9 Acknowledgement of author contributions: MR, LB, SA and JT designed the study, MR recruited participants and collected the data, MR analyzed the data, MR drafted the manuscript, all authors contributed to critical revisions of the paper, LB, SA and JV supervised the study. 


\section{INTRODUCTION}

"And I find that very hard. I think, should I... should I discuss that with her? Risking pulling the rug from under her even further."

Teacher educator Anna, reflecting in an interview [this study] on how to support student teacher Iris

During teacher education, student teachers reflect on teaching experiences in the light of their personal attributes and expectations of the teaching profession (Conway, 2001, Rodgers a Scott, 2008). These reflections can lead to doubts about current or to-be-developed abilities as a teacher when student teachers feel that their personal attributes conflict with the profession. Also, doubts can arise when student teachers notice that they are still missing certain attributes, which they therefore need to develop. Doubts can increase frustration or reduce self-efficacy and ultimately result in student teachers giving up on teacher education or deciding not to enter the teaching profession after graduating (Beijaard, Meijer it Verloop, 2004, Cole at Knowles, 1993). Hence, teacher educators are expected to support student teachers when they experience doubts about their abilities as a teacher (cf. Cuenca, 2012, Meijer, 2011), for instance by exploring student teachers' qualities (Korthagen, 2004).

Recently, it was found that teacher educators sometimes also raise questions that imply that it is critical for student teachers to change attributes, that teacher educators consider essential for the profession (Chapter 4). This finding aligns with scholars stressing the importance of assisting student teachers in dealing with problems while they still can receive support during teacher education (Meijer, 2011, Stokking, Leenders, de Jong \& van Tartwijk, 2003). However, indicating that change is critical to student teachers can be considered risky as it can evoke doubts in student teachers, with potential negative consequences for their well-being and developmental progress (Gipe at Richards, 1992, Tang, 2003). Moreover, indicating that change is critical appears to conflict with the generally accepted assumption in teacher programs that it is necessary to adapt supervision to student teachers' concerns (Korthagen, et al., 2001), reflecting a preference for having student teachers direct their own development (Beauchamp, 2015; Bronkhorst, Meijer, Koster \& Vermunt, 2011).

In this paper, we explore why and when, and how teacher educators indicate that change is critical to student teachers, given the risks involved. We analyze consecutive interviews with teacher educators and audio-taped supervision conversations from a one-year teacher education program to study teacher educators' actions and considerations in the context of authentic supervision relationships. 


\section{THEORETICAL FRAMEWORK}

\section{Student teachers Making Sense of Themselves as Teachers}

Student teachers' sense-making of one's self as a teacher over time (Ezzy, 1998; Ferreira, Salgado, Cunha, Meira a Konopka, 2005) is reflected in the dynamic constellation of personal attributes considered relevant for the profession by the student teacher (i.e. the vocational self-concept, Super, Strahishevsky, Matlin, at Jordaan, 1963). Student teachers' sense-making includes perceptions of their past and expectations of their future. New teaching experiences can put perceptions and expectations to the test. Consequent reflections may result in experiences of continuity but also discontinuity in a student teachers' vocational self-concept: instances of a sense of consistency or inconsistency about current or to-be-developed attributes relevant to the profession (cf. Akkerman at Meijer, 2011; Alsup, 2006; Beijaard a Meijer, 2017).

Experiences of continuity contribute to self-efficacy and general well-being (cf. Bruner, 1990; Caspi at Moffit, 1991; Sani, 2008; Zittoun et al., 2013). Empirical research illustrated that student teachers experience continuity when they feel that their attributes and experiences are in line with what is expected from them as a teacher, if they trust in their developmental progress and/or they know what they can do in order to develop (Chapter 2 and 3). Experiences of continuity are advocated for student teachers since they can contribute to the confidence needed to pursue development (Gipe at Richards, 1992; Tang, 2003).

Student teachers may also experience discontinuity at times, for instance when a "rapid succession of new experiences challenge existing schema, attitudes, and adaptation patterns" (Caspi it Roberts, 2001, p. 51). Student teachers have been found to experience discontinuity if they do not know what is expected of them in the profession, if they have doubts about self-attributes in relation to the profession and/or if they are uncertain whether they can change in the direction that is necessary (Chapter 2).

Experiences of discontinuity may hamper further development if the experiences are considered disproportionate or when such experiences last too long (Gipe at Richards, 1992, Tang, 2003). Whether or not experiences of discontinuity are harmful depends on the perceptions and expectations of individual student teachers and seems to be related to a compensating amount of experiences of continuity simultaneously. (Chapter 3 ). Again, what is considered reasonable in this context depends on the individual student teacher.

Researchers have reported predominantly on the potentially undesirable effects of experiences of discontinuity, documenting student teachers' typical tensions and coping strategies for dealing with experiences of discontinuity (e.g. Fuller, 1969; Fransson đ Grannäs, 2013; Pillen et al., 2013), although case studies testify to the productive potential of discontinuity for student teachers' development (Bronkhorst, Koster, Meijer, Woldman a Vermunt, 2014; Middleton, Abrans, Seaman, 2011). Accordingly, teacher educators have been stimulated to support student teachers in avoiding and dealing with experiences of discontinuity (Beltman, Mansfield At Price, 2011; Johnson et al., 2014). 


\section{Teacher Educators' Support of Student Teachers' Sense-Making}

Teacher educators are expected to use supervision conversations for discussing student teachers' reflections on their performance in practice, the professional demands, and vocationally relevant self-attributes (cf. Alsup, 2006; Beijaard a Meijer, 2017). Additionally, they use instruments such as journals and portfolios to stimulate student teachers to reflect on their teaching experiences and their development (e.g., Korthagen et al., 2001; van Tartwijk, van Rijswijk, Tuithof, a Driessen, 2008). In the literature, teacher educators are encouraged to adapt their supervision to the concerns of student teachers (Korthagen et al., 2001) and to emphasize the strengths of the student teachers (cf. Shoffner, 2011). Teacher educators have also been advised to address positive teaching experiences (Janssen, De Hullu, it Tigelaar, 2008; Korthagen et al., 2001) or assist student teachers in exploring alternative, effective teacher behavior in a systematic way in order to overcome problems in teaching practice (Bronkhorst, Meijer, Koster it Vermunt, 2011). By using such approaches, it is implied that teacher educators should emphasize experiences of continuity while assisting student teachers in overcoming experiences of discontinuity.

A recent study illustrated how in supervision conversations teacher educators sometimes introduce an issue that is not a concern of the student teacher, indicating that change is critical to student teachers (Chapter 4). The quote at the start of this chapter of teacher educator Anna illustrates that indicating critical change involves discomfort ("I find that very hard") as well as awareness of potential consequences for student teachers ("Risking pulling the rug from under her even further"), which raises the question why teacher educators would do this.

The literature across different domains offers different suggestions. It may be that teacher educators want to confront student teachers with potential problems to explore the viability of teaching as a career option for the long term (Rots, Aelterman \& Devos, 2014) and support student teachers in dealing with problems while they are in teacher education (Stokking, Leenders, de Jong it van Tartwijk, 2003; Meijer, 2011). This aligns with the idea that indicating that change is critical can be productive for student teachers' learning, as resulting experiences of discontinuity can be triggers for development (Akkerman \& Bakker, 2011; Bronkhorst et al., 2014). However, forcing student teachers to reflect on specific issues has been found to result in student teachers' avoidance of the problem, feelings of lack of control, and hostility towards their supervisor (Beauchamp, 2015). Moreover, an enduring sense of discontinuity can have negative consequences such as decreasing self-esteem, uncertainty, self-efficacy and motivation (Carpentier at Mageau, 2013; Fedor, Davis, Maslyn it Mathieson, 2001; Lechermeier it Fassnacht, 2018). We expect that when teacher educators indicate that change is critical to student teachers, they somehow account for expected benefits and risks and weigh available information as well as intuition (comparable to strategies for supporting clients, patients and pupils described by e.g. Audétat, Laurin, Dory, Charlin at Nendaz, 2017; Eva, 2004, Norman et al., 2017, Vanlommel, 2018).

Another question that arises, is how teacher educators stress that change is critical in a supervision conversation. Supervisors in different domains have been found to distort, delay or withhold 
information that indicates that change is critical or deliver it with anxiety (Carpentier a Mageau, 2013, p. 424, see also Lizzio, Wilson a Mackay, 2008), because of the potential negative consequences for the recipients and the quality of the supervision relationship. This caution in stressing the need for change can also be expected in teacher education since it can be considered at odds with the aforementioned supervision approaches stressing student teachers' qualities and adaptively supporting student teachers' directing their own development (Koetsier a Wubbels, 1995; Korthagen et al., 2001). Therefore, we aim to answer the following research question: Why and when, and how do teacher educators indicate that change is critical for student teachers?

\section{Method}

\section{Participants and Context}

We purposefully selected six teacher educators from a one-year ${ }^{10}$, post-master teacher education program. The program is located at a research university in the Netherlands and allows student teachers to obtain a subject-matter specific teaching license for secondary education.

The selected six teacher educators have two to twenty years of supervision experience in this teacher education program and each supervised at least five student teachers. All teacher educators have a subject-specific teacher license for secondary education themselves and also have experience with teaching in secondary schools for several years. Table 2, included in the Results section, gives an overview of the supervisors and the student teachers that participated in this study. The teacher educators are familiar with, and trained in, adapting to student teachers for optimizing supervision (cf. de Kleijn, Meijer, Brekelmans, at Pilot, 2015; Van de Pol, Volman, ¿t Beishuizen, 2010).

In the teaching philosophy of the teacher education program in which these teachers educators work, the pedagogy of realistic teacher education has a central place (Korthagen et al., 2001). In this philosophy, adapting to student teachers' concerns, learning from experiences, and using theory to analyze and understand these experiences are key ingredients. Already after the first week after the start of the program, student teachers combine courses at the university with teaching at placement schools. Internships are organized in such a way, that student teachers' responsibility for the teaching of classes in their placement schools gradually increase during the program (Koetsier a Wubbels, 1995).

In this teacher education program, the teacher educators organize courses in which theory is

10 Student teachers can also complete the program in two years when they study part-time, for instance because they combine studying with a paid job in teaching or when they participate in one of the Education and Communication Master programs, in which subject specific courses in the domain of teaching and learning of school subject (the domain of these master programs) are combined with courses with a focus on preparing students for teaching the subject as teachers. 
discussed, and student teachers are stimulated to reflect on their teaching experiences in the schools. The teacher educators supervise a selection of the student teachers from these courses individually and they organize, also on request of the student teachers, several supervision conversations during the teacher education program. At least twice a year there is a formal meeting in which the so-called practice dossier is discussed. This dossier is a portfolio-like document in which student teachers show the level of their professional performance using documents, videos, evaluations and reflections (Van Tartwijk, Van Rijswijk, Tuithof it Driessen, 2008). Other, more informal, supervision meetings include reflection conversations after lesson visits and conversations about developmental progress without a practice dossier.

\section{Procedure}

We informed the teacher educators about the design of the study and after that the teacher educators informed their student teachers, telling them that all data gathered for this study would be processed anonymously and that they could quit their participation in the study at any time without any consequences for their progress in teacher education. Furthermore, all student teachers were informed that the data would not be discussed between the teacher educators and the researchers to avoid possible consequences for the assessment of the student teachers. All teacher educators and student teachers gave informed consent by signing a consent form. The study was approved by the Ethical Committee of the Faculty of Social and Behavioral Sciences of the university.

\section{Data sources}

We asked the six teacher educators to audiotape the supervision conversations themselves, because we wanted the data collection to be as little disruptive as possible. The length of a supervision conversation varied from about ten minutes up to seventy minutes, the average length was thirty minutes. To be able to analyze a variety of types of supervision conversations, we selected 42 of 167 supervision meetings, equally distributed in time (first semester or second semester), over type of meeting (formal, i.e. discussing a practice dossier or informal), and over teacher educators.

We also interviewed each of the six teacher educators three times during the one-year period in which they supervised the student teachers, in order to collect a rich and complete picture of the reasoning involved in supporting the student teachers' development. The first interview was held after about six weeks after the start of the teacher education program, making sure that teacher educators did have time to get to know their student teachers during the introductory conversation. The second and third interview were held halfway through and at the end of the one-year period.

The interviews all had a semi-structured design. The lead author, who did the interviewing, 
asked general questions to the teacher educators about how they conceived and supported student teachers' development, as an intentionally open approach for exploring whether and how teacher educators indicate that change is critical to student teachers during regular supervision. The interviews included questions exploring (1) the supervisors' perceptions of student teachers' development (e.g. "What can you say about the teacher developmental process of student teachers that you supervise?") and (2) the supervisors' perceptions of their own supervision and support of student teachers (e.g. "What do you do to support student teachers to identify with the profession?"). Specific topics were student teachers' sense-making as teachers, occurring tensions in student teachers' development, changes in development over time, and support of student teachers' development in and outside the context of teacher education. In the interviews, we used techniques to stimulate the teacher educators to elaborate on abstract and complex concepts (cf. elicitation techniques; Barton, 2015). For instance, we used sorting cards to stimulate teacher educators to reflect on differences and similarities between student teachers.

\section{Analysis}

All 42 supervision conversations were transcribed by the first author. In the resulting transcription sequences related to one theme or topic (units of meaning), discussing perceptions of the past and/or expectations of the future, were identified using a detailed scheme that was developed in an earlier study (Chapter 3, see Appendix 1). Subsequently, the supervision conversations were characterized in terms of the dominant perception of the past and the dominant expectation of the future being discussed (i.e. sense of continuity, sense of discontinuity or ambiguous sense of (dis)continuity, see Table 2). Dominance was determined by considering the emphasis throughout the entire conversation, establishing which perceptions and expectations were most elaborated on and represented the general sense of (dis)continuity expressed by the student teacher (similar to the procedure used for the teacher profiles in Chapter 2).

Then, instances in which teacher educators indicated change (i.e. introducing information that was new, unsettling, unwelcome and/or unknown to the student teachers) were identified $(\mathrm{N}=37)$. Drawing on Ibrahim (2013), in each of these 37 instances teacher educators interventions were characterized in terms of ranging from directive to nondirective (Table 2, in the column type of interventions). Student teacher reactions, ranging from no (verbal) acknowledgement to actively debating the change, were described for each instance. Also, we listed if the sequence occurred in a supervision meeting of formal or informal nature and if it was held in the first or second semester (column type of meeting(s) in Table 2).

The interviews were transcribed verbatim by a student assistant. Building on research on professional self-understanding (Kelchtermans, 2009) and supervision in the context of student teachers' development (Byrd At Fogleman, 2013; Crasborn, Hennissen, Brouwer, Korthagen $A$ Bergen, 2011; Cuenca, 2013), all instances in which a teacher educators described their supervision approach were identified and summarized per teacher educator by a research assistant and 
verified by the first author (see supervision approach, Table 2). In this analysis, the specific attention for considerations of why and when teacher educators indicate that change is critical lead to the identification of three interrelated themes each teacher educator considered distinctively when introducing change, detailed in the results. In parallel, teacher educators' descriptions of each of their student teachers' development were identified and summarized per student teacher by the same research assistant and checked by the first author (see characterization of the student teacher in Table 2).

Last, in the interviews we traced teacher educators' specific considerations before, and reflections afterwards, of the 37 sequences identified in the supervision conversations, specifically focusing on considerations pertaining to why and when, and how change is indicated. Findings in terms of why and when, and how teacher educators indicated the necessity of change in the interviews and the supervision conversations appeared to align and we present the findings accordingly in the results.

\section{RESULTS}

\section{Why and When Teacher Educators Indicate that Change is Critical}

Teacher educators indicated that change is critical when (1) they considered student teachers' attributes inadequate, signaled by the use of words like: insufficient, problematic, too much or not enough and (2) the teacher educators estimated that change is doable for the student teachers, signaled by using words like experiment, develop, learn, and step-by-step. For instance, in an interview teacher educator Ken states in his own words:

If student teachers show behavior that makes me think 'Yeah, well, it tells me something about you but it is really not fitting with the image I have of you as a teacher', then we will have a conversation about that.

The overview of the supervision meetings presented in Table 2 shows that teacher educators indicated critical change in different situations. Change was indicated in the first and second half of the teacher education program and in meetings of an informal as well as a formal nature. Teacher educators indicated that change was critical to different types of student teachers, as they were characterized by the teacher educators, both in conversations in which student teachers displayed a general sense of continuity (suggesting a positive, confident attitude about development as a teacher), an ambiguous sense of (dis)continuity, and in conversations in which student teachers expressed a general sense of discontinuity (suggesting doubts and insecurity about development as a teacher). Table 2 shows that two teacher educators, Anna and Matt, indicated change more often than the other teacher educators. 


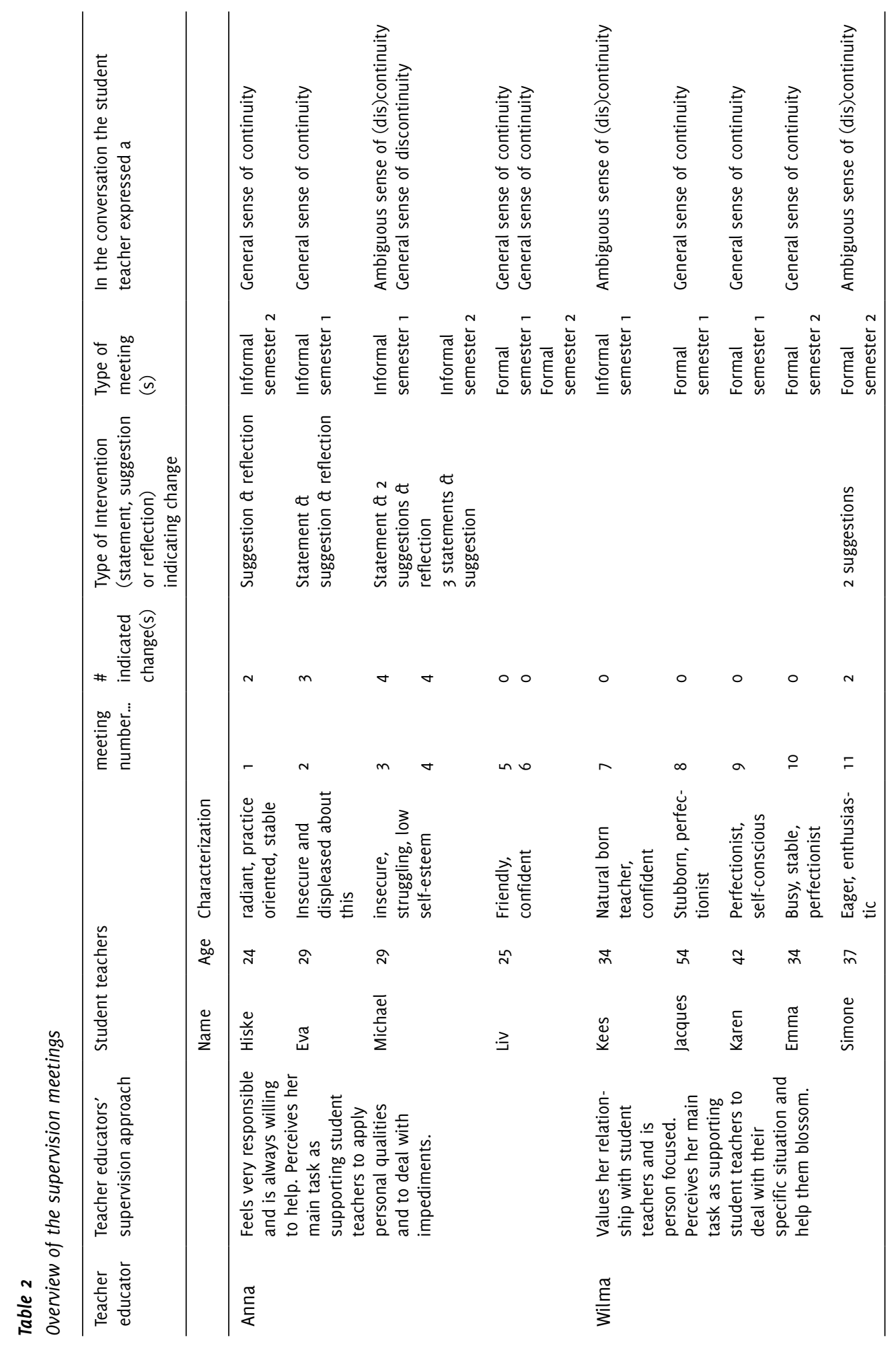




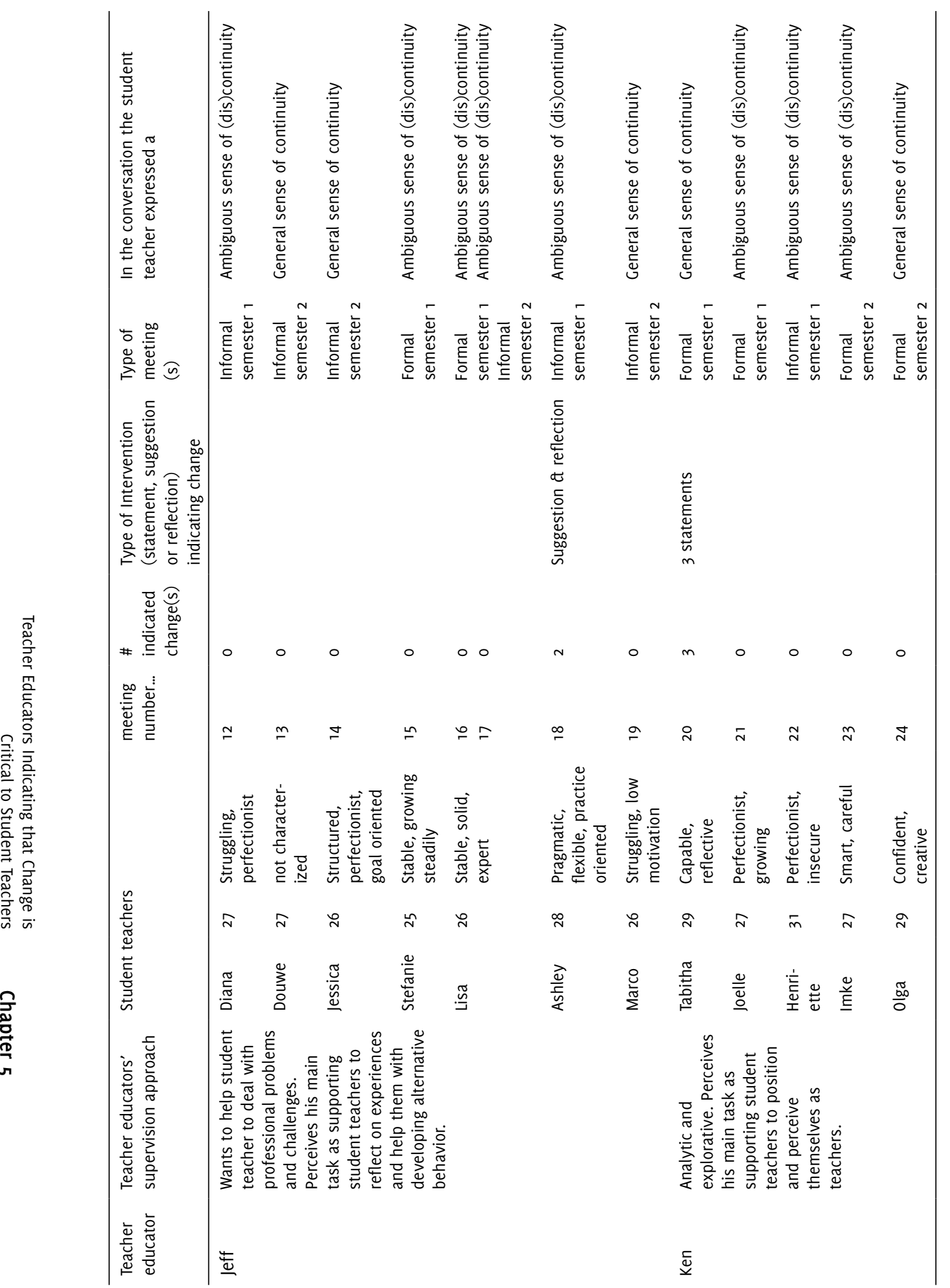




\begin{tabular}{|c|c|c|c|c|c|c|c|c|c|c|}
\hline 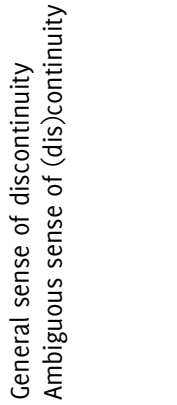 & 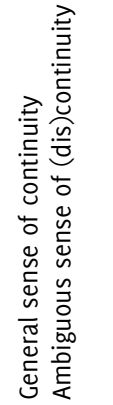 & & 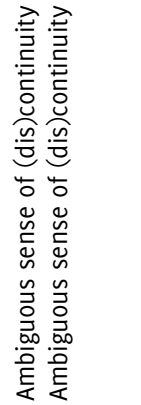 & 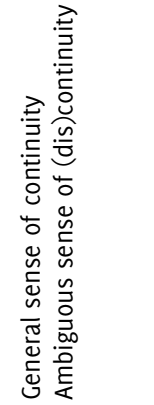 & 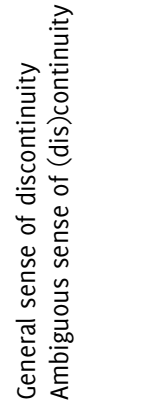 & 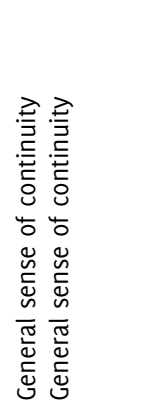 & 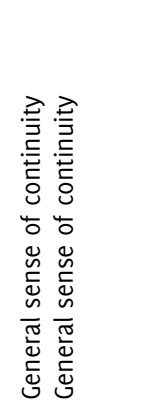 & 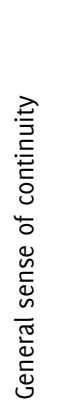 & 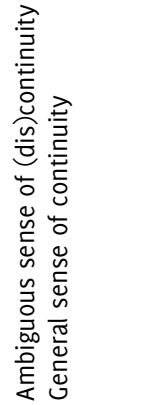 & 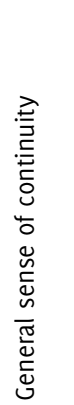 \\
\hline 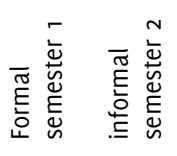 & 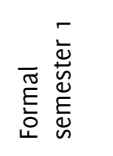 & 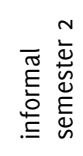 & 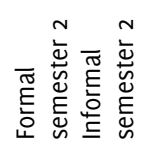 & 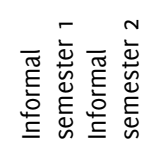 & 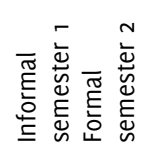 & 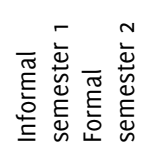 & 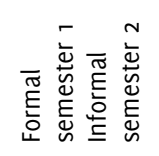 & 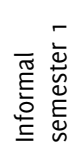 & 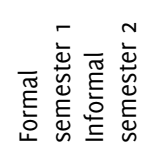 & 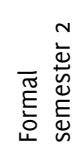 \\
\hline 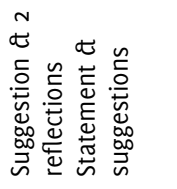 & 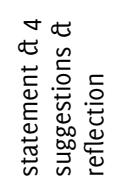 & & & 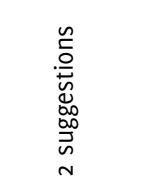 & 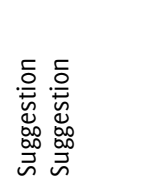 & & & 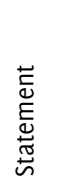 & & 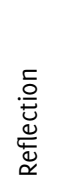 \\
\hline$m \sim$ & $0 \quad 0$ & & $\circ 0$ & O N & - & $\circ 0$ & $\circ 0$ & - & $\circ 0$ & - \\
\hline$\stackrel{\sim}{\sim}$ & $\hat{\sim} \quad \infty$ & & $\stackrel{i}{\mathrm{n}}$ & $\bar{m} \tilde{m}$ & $m$ 品 & $\stackrel{n}{m} \stackrel{\circ}{m}$ & $\hat{m} \stackrel{\infty}{m}$ & $\stackrel{a}{m}$ & \& F & ₹ \\
\hline 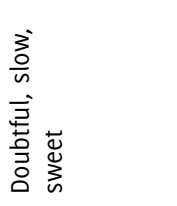 & 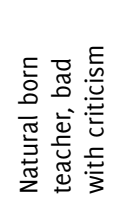 & & 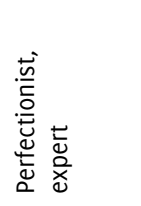 & 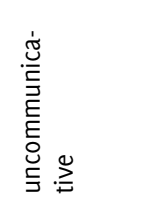 & 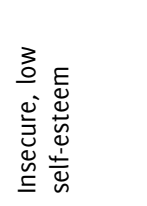 & 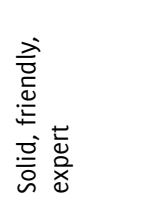 & 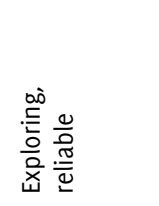 & 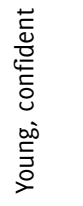 & 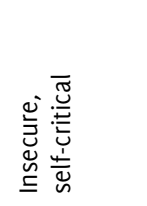 & \\
\hline$\stackrel{\infty}{\sim}$ & N & & $\hat{\imath}$ & i & $\stackrel{\sim}{N}$ & A & $\stackrel{4}{A}$ & $\stackrel{m}{\sim}$ & $\stackrel{m}{\sim}$ & A \\
\hline 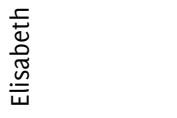 & 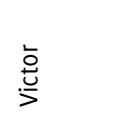 & & $\begin{array}{l}\frac{5}{0} \\
\frac{\pi}{\pi} \\
\frac{\pi}{n}\end{array}$ & $\frac{u}{\tilde{\sigma}}$ & 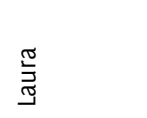 & $\frac{n}{9}$ & $\underset{\stackrel{\vec{\oplus}}{\vec{y}}}{\overrightarrow{2}}$ & $\cong$ & $\begin{array}{l}\text { ते } \\
\text { 요 }\end{array}$ & $\begin{array}{l}\overline{\bar{\nu}} \\
\stackrel{\vec{\partial}}{\alpha}\end{array}$ \\
\hline 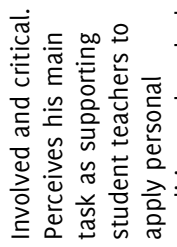 & 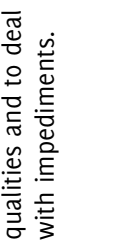 & & & & & 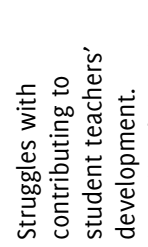 & 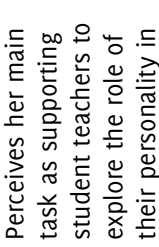 & 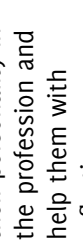 & 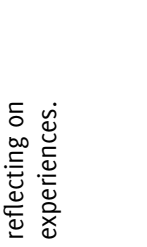 & \\
\hline 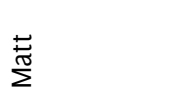 & & & & & & $\begin{array}{l}\text { ్్ } \\
\frac{\pi}{0}\end{array}$ & & & & \\
\hline
\end{tabular}


The teacher educators in this study shared basic assumptions about the supervision of student teachers' development, characterizing it as adapting to individual student teachers' needs and showing to be continuously on the alert for changes within student teachers. Nevertheless, they differed in when they considered student teachers' attributes inadequate and/or change doable. Differences in pertained to (1) valuation of professional standards, (2) essential attributes of student teachers, and (3) the timing of developmental interventions.

A first difference between teacher educators concerned their valuation of the professional standards. All teacher educators used the same professional standard for assessing the student teachers, namely the set of rubrics describing adequate teacher behavior implemented by the teacher education program based on national standards. Nonetheless, individual teacher educators emphasized specific aspects of the standard as especially valuable (see also column teacher educators' supervision approach in Table 2). For instance, teacher educator Anna, who described her supervision as supportive of concerns and personal, values a (student) teacher to be prepared for class:

If you have to improvise during a lesson, you make it difficult for yourself. So, I'm really strict about that. Once I visited someone who says: 'Yeah, I'm going to see how it goes'. Then I said: 'Really, you have to be kidding me?!' I find that really a disgrace. I think pupils are entitled to that [good preparation], and yeah you are less experienced of course ... so you have to make sure you have your facts in check.

In this quote from one of the interviews, Anna elaborated on why she values good preparation, for the pupils and for the student teachers ("If you have to improvise, you make it difficult for yourself"). She finds being prepared clearly important; she claimed to be "really strict" about it in supervision. Other teacher educators did not emphasize the importance of this aspect of teaching and considered other aspects of the professional standard as especially valuable. For instance, Jeff emphasized the importance of activating the learning of pupils in his second interview, and he reflected on a lesson visit of student teacher Ashley:

[During the lesson] only the group of pupils that gave a presentation were active.

The other pupils were consuming and non-active. And she literally told a pupil: 'As long as you are present and quiet, then it is ok.' This was illustrative of her pragmatic approach. She did not think about how to activate the thinking and reflections of the pupils. Ashley really needs information from the outside to realize that (...) She is not independent enough to do that herself.

Jeff mentioned that he felt the need to introduce information about activating pupils' learning to student teacher Ashley ("she needs information from the outside to realize that").

A second difference between teacher educators concerned essential student teachers' attributes. All teacher educators considered attributes such as indecisiveness, being overcontrolling, irresponsibility or flippancy as inadequate, hampering student teachers' development, and thought these should be addressed. Some teacher educators (Anna, Wilma and Matt), however, also considered change to be critical when student teachers could or would meet a sufficient 
professional level of teaching. They specified that student teachers who they referred to as "natural born teachers" sometimes also needed to be reminded that their teaching could always be improved. For instance, teacher educator Matt commented on student teacher Victor, who he described as someone who does not respond to criticism well:

Victor could almost have obtained his certificate after half a year. But he has to learn to be open to criticism and become a nicer person. Yeah, he has to fail a couple of times so he will think: 'ow shit, this is unattractive quality of me'. People have to confront him a number of times, be blunt with him.

Matt seemed to assume that "failing a couple of times" would help Victors' development. This quote also reflects teacher educator Matt's willingness to stimulate Victor into becoming "a nicer person".

Another difference between teacher educators' considerations of essential student teachers' attributes was whether or not their focus included the personal situation of the student teacher. For instance, teacher educator Ken separated "personal questions" from "being a teacher":

For me, the focus of student teachers' development is being a teacher. That is why we meet. So I do not support student teachers about personal questions.

Contrarily, teacher educator Wilma reflected on the interconnectedness of personal problems and student teachers' development:

You have to dare to engage in the quest of the student teachers, because it is often very personal. For instance, that lady who was going through a divorce. Yes, that is part of our supervision conversations. And it should be.

Interviewer: And, why is it necessary according to you?

reah, because... I just know it...(...) and I give her a specific advice because I know from experience of the claims her school will try to put on he. I say to her: 'you have to deal with your children now, they have to adjust to the situation, so take it easy in your practice school.' (...) It is not as if asking about their private situation is the standard, but somehow it always comes up (...) It is also important to get a complete image of a student teacher.

Teacher educator Wilma stressed the importance, and inevitability, of taking the whole person of the student teacher into account when supporting student teachers' development.

The third difference concerned teacher educators' considerations about the timing of developmental interventions. Some teacher educators expressed limited reflections on the timing of indicating that change is critical to student teachers, whereas others expressed more considerations, including whether change should be effectuated now or in a later stadium and/or at what moment the change should be indicated. Various concerns were taken into account, such as student teachers being able to accept the information at this moment, the urgency of the perceived issues and the ability of student teachers to persevere throughout teacher education. For instance, in her first interview teacher educator Wilma elaborated on a dilemma she experienced 
when considering indicating critical change at a certain point in a student teachers' development ${ }^{11}$ : That is my dilemma. On the one hand I want to provide her with a basis, communicate that she can be who she wants to be. And after that we will discuss her [negative] views about the educational system and her position as a teacher. I think it is too soon to address this, but at the same time I think that if I don't do it [address her attitude] she will come into conflict with the group of students or her colleagues.

Teacher educator Wilma questioned when confronting the student teacher with her aversive attitude towards the educational system would be beneficial for her developmental progress.

In general, all teacher educators were explicitly aware and censorious of their own judgement when they considered to indicate critical change to student teachers. Teacher educator Bianca reflected on a supervision conversation with student teacher Bobby, whom she characterized as insecure and self-critical. In the conversations, Bobby was startled after Bianca reflected on problems with classroom management. Based on this experience, Bianca reasoned that:

I have to be careful in how I address my concerns and I have to check how she receives my feedback. She is way more insecure then I first thought. So, I really have to be more careful.

Interviewer: And what does careful mean? Be less confronting?

Yes, ask more questions, check how she herself thinks about it. I do not know if my assessment is correct, I have to check this.

\section{How Teacher Educators Indicate that Change is Critical to Student Teachers in Supervision Conversations}

Teacher educators used three qualitatively distinctive interventions when they indicated change: a directive statement (e.g., "You have to force the pupils to go to work"), a somewhat explorative suggestion (e.g., "You could try to rely more on your routines") and an explorative reflection (e.g., "I would like to prevent you from experiencing severe problems in the classroom"). The intervention used by the teacher educator appeared to align with their reflections about the student teachers in the interviews.

\section{A directive way of indicating critical change}

In about a third of the cases (11/37), as can be seen in Table 2, column type of intervention, change was indicated by using statement-like interventions, including suggestions for the nature of change. These statements and suggestions elicited little discussion about the change itself. Simultaneously, the teacher educators expressed little to no hesitations about whether or not student teachers' attributes were indeed inadequate and/or change was doable for the student

11 This student teacher quit the teacher education program after two months and is therefore not included in the study/Table 2 
teacher. That is to say, the change that should be realized seemed evident to the teacher educators and no reservations were expressed about the student teachers' ability to continue development. For instance, teacher educator Bianca talked with student teacher Iris about her developmental progress in her first practice period (supervision meeting \#39 in Table 2) and she stated:

Bianca $\quad I$ think at a certain moment you should make your progress explicit in

(teacher educator) your reflection reports. Now, it is really a lot, you have a muddle of goals which should be structured. You talk about it quite well, but...

Iris Yeah, ok.

(student teacher)

In the second interview we had with teacher educator Bianca, she reflected on her supervision of Iris and said:

In the assessment halfway through the first practice period I said: "Yeah, I like that things are going will, but this is not what I expect..." Well, I phrased it differently, but... If she wants me to endorse her developmental progress [which is part of the assessment of the practice dossier], she has to make sure that in her practice dossier her development is well documented.

It seemed that for Bianca telling the student teacher to change was commonsensical and unproblematic: the student teacher should make moderations to the practice dossier to allow Bianca to assess the quality of her teaching. Student teacher Iris seemed to confirm the statement of Bianca in the supervision conversation by responding with 'Yeah, ok'.

Likewise, teacher educator Matt confronted student teacher Laura in a supervision conversation about her attitude in the teacher education program (supervision meeting \#39 in Table 2):

Matt

(teacher educator)

Laura

(student teacher)

Matt

Laura
You are late with quite a number of assignments. You also did not inform me. That is sloppy. What is the reason for this?

I have not made time for it yet. Then, I think that I have not read enough, like I said before. First, I will go searching for all kinds of information which makes me inefficient. I go searching for stuff, which is not so much work as such, but I do not make the time.

But if it is not so much work you just can do it. There must be something behind it.

Yeah, the fear it won't be good enough.

In this sequence, teacher educator Matt stated that there should be a reason behind her sloppy behavior. Student teacher Laura responded by pointing to her fear of failure as an explanation of the sloppiness that Matt referred to. In an interview, teacher educator Matt explained how he valued good cooperation with colleagues as a key characteristic of a professional teacher, referring to the behavior of Laura in which he missed this:

Laura often oversleeps, she doesn't follow up on agreements, she doesn't respond to e-mails. Yeah, that is not ok for a team player. That is my ethical stance. I then tell her: Laura: if you have a job in about two years... you will not get a permanent position if 
you act like this. A team will spit you out. Sounds harsh, but really, this student-like behavior...

As such, in light of his professional standard ("That is my ethical stance"), Matt considered change for Laura as a team player evident. Matt did not include reservations about how his statement would affect Laura's self-concept and/or development throughout teacher education.

\section{A considerate way of indicating critical change}

In a majority of the cases (26/37) the teacher educators used considerate, less directive interventions, i.e. suggestions and reflections, including legitimations to indicate why change is critical to student teachers. These suggestions and reflections elicited further discussion with the student teacher about the indicated change. Simultaneously, in the interviews the teacher educators mentioned additional considerations: the inadequacy of student teachers' attributes seemed less evident and/or reservations about the student teachers' ability to change were made. We also found that these instances of indicating change triggered teacher educators' reflections on the supervision process itself afterwards.

A sequence from a supervision conversation between teacher educator Anna and student teacher Michael after a lesson visit is an example of a considerate way of indicating critical change (supervision meeting \# 3 in Table 2). In this conversation, Michael reflected on his classroom management and how he wanted to get the attention of pupils:

Michael I always want that people pay attention because it is interesting what I (student teacher) have to say. I want pupils to think "I cannot do that yet" and then become interested. And not because they are forced. Because I was always forced to listen, and I find that so very difficult. I find it really hard to take that [directive] role, I resent it...it hits me in my core, it really is my identity.

Anna I get your point, but I think you have to pull a switch in your head if you

(teacher educator) are in front of the class. Each teacher sometimes has to do something he does not like. It really is not so terrible if you teach a subject you do not care for yourself. It is important that you then really pull that mental switch...

In this supervision conversation, teacher educator Anna suggested to student teacher Michael how he should change ("pull a switch in your head") and legitimized this by elaborating on how each teacher sometimes has to do something he or she does not like and that he shouldn't bother about that too much ("it really is not so terrible").

In the interview halfway through the teacher education program, Anna was asked to elaborate on the development of the student teachers she supervised, and she typified Michaels' development as complicated. She talked about the relevance, the nature and timing of indicating change in the specific supervision conversation:

It was a first-grade class...noise, noise, noise. At one moment a bottle of lemonade literally flew across the classroom. Well, I rose and took the bottle, I did not look but I 
thought that plastic might break and then we have a classroom full of lemonade and we can't have that. I could have done two things: tell Michael this is not ok or do it myself and having a few pupils noticing that [my intervention]. So, I thought let me do this, in this chaos almost nobody will notice. And that [intervening during a lesson visit] is really against my principles. And then we have to have the supervision conversation and I do not know where to start... and then he says, 'I can only stay for half an hour because I have therapy.' Because he is also over his head in therapy. And then I'm really dissatisfied about my supervision, because I'm too directive. But then I think: he should learn something from this. (...) He has all the talent in the world, he speaks wonderful English because he knows his languages. He has got what it takes, but he cannot put it to use at all yet. (...).

In the interview, Anna reflected on the timing of when to indicate change because "he has got what it takes, but he cannot put it to use at all yet" and she deliberated on additional considerations about Michaels' ability to deal with hearing that change is critical ("over his head in therapy") and the necessity of the change ("But then I think: he should learn something from this [the chaotic lesson]"). The incident prompted Anna to reflect on her supervision approach as such ("then I'm really dissatisfied about my supervision"), evaluating her interventions retrospectively as "too directive".

Similarly, teacher educator Matt reflected with student teacher Marc in a supervision conversation on why he addressed an issue that he believed would hamper Marc's development (supervision meeting \#32 in Table 2):

Matt I think that if you would teach a fourth grade at my own school [the (teacher educator) school Matt works as a teacher himself] it would not be nice for you. In this school [the practice school of Marc], students have learned to work themselves. If there is disorder in the classroom, they focus on their own learning. In my school they are not familiar with this pedagogy. It would be very hard for you in this kind of classes at the moment.

Marc Well, that would not be nice. Actually, I'm a bit lost for words. I don't

(student teacher) know what to say if I'm honest - I am not surprised but it feels like a blow in the head.

Matt Yes, I can imagine that, but I have to be honest about what I see, also to protect you. I think you should take a few steps before I can say that you can apply for jobs at different kind of schools.

Teacher educator Matt put a lot of effort in explaining and legitimizing his intervention in this supervision conversation, elaborating on why he felt change is critical ("it would be very hard for you in this kind of class at the moment"), stressing his concern for Marc ("It would not be nice for you") and explaining why he offered this information ("to protect you"). Marc's response indicates that Matt's words hit home ("feels like a blow in the head").

In the third interview Matt looked back on the supervision conversation when asked to reflect 
on the developmental progress of Marc:

In February he experienced a dip, because I confronted him quite hard. Then I said that he actually did not realize how some pupils completely ignored him. So, then I really confronted him, like "Marc open your eyes... you did not even..." That shook him a lot. Interviewer: How did you notice that...

Well, he asked for another supervision conversation and in his evaluation, he wrote about it and during the conversation he said "Oh, if really find this confronting, I really don't know how to..." He literally said it. He did not know how to react.

Retrospectively, teacher educator Matt reconsidered his supervision approach, characterizing his intervention as confrontational and referring to a harsh message ("Marc, open your eyes...") that differs from the more cautious approach he took in the supervision conversation (I think that (...) It would not be nice for you).

\section{CONCLUSION}

In this study, we aimed to understand why and when, and how teacher educators in a teacher education program indicate that change is critical to student teachers, potentially evoking experiences of discontinuity. We analyzed 18 interviews with six teacher educators about supporting student teachers' development and critical change and 42 supervision conversations of the six teacher educators and their 31 student teachers, collected in a one-year post-master teacher education program. The research question we aimed to answer was: Why and when, and how do teacher educators indicate that change is critical to student teachers?

Results regarding the "why and when" showed that teacher educators indicated that change is critical when (1) they considered student teachers' attributes inadequate and (2) they estimated that change is doable for the student teachers. Instances of indicating change occurred in different situations; they were not tied to one type of student teacher or one type of meeting and were spread across formal and informal meetings in the first and second half of the program. Instances of indicating that change is critical occurred in conversations in which student teachers themselves predominantly expressed a sense of continuity, but also discontinuity.

Teacher educators differed in deciding on why and when change is critical and differences pertained to considering the valuation of professional standards, essential attributes of student teachers and the timing of developmental interventions. Regarding the valuation of professional standards, we found that individual teacher educators emphasized specific aspects of the standard as especially valuable for student teachers' development. In terms of essential attributes of student teachers, we found that some teacher educators also indicated that change is critical to student teachers that already met the needed professional level of teaching. We also found that some teacher educators included the personal situation of a student teacher, whereas others explicitly limited their focus on attributes they themselves considered relevant for the profession. 
In terms of the timing of developmental interventions we found that some teacher educators did not explicitly consider the timing of indicating critical change, whereas others elaborately reflected on benefits and risks involved in indicating change at a certain moment.

Regarding the "how", our results showed that the teacher educators used three qualitatively distinctive interventions to indicate change in supervision conversations: statement-like interventions, suggestions, and reflections. In about a third of the cases, statement-like interventions were used, including suggestions for the nature of change and eliciting limited discussion about the indicated change itself with the student teachers. Simultaneously, the teacher educators expressed little to no hesitations about indicating change in the interviews: the change that should be realized seemed evident to the teacher educators and they expressed no reservations about the student teachers' ability to continue development. In about two thirds of the cases teacher educators intervened in a more considerate way using suggestions and reflections, including legitimations that elicited further discussion of the indicated change with the student teacher. Simultaneously, the teacher educators expressed additional considerations about indicating that change is critical in the interviews. These considerations pertained to whether or not the inadequacy of student teachers' attributes was evident and/or reservations about the student teachers' ability to continue development were made, including dealing with the potential discomfort that student teachers may experience as a result of the change. Moreover, we found that these instances and thoughts triggered reconsiderations of the supervision of the student teacher.

\section{DISCUSSION}

The reason for teacher educators to indicate that change is critical for student teachers' development seems plausible as it aligns with general goals for supporting student teachers' development: helping student teachers to progress throughout teacher education towards the intended outcome (i.e. mastering the critical aspects of teaching). However, the results showed that assessing why and when change is critical is a complex process, comparable to what has been found in other domains (cf. Audétat et al., 2017; Eva, 2004, Norman et al., 2017, Vanlommel, 2018). Specifically, results of this study show how different and sometimes competing considerations are involved, pertaining to respectively the valuation of professional standards, essential attributes of student teachers and the timing of developmental interventions.

Particularly challenging in assessing if and when change is critical is that the professional standards used in the teacher education program purposefully leave room for a teacher educators' specific emphasis, as they do not describe a set profile consisting of mandatory concrete behavior (van Tartwijk et al., 2008). While it is important to have relatively "open" standards because of the variety of educational settings and thus internships in which student teachers operate (i.e. with teaching ranging from lecturing to coaching), teacher educators are also expected to align their criteria in assessments. Our results showed that two teacher educators indicated change more 
often than the other teacher educators. Even though our analysis does not afford a definitive explanation for why this is the case, it may be that teacher educators not only differ in what aspects they in particular emphasize when valuing the professional standards, but that they also set a different bar. Moreover, student teachers' attributes are plural and change over time (Chapter 2 and 3), meaning that teacher educators continuously need to assess if the change they consider critical is or cannot be compensated by other attributes or if the change will occur "naturally" in student teachers' development without intervention on their part (see also Chapter 4). Last, the timing of interventions in a one-year teacher education program, in which student teachers have to learn a lot in a short period of time, involves tight planning (Alsup, 2006; Chapter 3 ). This study illustrates how teacher educators have to handle a complex set of nested and interrelated reflections, analyzing and anticipating possible consequences of a certain course of action. Consequently, assessing if and when change is critical draws on a teacher educators' professional responsibility and accountability (similar to what has been found for other professions cf. instance Norman et al., 2017, Vanlommel, 2018).

Also, we need to take the fact into consideration that next to supporting student teachers' development, teacher educators have to evaluate if and when student teachers meet the criteria for graduation. Results showed that teacher educators sometimes consider current or developed student teachers' attributes inadequate (considerations pertaining to evaluation), while unsure if the student teacher can manage the change, as discontinuity might be evoked (considerations pertaining to supporting development). This conflict in responsibilities marks a dilemma for teacher educators (Cuenca, 2013); teacher educators have to monitor if and when the student teachers develop into capable teachers and at the same time have to support their developmental progress throughout teacher education.

Results showed that how teacher educators indicate change is critical to student teachers can be quite directive or considerate. Simultaneously, we found that teacher educators can be seemingly sure and decisive or hesitant and doubtful about whether or not change is critical. Although our design does not warrant causal interpretations, these findings pertaining to how and why educators indicate change is critical seem related. For instance, in the instances in which the teacher educators did include little to no hesitations, the student teacher showed little to no response. This can mean that the student teacher accepted the indicated change as logical and manageable, but it can also mean that the student teacher did not feel free to discuss or contradict the statement of the teacher educator. In the instances in which the teacher educator him or herself expressed additional considerations about the change, student teachers elaborated on the change itself. This can mean that the perception of the teacher educator aligned with the perception of the student teacher (i.e. considering whether attributes are inadequate and change doable), but it can also mean that the nuances and legitimations of the teacher educators invited reflections about the indicated change itself.

Results also illustrated that indicating that change is critical to student teachers can be risky since statements, suggestions and reflections can indeed evoke experiences of discomfort and 
discontinuity in student teachers. On the one hand, this seems to be intended by the teacher educators, as they want to point student teachers towards attributes that are essential. on the other hand, teacher educators want to make sure that potential experiences of discontinuity are temporal, applying dialogical strategies identified as found in a previous study (Chapter 4), that help to create room for experiences of continuity next to the experiences of discontinuity.

\section{Limitations and Future Research}

The design of the study did not allow us to explore why and when teacher educators decide not to indicate change in supervision conversations. Future research could explore in what ways teacher educators' considerations differ when they decide against it. Such research could for instance use vignettes and/or stimulated recall interviews after supervision conversations. Also, student teachers' contributions in the supervision conversations raise questions about the impact of interventions on student teacher' development, the supervision relationships and student teachers' feelings of (un)safety, that we cannot answer with the current design. In future research, including interviews with the student teachers could inform us how they perceive teacher educators urging them to change.

In this study, we included only university-based teacher educators, from a particular teacher education program adhering to the pedagogy of realistic teacher education (Korthagen et al., 2001). We recommend future research on potential differences between university-based teacher educators and school-based educators (i.e. mentors) in whether and how they stress the need for critical change to student teachers. Such research could explore if considerations of other supervisors pertain to different attributes and/or if they put other emphases when regarding professional standards. Further research focused on indicating critical change in other types of teacher education programs could question if teacher educators include different considerations when the teacher education program is longer and/or not specifically adheres to the pedagogy of realistic teacher education.

\section{Suggestions for Practice}

Results alert us to the fact that the professional standards leave room for teacher educator' specific interpretations, as is the case in different teacher education programs (Darling-Hammond at Bransford, 2007). Consequently, we recommend that teacher educators and policy makers explicitly discuss how they interpret professional standards. Calibrating interpretations of the professional standard will allow supervisors to reflect on what professional responsibility in supporting student teachers entails, especially when indicating that change is critical to student teachers.

Results suggest that indicating critical change to student teachers can be part of a teacher education program that champions a concern-based, adaptive approach. In such instances, a teacher educator is not so much adaptive to the situational needs of student teachers but adapts 
his or her interventions to student teachers' development over time.

The results provide a warning that such interventions can be discomforting to teacher educators. Collegial consultation may enable teacher educators to openly discuss the anxiety that can be involved in indicating critical change (cf. Beauchamp, 2015; Lizzio et al., 2008). Moreover, discussing professional doubts will support teacher educators' development, also since the results illustrate how teacher educators adjust their supervision over time because of the interaction with student teachers and the responses to discussing experiences of discontinuity evoked by indicating that change is critical. We recommend creating a professional community for teacher educators that equally values discussing challenges and friction (cf. Carpentier C Mageau, 2013) as discussing the typically scheduled evaluations and efficiency. 


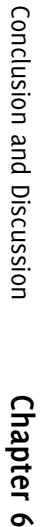




\section{CHAPTER 6 \\ Conclusion and Discussion}

The aim of this thesis was twofold. First, we aimed to characterize student teachers' development in terms of continuity and discontinuity, that is a sense of consistency or inconsistency about current or future attributes as a teacher, in and over time. Second, we aimed to understand how discontinuity can have a function in developmental progress throughout teacher education. In this final Chapter we first describe and discuss the results of the four different studies included in this thesis. After discussing the findings, we subsequently reflect on the concepts, designs and context of the four studies. After that, we elaborate on limitations and suggestions for future research. Finally, we present suggestions for practice

\section{DISCUSSION OF THE RESULTS}

\section{Past Perceptions and Future Expectations: Sensed (Dis)continuity at the Start of Teacher Education}

In our first study, described in Chapter 2 of this dissertation, we explored differences in student teachers' expectations and perceptions at the start of teacher education. We studied 35 teacher profiles (written vocational self-concepts at the start of teacher education) and showed that student teachers differ considerably in how they describe themselves as teachers at the start of teacher education. We identified four types of perceptions of the past and four types of expectations of the future throughout the teacher profiles. These perceptions and expectations form a framework that supports the understanding of differences among student teachers, see Table 1. 
Table 1

Past perceptions and future expectations illustrative of a sense of (dis)continuity

\begin{tabular}{|c|c|c|}
\hline Perceptions of the past & Description & $\begin{array}{l}\text { Expressing a } \\
\text { sense of }\end{array}$ \\
\hline $\begin{array}{l}\text { Consistency related to } \\
\text { attributes }\end{array}$ & $\begin{array}{l}\text { References that reflect certainty and confidence about } \\
\text { specific attributes and abilities as they are known to } \\
\text { the student teacher. }\end{array}$ & continuity \\
\hline $\begin{array}{l}\text { Consistency related to } \\
\text { experiences }\end{array}$ & $\begin{array}{l}\text { References to specific experiences with teaching, with } \\
\text { other professional experiences and/or as a student. }\end{array}$ & continuity \\
\hline No past & No description of the past & discontinuity \\
\hline Problems in the past & $\begin{array}{l}\text { References about negative attributes and problems } \\
\text { that reflect weak teacher conduct. }\end{array}$ & discontinuity \\
\hline \multicolumn{3}{|l|}{ Expectations of the future } \\
\hline Confidence & $\begin{array}{l}\text { References indicating clarity and certainty of expected } \\
\text { attributes and professional conduct as a teacher and } \\
\text { indicating confidence in a continuous development. }\end{array}$ & continuity \\
\hline Development & $\begin{array}{l}\text { References indicating probability of anticipated } \\
\text { attributes and professional conduct as a teacher and } \\
\text { indicating a phased nature of the developmental } \\
\text { trajectory. }\end{array}$ & continuity \\
\hline Goals & $\begin{array}{l}\text { References indicating pursued attributes and } \\
\text { professional conduct, without specific information } \\
\text { about what it will take to reach these goals. }\end{array}$ & discontinuity \\
\hline Challenges & $\begin{array}{l}\text { References problematizing the feasibility of required } \\
\text { attributes and professional conduct and the develop- } \\
\text { mental trajectory towards this. }\end{array}$ & discontinuity \\
\hline
\end{tabular}

In the teacher profiles, we distinguished three types of sensed (dis)continuity, illustrative of three different ways of identifying with the profession at the start of teacher education. First, profiles that expressed a general sense of continuity (14 out of 35), that is, feelings of consistency in development as a teacher in light of past perceptions and future expectations, suggested a positive attitude toward development as a teacher. Second, profiles that expressed an ambiguous sense of (dis)continuity (13 out of 35 ), that is feelings of consistency because of the past and feelings of inconsistency in light of the future about development as a teacher, illustrated how student teachers perceived development as a teacher as a changeable process, including specific points of improvement. Third, profiles that expressed a general sense of discontinuity (8 out of 35), that is feelings of inconsistency about development as a teacher because of the past and the future, were illustrative of the common understanding of teacher development as a challenging and strenuous process (Beijaard et al., 2004).

Although a general sense of continuity is commonly considered preferable for further professional development (Onafowora, 2005), it also can hamper development. When student teachers 
fail to realistically explore adjustments for professional development when they are needed (Caspi at Robers, 2001), they might get a false sense of infallibility (Greenwald ct Pratkanis, 1984) and/or are shocked when new experiences unexpectedly disrupt their sense of continuity (Alsup, 2006). In contrast, when perceptions of the past seem to specify expected difficulties for the future (as with an ambiguous sense of (dis)continuity), they provide student teachers with concrete points to worry about when entering teaching practice. Yet, a sense of discontinuity can function as a self-fulfilling prophecy, hampering further development when new experiences are interpreted while failure is already expected (Alsup, 2006; Greenwald it Pratkanis, 1984). On the other hand, student teachers with a sense of discontinuity seemed to be aware of the challenges that are an apparent part of teacher education and are prepared for the necessity of dealing with obstacles during teacher education.

In this study, almost a third of the 35 student teachers who participated perceived their development as a teacher as challenging and strenuous at the start of teacher education; a majority of the student teachers expressed confidence in their own development. The study showed significant intraindividual differences between student teachers at the start of teacher education in terms of identifying with the profession, raising questions about if and how identifying with the profession changes throughout teacher education.

\section{Changes in Sensed (Dis)Continuity in the Development of Student Teachers throughout Teacher Education}

In our second study, reported in Chapter 3, we focused on changes in the extent to which student teachers perceive and expect (dis)continuity in their development during teacher education. We studied 25 audiotaped supervision conversations of six student teachers to investigate when and how the initial sense of (dis)continuity of student teachers changes. In this study, we focused in detail on the way the six student teachers reflected on their vocational self-concept in the supervision conversations during teacher education; this resulted in an expanded framework for identifying past perceptions and future expectations of student teacher throughout teacher education (see Appendix 1).

Results showed that sensed (dis)continuity varies over time within student teachers in different ways, both in terms of when sensed (dis)continuity changes and, as well, the types of past perceptions and future expectations. An initial sense of (dis)continuity could not be related to a specific developmental trajectory and/or successful completion of teacher education.

Only one of the developmental trajectories described in this study could be related to the developmental pattern of overcoming disillusionment described in retrospective research (e.g., Meijer, de Graaf $\{$ Meirink, 2011). Another student teacher, who started off confident and enthusiastic gained a more detailed image of the profession over time, which helped him specifying its demands. However, he decided to quit teacher education, because of this, while recognizing himself that his performance level as a teacher was excellent. This reaffirms the importance of 
considering student teachers' sense-making for developmental progress.

This study showed that the three student teachers who graduated from the teacher education program expressed a dominant sense of continuity in their final conversation. Finalizing a developmental trajectory in teacher education seemed to coincide with perceiving coherence in past development as well as expressing confidence in future professional development. The student teachers who experienced insufficient continuity outweighing the sense of discontinuity were found to stop their development in teacher education, which elicits questions about if and how student teachers and teacher educators can address experiences of discontinuity in such a way that developmental progress is supported.

\section{The Function of Discontinuity in Developmental Progress}

In the third and fourth study, we focused more specifically on experiences of discontinuity in the development of student teachers. A sense of inconsistency about current or future attributes as a teacher seem inevitable in the process of reflecting on one's self as a teacher because of the often-confronting new experiences that are part of the first steps in the new profession. They also can be considered desirable because of their potential impact on learning; at the same time they are risky, as they can prompt or expand diminishing self-confidence and contribute to someone leaving the profession hastily and/or in an ill-advised fashion. In the second part of this thesis, we aimed to expand our understanding of how discontinuity can have a function in developmental progress.

\section{Teacher Educators and Student Teachers Discussing Discontinuity}

For our third study, presented in Chapter 4, we described how student teachers and university supervisors introduce and explore experiences of discontinuity during teacher education in such way that ongoing development is enabled. We studied 110 sequences from 42 audio-taped supervision conversations.

Results showed that discontinuity was a common feature of the supervision conversations we studied, introduced by both student teachers and teacher educators and in different types of supervision meetings (first and second half of the teacher education program, formal and informal). This means that discussing sometimes complex and personal topics is an explicit part of supervision in teacher education. Student teachers felt safe enough to introduce discontinuity, even if the supervision meetings were meant for monitoring and assessing student teachers' development.

After the introduction of discontinuity, teacher educators and student teachers together discussed its meaning; such discussions were aimed at exploring possibilities for ongoing development. Three dialogical strategies were used, usually in combination (see Table 2): (1) trusting in development (accepting that something has to change and trusting that this can happen because 
of what was already there and/or what will be); (2) compensating from the professional self (acknowledging that there is a problem or weakness and that there are other, additional qualities and skills available); and (3) re-evaluating the relevance of the sense of discontinuity (reconsidering the discontinuity itself in terms of its threat to further development).

\section{Table 2}

Three dialogical strategies and reflective questions for discussing experiences of discontinuity

\begin{tabular}{|c|c|c|}
\hline Dialogical strategy & Description & Reflective questions \\
\hline Trusting in development & $\begin{array}{l}\text { accepting that something has to change and } \\
\text { trusting that this can happen because of what } \\
\text { was already there and/or what is to come. It } \\
\text { relates to trust that change is possible. }\end{array}$ & $\begin{array}{l}\text { How was it before } \\
\text { and/or will it improve? }\end{array}$ \\
\hline $\begin{array}{l}\text { Compensating from the } \\
\text { professional self }\end{array}$ & $\begin{array}{l}\text { acknowledging that there is a problem or } \\
\text { weakness as well as that additional qualities } \\
\text { and skills exist. It pertains to relevant } \\
\text { attributes that outweigh discontinuity. }\end{array}$ & $\begin{array}{l}\text { What qualities and } \\
\text { skills also matter? }\end{array}$ \\
\hline $\begin{array}{l}\text { Re-evaluating the } \\
\text { relevance of the sense of } \\
\text { discontinuity }\end{array}$ & $\begin{array}{l}\text { reconsidering the discontinuity itself in terms } \\
\text { of its threats to further development. It is } \\
\text { related to the experience of discontinuity and } \\
\text { the exploration of an alternative standard. }\end{array}$ & $\begin{array}{l}\text { To what extend is this } \\
\text { actually an obstacle } \\
\text { for further develop- } \\
\text { ment? }\end{array}$ \\
\hline
\end{tabular}

We found that the discussion of discontinuity altered the experience of inconsistency of the student teacher. Most often (96 out of 110), the perspective on discontinuity changed, creating space for an additional experience of continuity. We also found that sometimes (14 out of 110) discussing discontinuity resulted in the deepening or strengthening of the experience of inconsistency when the student teacher placed the problem outside his/her span of control or when the student teacher extended the scope of the problem.

This study underlined how supervision conversations in teacher education are dialogical in nature, also when it comes to reflecting on doubts about development as a teacher (Ezzy, 1998; Hermans, 2003), and showed how inconsistencies in development can be addressed without providing a concrete solution for the problem at hand.

\section{Teacher Educators Indicating that Change is Critical to Student Teachers}

In our fourth study, described in Chapter 5 of this dissertation, we explored why and when, and how teacher educators indicate that change is critical to student teachers, despite the potential risks and discomfort for both the student teachers and teacher educators involved. We studied 37 sequences from 42 audio-taped supervision conversations and 18 interviews with teacher educators. Results regarding the "why and when" showed that teacher educators indicated that change is 
critical if (1) they considered student teachers' attributes to be inadequate and (2) they estimated that change is doable for the student teachers. Instances of indicating change were spread across formal and informal meetings in the first and second half of the program and in conversations in which student teachers themselves predominantly expressed a sense of continuity, but also discontinuity.

Teacher educators differed in deciding on why and when change is critical. These differences pertained to simultaneously considering the valuation of professional standards, essential attributes of student teachers and the timing of developmental interventions. Regarding the valuation of professional standards, we found that individual teacher educators emphasized specific aspects of the standard as especially valuable for student teachers' development. In terms of essential attributes of student teachers, we found that some teacher educators also indicated that change is critical to student teachers that already met the needed professional level of teaching. We also found that some teacher educators included the personal situation of a student teacher, whereas others explicitly limited their focus on attributes they themselves considered relevant for the profession. In terms of the timing of developmental interventions we found that some teacher educators did not explicitly consider the timing of indicating critical change, whereas others elaborately reflected on benefits and risks involved in indicating change at a certain moment.

Regarding the "how", our results showed that the teacher educators used three qualitatively different interventions to indicate change in supervision conversations: statement-like interventions, suggestions, and reflections. In about a third of the cases, statement-like interventions were used, including suggestions for the nature of change and eliciting limited discussion about the indicated change itself with the student teachers. Simultaneously, the teacher educators expressed little to no hesitations about indicating change in the interviews: the change that should be realized seemed evident to the teacher educators and they expressed no reservations about the student teachers' ability to continue development. In about two thirds of the cases teacher educators intervened in a more considerate way, using suggestions and reflections, including legitimations that elicited further discussion of the indicated change with the student teacher. Simultaneously, the teacher educators expressed additional considerations about indicating change in the interviews. These considerations pertained to whether or not the inadequacy of student teachers' attributes was evident and/or reservations about the student teachers' ability to continue development were made, including dealing with the potential discomfort that student teachers may experience as a result of the change. Moreover, we found that these instances and thoughts triggered reconsiderations of the supervision of the student teacher.

This study showed that indicating that change is critical does occur and can be characterized as a complex process, involving the teacher educator, the specific student teacher and the moment in teacher education. Results showed that indicating change can evoke experiences of discontinuity and discomfort in student teachers. Teacher educators acknowledged and reflected on the risks involved in indicating that change is critical and were explicitly aware and censorious of their own considerations. 


\section{CONSEQUENCES FOR UNDERSTANDING AND SUPPORTING STUDENT TEACHERS' DEVELOPMENT}

The first two studies in this dissertation show that student teacher development can be characterized as idiosyncratic and unpredictable when it comes to feelings of (in)consistency in and over time. The vocational self-concepts of student teachers at the start of teacher education differ significantly in terms of which past perceptions and future expectations are considered relevant attributes for the profession. This calls for attention to individual student teachers' sense-making and the experience of (dis)continuity when studying and designing teacher education programs. Also, vocational self-concepts of student teachers were found to change throughout teacher education, both in terms of when and how past perceptions, future expectations and associated feelings of (dis)continuity change. This calls for continued alertness towards changes in student teachers' sense-making and efforts to customize supervision accordingly. The third and fourth study in this dissertation showed that discontinuity can have a function in developmental progress, as long as it is counterbalanced with (future) experiences of continuity in supervision conversations. Both studies illustrated how personal and complex problems are a part of student teachers' development and, therefore, teacher educators' supervision. This calls for acknowledging that a sense of inconsistency can have a meaningful role in developmental progress: embracing uncertainty and doubt can be a valuable ingredient of elongated development, as long as it is expected that a sense of consistency can be reestablished.

\section{REFLECTIONS}

This thesis departed from various assumptions about student teachers' development and the frameworks and instruments developed in our studies should be considered and used within this conceptualization. We now reflect on the way in which these informed key concepts and the research design and accordingly account for what we can and cannot assert about student teachers' development.

\section{Reflections on Concepts}

In this dissertation, we considered student teachers' development in terms of the process of reflecting on one's self as a teacher. We focused on the idiosyncratic constellation of self-attributes considered relevant for the profession, the vocational self-concept (Super et al., 1963). Using the vocational self-concept allowed us to explore the perspective of the student teacher, including the different past perceptions and future expectations. We were able to describe student teachers' sense-making in a detailed and nuanced manner and, as well, focus on differences and changes of sense-making processes within and among student teachers. Our choice for focusing on the 
vocational self-concept in this dissertation did not allow us to describe student teachers' attributes from an outsider perspective. Also, we were not able to compare and contrast student teachers' sense-making and vocational self-concept with (assessments of) their performance in school practice.

We focused on sense-making throughout teacher education, including idiosyncratic past perceptions and future expectations relevant for the profession according to the student teacher, this allowed us to study student teachers' development beyond the boundaries of teacher education. For student teachers, development as a teacher concerns a reflective process that starts the moment he or she starts to think about teaching as a career option. Sense-making includes actively and iteratively giving meaning to new experiences, also possibly beyond the context of teacher education, that provide information about the current and imagined self as teacher (Kelchtermans, 2005; Korthagen, 2005; Rodgers a Scott, 2008). We were able to explore how experiences before the start of teacher education and/or with family or friends outside of teacher education can also be relevant for reflections on self-attributes. Our focus on the student teachers' sense-making did not allow us to describe how others value the student teachers' developmental trajectory or how student teachers themselves valued their developmental progress after graduating teacher education.

By focusing on experiences of discontinuity in relation to experiences of continuity in the sense-making of student teachers, we acknowledged the challenges and strains related to student teacher development (cf. Alsup, 2006; Beijaard it Meijer, 2017). Our focus enabled us to illustrate how development throughout teacher education can be discomforting and difficult as well as energizing and hopeful, helping us to gain a detailed understanding of how experiences that are common in teacher education can elicit different emotions in different student teachers. By focusing on experiences of discontinuity in Chapters 4 and 5, we were also able to explore how disruption and insecurity can be a functional part of development as a professional in an educational setting. Our focus limited us in elaborating on when, how or why experiences of continuity are addressed between teacher educators and student teachers.

By focusing on the dialogical and interactive nature of supervision conversations in teacher education, we were able to describe how perceptions of the past, expectations of the future and associated experiences of (dis)continuity are discussed and changed in relation to the input of others (cf. Lyra, 1999). This focus provided a detailed understanding of how student teachers and teacher educators together make sense of the ongoing development of the student teacher. By focusing on supervision conversations, we disregarded how issues such as trust and rapport in the supervision relationship are related to the input of both student teachers and teacher educators.

\section{Reflections on Design and Context}

In the design of this dissertation, we invested in collecting original data sources of student teach- 
ers and teacher educators in teacher education, including authentic teacher profiles and natural supervision conversations at various points throughout teacher education. This natural design was time-consuming as well as labor intensive (Leonard-Barton, 1990); it also enabled us to describe development holistically from the unfolding perspective of student teachers and teacher educators, and, as it happened, also included cases of student teachers who decided to quit teacher education.

The authentic data sources were collected in a one-year, post-master's teacher education program $^{12}$, that is characterized by the pedagogy of realistic teacher education, including a concern-based approach and an emphasis on learning from experiences in connection to theory (Korthagen et al., 2001). The teacher educators in this program can autonomously schedule supervision conversations and are trained in stimulating reflection on experiences in student teachers and adapting supervision to the needs of learners. The findings of our studies should be seen in light of associated assumptions about student teachers' development and teacher educators' supervision approaches.

In terms of study design, being a teacher educator in the same teacher education program that was selected to collect data was beneficial for gaining access to a large sample of unique data sources of a sensitive nature. In terms of analysis, awareness of the complexity of supervision of experiences of (dis)continuity from an insider perspective contributed to the detailed analysis of the data. Yet, the closeness of the researcher to the participants and the teacher education program was also challenging because of feelings of loyalty and potential bias because of preassumptions in analysis and interpretation. Because of this, we included checks for trustworthiness and transparency such as executing an audit trail, interrater reliability and discussing preliminary results with significant others (i.e. other researchers, school-based teacher educators). We also discussed analyses and results iteratively in the research team, in which experience in and with teacher education was combined with broader educational research perspectives.

\section{LIMITATIONS AND FUTURE RESEARCH}

In our studies, we focused on student teachers' perceptions, supervision conversations and teacher educators' support of student teacher development in terms of experiences of (dis)continuity. Our choices resulted in a number of limitations that additional instruments and/or approaches could supplement in future research. An analysis of the content of student teachers' practice dossiers discussed in the supervision conversations could have added to our insights

\footnotetext{
12 Student teachers can also complete the program in two years when they study part-time, for instance because they combine studying with a paid job in teaching or when they participate in one of the Education and Communication Master programs, in which subject specific courses in the domain of teaching and learning of school subject (the domain of these master programs) are combined with courses with a focus on preparing students for teaching the subject as teachers.
} 
about past perceptions, future expectations and associated experiences of (dis)continuity in the sense-making of student teachers. We also think that the results of the studies in this dissertation could have benefited from including and analyzing interviews with the participating student teachers. Interviews would have allowed an exploration of how student teachers value teacher educators' support when experiencing of continuity and discontinuity and, as well, their perceptions of teacher educators indicating the necessity of change in supervision conversations. To broaden our perspective on the nature of the support of student teachers' sense-making it would have been interesting to extend our data collection with data from mentor teachers and school-based teacher educators. For instance, audiotaped supervision conversations between the participating student teachers and their school mentors would have allowed an exploration of similarities and differences in discussing (dis)continuities, as the institute and school have been described as different practices within a teacher education program.

The limitations and results of the studies in this dissertation point towards different avenues for further research. To explore the alignment of the perceptions of student teachers, teacher educators, and other supervisors involved, we recommend that future research explores how student teachers' vocational self-concepts relate to the perceptions of significant others. This could enable an understanding of a communal language for discussing perceptions and expectations. Moreover, future research could consider the relation between student teachers' sense-making and teaching performance. Additionally, future research could focus on stabilities and changes of teachers' sense-making during teacher education in relation to the first and later stages of one's professional career in order to explore if and how teachers' sense-making changes after graduation. We recommend that, in future research, the balance between experiences of continuity and discontinuity that is beneficial for developmental progress will be explored.

Future research, for instance, could study the relation between experiences of discontinuity and feelings of resilience (Johnson et al., 2014). For school leaders and policy makers it would also be interesting to explore if and how experiences of discontinuity and continuity come to the fore in work role transitions (cf. Ibarra \& Barbalescu, 2010), such as when teachers work in school reforms, change schools or take up new tasks or roles in a school; this could afford a better understanding of teacher attrition. Also, since the student teachers in these studies felt free to introduce experiences of discontinuity, even though the teacher educators were also responsible for assessing the student teachers, we recommend exploring benefits and challenges of teacher educators' combining assessment and supervision. Moreover, we think it would be worthwhile to investigate when student teachers feel confident enough to introduce experiences of discontinuity in supervision.

The collection and analysis of the authentic data sources was both time-consuming as well as labor-intensive, but resulted in instruments and analytic-schemes that now could be used on a larger-scale to explore the past perceptions, future expectations, and experiences of (dis)continuity of (student) teachers. We propose further research to explore how experiences of discontinuity are discussed in various types of teacher education programs, for example ones that include 
alternative approaches for student teachers' reflection and adaptive supervision, and ones that do not apply the pedagogy of realistic teacher education (Korthagen et al., 2001).

\section{SUgGestions fOR PRACTICE}

The studies in this dissertation can inform teacher education practice in a number of ways. We encourage teacher educators to include instruments and supervision conversations in teacher education that enable student teachers and teacher educators to discuss student teachers' identification with the profession and experiences of (dis)continuity in their development. Teacher profiles (cf. Chapter 2) proved to provide rich written reflections that allowed for tapping into idiosyncratic perceptions and expectations and the associated sense of consistency (or lack thereof) in development throughout teacher education. Also, the framework developed in Chapters 2 and 3 and presented in Appendix 1, can assist both student teachers and teacher educators in reflecting on past perceptions and future expectations. Since experiences of (dis)continuity were found to change unpredictable over time, we recommend that student teachers and teacher educators pay attention to changes of the teacher profile after the start of teacher education and regularly discuss experiences of (dis)continuity.

Reflections on the constellation of self-attributes and associated feelings of (in)consistency and changes therein can be framed by the questions elaborated on in Chapter 4, summarized in Table 2 of this chapter. The results of the studies in this dissertation show that discussing development in terms of progress, attributes and doubts assists student teachers and teacher educators in balancing experiences of discontinuity with continuity, which enables developmental progress. Chapter 5 illustrates how teacher educators consider indicating change for development as a teacher, allowing for specific reflections on interpretations of professional standards, student teachers' attributes and timing of indicating change.

The suggestions for practice appeal to the teacher educator as a professional who is willing to take responsibility and be accountable for supervising development that is inherently complex, dynamic and often pertaining sensitive issues. We recommend that teacher educators be acknowledged and supported for taking this responsibility. For us, this implies that:

- Teacher education programs enable teacher educators to put time and effort in getting to know the individual student teachers they support.

- Teacher education programs provide possibilities for regular checks of teacher educators' observations and perceptions throughout teacher education.

- Teacher educators can rely on their peers to discuss possible risks and discomfort associated with supporting development and experiences of discontinuity. This collegial consultation could also contribute to explicating and attuning interpretations of student teachers' development, teacher educator' specific standards and teacher education program broad standards. 


\section{References}

Ahonen, Elsi, Kirsi Pyhältö, Janne Pietarinen, and Tiina Soini. 2015. Student Teachers' Key Learning Experiences Mapping the Steps for Becoming a Professional Teacher. International Journal of Higher Education 4 (1): $151-165$.

Akkerman, S., Admiraal, W., Brekelmans, M., a Oost, H. (2008). Auditing quality of research in social sciences. Quality $\circlearrowright$ Quantity, 42(2), 257-274.

Akkerman, S. F., ¿t Bakker, A. (2011). Boundary crossing and boundary objects. Review of educational research, 81(2), 132-169.

Akkerman, S. F., At Meijer, P. C. (2011). A dialogical approach to conceptualizing teacher identity. Teaching and Teacher Education, 27(2), 308-319. doi: 10.1016/j.tate.2010.08.013

Alsup, J. (2006). Teacher identity discourses: Negotiating personal and professional spaces. Mahwah, NJ: Lawrence Erlbaum Associates.

Audétat, M. C., Laurin, S., Dory, V., Charlin, B., \& Nendaz, M. R. (2017). Diagnosis and management of clinical reasoning difficulties: Part I. Clinical reasoning supervision and educational diagnosis. Medical teacher, 39(8), 792-796.

Beauchamp, C., \& Thomas, L. (2009). Understanding teacher identity: An overview of issues in the literature and implications for teacher education. Cambridge Journal of Education, 39(2), 175-189. doi: $10.1080 / 03057640902902252$

Beauchamp, C. (2015). Reflection in teacher education: issues emerging from a review of current literature. Reflective Practice, 16(1), 123-141.

Beijaard, D., Meijer, P. and Verloop, N. (2004). Reconsidering research on teachers' professional identity. Teaching and Teacher Education, 20: 107-128.

Beijaard, D., A Meijer, P. C. (2017). Developing the personal and professional in making a teacher identity. In D. J. Clandinin i J. Husu (Eds). The SAGE Handbook of Research on Teacher Education (pp. 177-192). London, England: Sage Publications.

Beltman, S., Mansfield, C. a Price, A. (2011). Thriving not just surviving: A review of research on teacher resilience. Educational Research Review, 6(3), 185-207.

Boeije, H. (2002). A purposeful approach to the constant comparative method in the analysis of qualitative interviews. Quality and Quantity, 36(4), 391-409.

Britzman, D. P. (2007). Teacher education as uneven development: Toward a psychology of uncertainty. International Journal of Leadership in Education, 10(1), 1-12.

Bronkhorst, L. H., Meijer, P. C., Koster, B., đ Vermunt, J. D. (2011). Fostering meaning-oriented learning and deliberate practice in teacher education. Teaching and teacher Education, 27(7), 1120-1130.

Bronkhorst, L. H., van Rijswijk, M. M., Meijer, P. C., Koster, B., A Vermunt, J. D. (2013). University teachers' collateral transitions: continuity and discontinuity between research and teaching. Infancía y Aprendizaje, 36(3), 293-308.

Bronkhorst, L. H., Koster, B., Meijer, P. C., Woldman, N., đt Vermunt, J. D. (2014). Exploring student teachers' resistance to teacher education pedagogies. Teaching and Teacher Education, 40, 73-82.

Bronkhorst, L. H., Meijer, P. C., Koster, B., đ Vermunt, J. D. (2014). Deliberate practice in teacher education. European Journal of Teacher Education, 37(1), 18-34. 
Brouwer, N., ¿t Korthagen, F. A. J. (2005). Can teacher education make a difference? American Educational Research Journal, 42(1), 153-224.

Bruner, J. S. (1990). Acts of meaning. Cambridge, MA: Harvard University Press.

Buckner, R. L., ct Carroll, D. C. (2007). Self-projection and the brain. Trends in Cognitive Sciences, 11(2), 49-57.

Byrd, D., Ct Fogelman, J. (2013). The role of supervision in teacher development. In A. Cuenca (Eds.), Supervising student teachers: Issues, perspectives, and future directions (pp. 191-210). New York, NY: Sense

Carpentier, J., at Mageau, G. A. (2013). When change-oriented feedback enhances motivation, well-being and performance: A look at autonomy-supportive feedback in sport. Psychology of Sport and Exercise, 14(3), 423-435.

Caspi, A., Ċ Moffitt, T. E. (1991). Individual differences are accentuated during periods of social change: the sample case of girls at puberty. Journal of Personality and Social Psychology, 61(1), 157-168. doi: 10.1037/00223514.61.1.157

Caspi, A., Ct Roberts, B. W. (2001). Personality development across the life course: The argument for change and continuity. Psychological Inquiry, 12(2), 49-66.

Cole, A. L., ¿t Knowles, J. G. (1993). Shattered images: Understanding expectations and realities of field experiences. Teaching and Teacher Education, 9(5), 457-471.

COLUU (Centrum voor Onderwijs en Leren Universiteit Utrecht) (2013). Zelfevaluatierapport Eenjarige Educatieve Masteropleidingen. Utrecht: Universiteit Utrecht.

Conway, P. F. (2001). Anticipatory reflection while learning to teach: From a temporally truncated to a temporally distributed model of reflection in teacher education. Teaching and Teacher Education, 17(1), 89-106.

Crasborn, F., Hennissen, P., Brouwer, N., Korthagen, F., ¿t Bergen, T. (2011). Exploring a two-dimensional model of mentor teacher roles in mentoring dialogues. Teaching and Teacher education, 27(2), 320-331.

Cuenca, A. (Ed.) (2013). Supervising student teachers: Issues, perspectives, and future directions: New York, NY Sense.

d'Argembeau, A., Lardi, C., Ct Van Der Linden, M. (2012). Self-defining future projections: Exploring the identity function of thinking about the future. Memory, 20(2), 110-120.

Darling-Hammond, L., ¿t Bransford, J. (Eds.). (2007). Preparing teachers for a changing world: What teachers should learn and be able to do. John Wiley a Sons.

De Kleijn, R. A., Meijer, P. C., Brekelmans, M., đt Pilot, A. (2015). Adaptive research supervision: exploring expert thesis supervisors' practical knowledge. Higher Education Research $\circlearrowright$ Development, 34(1), 117-130.

Ecclestone, K., Biesta, G., at Hughes, M. (Eds.). (2009). Transitions and learning through the lifecourse. London: Routledge.

Eva, K. W. (2005). What every teacher needs to know about clinical reasoning. Medical education, 39(1), 98-106.

Ezzy, D. (1998). Theorizing narrative identity. The Sociological Quarterly, 39(2), 239-252. doi: 10.1111/j.1533-8525.1998. tboos02.x

Fedor, D. B., Davis, W. D., Maslyn, J. M., Ct Mathieson, K. (2001). Performance improvement efforts in response to negative feedback: The roles of source power and recipient self-esteem. Journal of Management, 27(1), 79-97.

Ferreira, T., Salgado, J., Cunha, C., Meira, M., ¿t Konopka, A. P. (2005). Talking about voices: A critical reflection about levels of analysis on the dialogical self. The dialogical self: Theory and research, 121-130.

Flores, M.A. (2014). The development of teacher professional identity: influencing contexts and inner tensions. In: J.M. Sancho, G. Correa, X. Giró at L. Fraga (Eds.) Aprender a Ser Docente En Un Mondo En Cambio (p. 45-55). Barcelona: University of Barcelona. 
Fransson, G., đ Grannäs, J. (2013). Dilemmatic spaces in educational contexts-towards a conceptual framework for dilemmas in teachers work. Teachers and Teaching, 19(1), 4-17.

Freeman, D. (1993). Renaming experience/reconstructing practice: Developing new understanding of teaching. Teaching and Teacher Education, 9(5), 485-497.

Fuller, F. F. (1969). Concerns of teachers: A developmental conceptualization. American educational research journal, 6(2), 207-226.

Gipe, J. P., at Richard, J. C. (1992). Reflective thinking and growth in novices' teaching abilities. Journal of Educational Research, 86(1), 52-57.

Greenwald, A. G., at Pratkanis, A. R. (1984). The self. In R. S. Wyer At T.K. Srull. (Eds.) Handbook of social cognition, $129-178$.

Habermas, T., a Bluck, S. (2000). Getting a life: the emergence of the life story in adolescence. Psychological Bulletin, 126(5), 748.

Hamman, D., Coward, F., Johnson, L., Lambert, M., Zhou, L., đt Indiatsi, J. (2013). Teacher possible selves: How thinking about the future contributes to the formation of professional identity. Self and Identity, 12(3), 307-336.

Hammerness, K., Darling-Hammond, L., Bransford, J., Berliner, D., Cochran-Smith, M., McDonald, M., at Zeichner, K. (2005). How teachers learn and develop. Preparing teachers for a changing world: What teachers should learn and be able to do, 358-389.

Hargreaves, A. (2005). Educational change takes ages: Life, career and generational factors in teachers' emotional responses to educational change. Teaching and Teacher Education, 21(8), 967-983.

Hermans, H. J. (2002). The Dialogical Self as a Society of Mind Introduction. Theory O Psychology, 12(2), 147-160.

Hermans, H.J. (2003). The construction and reconstruction of a dialogical self. Journal of Constructivist Psychology, 16(2), 89-130. doi: 10.1080/10720530390117902.

Hong, J. Y. (2010). Pre-service and beginning teachers' professional identity and its relation to dropping out of the profession. Teaching and teacher Education, 26(8), 1530-1543.

Hong, J., Greene, B., a Lowery, J. (2017). Multiple dimensions of teacher identity development from pre-service to early years of teaching: A longitudinal study. Journal of Education for Teaching, 43(1), 84-98.

Ibarra, H., A Barbulescu, R. (2010). Identity as narrative: Prevalence, effectiveness, and consequences of narrative identity work in macro work role transitions. Academy of management review, 35(1), 135-154.

Ingersoll, R. M., a Strong, M. (2011). The impact of induction and mentoring programs for beginning teachers a critical review of the research. Review of Educational Research, 81(2), 201-233.

Inspectie van het Onderwijs. (2019). De staat van het onderwijs: Onderwijsverslag 2017/2018. Utrecht: Inspectie van het Onderwijs.

Janssen, F., De Hullu, E., a Tigelaar, D. E. H. (2008). Positive experiences as input for reflection by student teachers. Teachers and Teaching: Theory and Practice, 14(2), 115-127. doi:10.1080/13540600801965903

Johnson, B., Down, B., Le Cornu, R., Peters, J., Sullivan, A., Pearce, J., đt Hunter, J. (2014). Promoting early career teacher resilience: A framework for understanding and acting. Teachers and Teaching, 20(5), 530-546.

Judge, T. A. (2009). Core self-evaluations and work success. Current Directions in Psychological Science, 18(1), 58-62. Kelchtermans, G. (2005). Teachers' emotions in educational reforms: Self-understanding, vulnerable commitment and micropolitical literacy. Teaching and Teacher Education 21(8), 995-1006.

Kelchtermans, G. (2009). Who I am in how I teach is the message: self-understanding, vulnerability and reflection. Teachers and Teaching: theory and practice, 15(2), 257-272. 
Kira, M., ¿t Balkin, D. B. (2014). Interactions between work and identities: Thriving, withering, or redefining the self? Human Resource Management Review, 24(2), 131-143.

Klein, S. B., At Gangi, C. E. (2010). The multiplicity of self: neuropsychological evidence and its implications for the self as a construct in psychological research. Annals of the New York Academy of Sciences, 1191(1), 1-15.

Koetsier, C. P., a Wubbels, T. (1995). Bridging the gap between initial teacher training and teacher induction. Journal of Education for Teaching, 21(3), 333-345.

Konstam, V. (2015). Floundering or Experimenting: Finding a Vocational Home. In V. Konstam (Ed.), Emerging and Young Adulthood (pp. 95-113). Springer International Publishing.

Korthagen, F.A.J. (2004). In search of the essence of a good teacher: towards a more holistic approach in teacher education. Teaching and Teacher Education, 20(1), 77-97.

Korthagen, F. A., Kessels, J., Koster, B., Lagerwerf, B., at Wubbels, T. (2001). Linking practice and theory: The pedagogy of realistic teacher education. Mahwah, $\mathrm{N}$ ): Routledge.

Leary, M. R., ¿t Tangney, J. P. (2003). The self as an organizing construct in the behavioral and social sciences. In M. R. Leary C J. P. Tangney (Eds.), Handbook of self and identity (pp. 3-14). New York, NY: Guilford.

Leonard-Barton, D. (1990). A dual methodology for case studies: Synergistic use of a longitudinal single site with replicated multiple sites. Organization science, 1(3), 248-266.

Lizzio, A., Wilson, K., at MacKay, L. (2008). Managers' and Subordinates' Evaluations of Feedback Strategies: The Critical Contribution of Voice 1. Journal of Applied Social Psychology, 38(4), 919-946.

Lortie, D. (1975). Schoolteacher: A sociological study. London: University of Chicago Press.

Loughran, J. (2014). Professionally developing as a teacher educator. Journal of Teacher Education, 65(4), 271-283.

Lyra, M. C. (1999). An excursion into the dynamics of dialogue: Elaborations upon the dialogical self. Culture $O$ Psychology, 5(4), 477-489. doi: 10.1177/1354067X9954006

Mansfield, C. F., A Volet, S. E. (2010). Developing beliefs about classroom motivation: Journeys of preservice teachers. Teaching and Teacher Education, 26(7), 1404-1415.

Markus, H., ¿t Nurius, P. (1986). Possible selves. American Psychologist, 41(9), 954.

Markus, H., ¿t Wurf, E. (1987). The dynamic self-concept: A social psychological perspective. Annual Review of Psychology, 38(1), 299-337.

McAdams, D. P. (1993). The stories we live by: Personal myths and the making of the self. New York: Morrow.

McLean, K. C., Pasupathi, M., at Pals, J. L. (2007). Selves creating stories creating selves: A process model of selfdevelopment. Personality and Social Psychology Review, 17(3), 262-278.

McLean, K. C., ct Pasupathi, M. (2011). Old, new, borrowed, blue? The emergence and retention of personal meaning in autobiographical storytelling. Journal of Personality, 79(1), 135-164

Mead, G. H. (1934). Self, mind, and society. Chicago: University of Chicago Press.

Meijer, P. C. (2011). The role of crisis in the development of student teachers' professional identity. In A. Lauriala, R. Rajala, H. Ruokamo, đt 0. Ylitapio-Mäntylä (Eds.) Navigating in educational contexts: Identities and cultures in dialogue (pp. 41-54). Rotterdam, The Netherlands: Sense.

Meijer, P. C., De Graaf, G., द Meirink, J. (2011). Key experiences in student teachers' development. Teachers and Teaching: theory and practice, 17(1), 115-129.

Middleton, M., Abrams, E., Seaman, J. (2011) Resistance and disidentification in reflective practice with preservice teaching interns. New Directions for Teaching and Learning, 126 (2011), pp. 67-75, 10.1002/tl.445 
Miles, M.B. Ct Huberman, A.M. (1994). Qualitative Data Analysis: An Expanded Sourcebook. Thousand Oaks, CA: Sage.

Norman, G. R., Monteiro, S. D., Sherbino, J., Ilgen, J. S., Schmidt, H. G., a Mamede, S. (2017). The causes of errors in clinical reasoning: cognitive biases, knowledge deficits, and dual process thinking. Academic Medicine, 92(1), 23-30.

Onafowora, L. L. (2005). Teacher Efficacy Issues in the Practice of Novice Teachers. Educational Research Quarterly, $28(4), 34-43$.

Pajares, M. F. (1992). Teachers' beliefs and educational research: Cleaning up a messy construct. Review of Educational Research, 62(3), 307-332.

Patton, M. (1990). Qualitative Evaluation and Research Methods, 169-186. Beverly Hills, CA: Sage.

Pillen, M., Beijaard, D., द den Brok, P. (2013). Professional identity tensions of beginning teachers. Teachers and Teaching, 19(6), 660-678.

Poli, R. (2010). The many aspects of anticipation. Foresight, 12(3), 7-17.

Polkinghorne, D. E. (1996). Explorations of narrative identity. Psychological Inquiry, 7(4), 363-367.

Poortman, C. L., A Schildkamp, K. (2012). Alternative quality standards in qualitative research? Quality $\circlearrowright$ Quantity, 46(6), 1727-1751.

Rehfuss, M. C. (2009). The future career autobiography: A narrative measure of career intervention effectiveness. The Career Development Quarterly, 58(1), 82-90.

Rodgers, C. and Scott, K. (2008). The development of the personal self and professional identity in learning to teach. In M. Cochran-Smith, S. Feiman-Nemser, D.J. McIntyre, and K.E. Demers (Eds.), Handbook of research on teacher education: Enduring questions and changing contexts (pp. 732-755). New York: Routledge.

Roese, N. J., at Vohs, K. D. (2012). Hindsight bias. Perspectives on psychological science, 7(5), 411-426.

Rots, I., Aelterman, A., a Devos, G. (2014). Teacher education graduates' choice (not) to enter the teaching profession: does teacher education matter?. European Journal of Teacher Education, 37(3), 279-294.

Sani, F. (Ed.), (2008). Self continuity: Individual and collective perspectives. New York, NY: Taylor a Francis.

Savickas, M. L. (1997). Career Adaptability: An Integrative Construct for Life-Span, Life-Space Theory. The Career Development Quarterly, 45(3), 247-259.

Shoffner, M. (2011). Considering the first year: Reflection as a means to address beginning teachers' concerns. Teachers and Teaching, 17(4), 417-433.

Slotter, E. B., a Gardner, W. L. (2014). Remind me who I am: social interaction strategies for maintaining the threatened self-concept. Personality and Social Psychology Bulletin, 49, 1148-1161.

Stokking, K., Leenders, F., De Jong, J., a van Tartwijk, J. (2003). From student to teacher: Reducing practice shock and early dropout in the teaching profession. European Journal of Teacher Education, 26(3), 329-350. doi: $10.1080 / 0261976032000128175$

Super, D. E. (1980). A life-span, life-space approach to career development. Journal of Vocational Behavior, 16(3), 282-298.

Super, D. E., Starishevsky, R., Matlin, N., đt Jordaan, J. P. (1963). Career development: Self-concept theory. New York, NY: College Entrance Examination Board.

Sutton, R. E., at Wheatley, K. F. (2003). Teachers' emotions and teaching: A review of the literature and directions for future research. Educational psychology review, 15(4), 327-358.

Swennen, A., Jones, K., ¿ Volman, M. (2010). Teacher educators: their identities, sub-identities and implications for professional development. Professional development in education, 36(1-2), 131-148. 
Tang, S. Y. F. (2003). Challenge and support: The dynamics of student teachers' professional learning in the field experience. Teaching and teacher education, 19(5), 483-498.

Tigchelaar, A., Brouwer, N., Ct Korthagen, F. (2008). Crossing horizons: Continuity and change during second-career teachers' entry into teaching. Teaching and Teacher Education, 24(6), 1530-1550.

United Nations Education, Scientific and Cultural Organisation Institute of Statistics (UNESCO). (2013). A teacher for every child: Projecting global teacher needs from 2015 to 2030 (UIS Fact Sheet, October 2013, No. 27). Retrieved from http://www.uis.unesco.org/Education/Documents/fs27-2013-teachers-projections.pdf.

Van de Pol, J., Volman, M., at Beishuizen, J. (2010). Scaffolding in teacher-student interaction: A decade of research. Educational psychology review, 22(3), 271-296.

Vanlommel, K. (2018). Opening the black box of teacher judgement: the interplay of rational and intuitive processes (Doctoral dissertation, University of Antwerp).

Van Rijswijk, M., Akkerman, S. F., Schaap, H., \& van Tartwijk, J. (2016). Past perceptions and future expectations: Sensed (dis)continuity at the start of teacher education. Teaching and Teacher Education, 58, 99-108. doi: 10.1016/j.tate.2016.05.002

Van Rijswijk, M. M., Bronkhorst, L. H., Akkerman, S. F., a van Tartwijk, J. (2018). Changes in sensed (dis)continuity in the development of student teachers throughout teacher education. European Journal of Teacher Education, 41(3), 282-300.

Van Rijswijk, M.M., Bronkhorst, L.H.,van Tartwijk, J. đ Akkerman, S. F. (2019). Lerarenopleiders en studenten in gesprek over discontinuïteit in de ontwikkeling als leraar. Pedagogische Studiën, 96 (6), pp. 423-440.

Van Tartwijk, J., van Rijswijk, M., Tuithof, H., at Driessen, E. W. (2008). Using an analogy in the introduction of a portfolio. Teaching and Teacher Education, 24(4), 927-938.

Wang, H., Hall, N. C., A Rahimi, S. (2015). Self-efficacy and causal attributions in teachers: Effects on burnout, job satisfaction, illness, and quitting intentions. Teaching and Teacher Education, 47, 120-130.

Webb, S., at Warren, S. (2009). Who is the 'responsible learner'? Viewing learning careers through social narratives and recursive methodology. In J. Field, R. Gallacher, a R. Ingram (Eds.), Researching Transitions in Lifelong Learning (pp. 50-65). London: Routledge.

Wubbels, T. (1992). Taking account of student teachers' preconceptions. Teaching and Teacher Education, 8(2), 137-149.

Yin, R.K. (2009). Case study research: Design and Methods. Thousand Oaks, CA: Sage Publications.

Zembylas, M. (2003). Emotions and Teacher Identity: a post-structural perspective. Teachers and Teaching: Theory and Practice, 9(3), 213-238

Zittoun, T., Valsiner, J., Salgado, J., Gonçalves, M. M., Vedeler, D., at Ferring, D. (2013). Human development in the life course: Melodies of living. Cambridge: Cambridge University Press. 


\section{Nederlandse Samenvatting}

\section{ERVARINGEN VAN CONTINUÏTEIT EN DISCONTINUÏTEIT IN DE ONTWIKKELING VAN STUDENTEN IN DE LERARENOPLEIDING}

Tijdens de ontwikkeling van studenten in de lerarenopleiding zijn reflecties over hun zelfconcept als leraar vaak aan de orde. Als deze reflecties twijfels oproepen bij studenten kan dit grote gevolgen hebben, zoals stoppen met de opleiding of niet beginnen aan een baan als leraar, ondanks dat ze mogelijk wel geschikt zijn voor het beroep. Dit is in tijden van oplopende lerarentekorten een urgent probleem dat aandacht behoeft.

Onderzoekers die zich in de laatste decennia richten op de ontwikkeling van studenten in de lerarenopleiding maakten vaak gebruik van biografische bronnen en retrospectieve reflecties van studenten die de lerarenopleiding hebben afgerond. Op basis daarvan beschrijven veel van hen de "worstelingen" van studenten in de lerarenopleiding met hun ontwikkeling als leraar.

Een van die worstelingen doet zich voor wanneer studenten ervaren dat de eigenschappen die ze zichzelf toekennen niet goed aansluiten bij het beroep of wanneer eigenschappen die ze nodig achten voor het uitoefenen van het beroep (nog) ontbreken. In dit proefschrift beschrijven we dit als een ervaring van discontinuïteit in de ontwikkeling als leraar.

We rapporteren in dit proefschrift over vier studies die als doel hebben continuïteit en discontinuïteit in de ontwikkeling van individuele studenten tijdens de lerarenopleiding beter te kunnen begrijpen, ongeacht of ze die opleiding wel of niet afronden. In deze vier studies worden bewust met name authentieke databronnen uit een universitaire lerarenopleiding geanalyseerd.

\section{THEORETISCH KADER}

In onze studies karakteriseren we het proces van reflecteren op ontwikkeling als leraar als idiosyncratisch, dynamisch en beladen. Het proces is idiosyncratisch omdat persoonlijke percepties van het verleden en verwachtingen voor de toekomst voor elke student uniek zijn. Het proces is dynamisch omdat nieuwe ervaringen steeds weer (nieuwe) reflecties oproepen. Het proces is beladen omdat dergelijke reflecties van invloed zijn op het gevoel van welzijn, bijvoorbeeld in het geval van nieuwe inzichten over jezelf die als onaangenaam ervaren worden. Van lerarenopleiders wordt verwacht dat zij studenten in de lerarenopleiding ondersteunen bij het reflecteren op hun ontwikkeling als leraar, hoewel niet precies duidelijk is wat die ondersteuning in zou moeten houden.

om recht te doen aan de karakteristieken van het proces van reflecteren op de ontwikkeling 
als leraar in de context van een lerarenopleiding, hanteren we in dit proefschrift het volgende conceptuele kader:

Om unieke reflecties van individuele studenten over hun ontwikkeling als leraar te kunnen duiden gebruiken we, in navolging van Super en collega's (1963), het zelfconcept als beroepsbeoefenaar (vocational self-concept): de constellatie van persoonlijke eigenschappen die door het individu als relevant voor het beroep wordt gezien.

We beschouwen het reflecteren over jezelf als leraar als een proces van intrapersoonlijke betekenisgeving (sense-making), dat narratief en dialogisch van aard is en dat steeds gevoed wordt door (nieuwe) ervaringen. Het reflecteren op je ontwikkeling als leraar kan uitmonden in ervaringen van continuïteit en/of discontinuïteit. Dit zijn gevoelens van consistentie of inconsistentie met betrekking tot huidige, of te ontwikkelen, eigenschappen die door de student als relevant voor het beroep worden ervaren.

- Over het algemeen hebben mensen een voorkeur voor ervaringen van continuïteit, omdat deze bijdragen aan zelfvertrouwen en het vermogen om ontwikkeling vol te houden.

Ervaringen van discontinuïteit worden vaak negatief opgevat omdat ze kunnen leiden tot afnemen van zelfvertrouwen, frustratie en een grotere kans op het stoppen met verdere ontwikkeling. Ervaringen van discontinuïteit kunnen echter ook het leren aanwakkeren en zijn mede daarom relevant voor studenten en lerarenopleiders.

- Tijdens de lerarenopleiding zijn ervaringen van discontinuïteit vanzelfsprekend. De eerste stappen in het beroep leiden immers vaak tot confronterende nieuwe ervaringen. Dergelijk ervaringen kunnen leerzaam zijn omdat het vocational self-concept helderder wordt en duidelijk wordt waar ontwikkeling nodig is. Ze kunnen ook risicovol zijn omdat ze kunnen leiden tot afnemend zelfvertrouwen en/of het overhaast of ondoordacht stoppen met de opleiding omdat de student vindt dat het beroep onvoldoende bij hem of haar past.

- Het reflecteren van studenten op hun ontwikkeling als leraar wordt beïnvloed door de lerarenopleider, onder andere omdat reflecties besproken worden in begeleidingsgesprekken. Die begeleidingsgesprekken zijn dialogisch van aard: de inbreng van student en lerarenopleider is niet eenrichtingsverkeer, geïsoleerd of onafhankelijk van elkaar, aangezien percepties van het verleden en verwachtingen voor de toekomst gezamenlijk worden besproken.

\section{CONTEXT}

De vier studies in dit proefschrift zijn uitgevoerd in een universitaire lerarenopleiding voor lesgeven in het voortgezet onderwijs die wordt aangeboden aan de Universiteit Utrecht. De meeste studenten doorlopen deze opleiding als een tweede (bekostigde) master van een jaar (60 studiepunten) na het behalen van een mastergraad in een domein dat verwant is van het schoolvak waarin ze les gaan geven. Een groeiende groep studenten doorloopt deze lerarenopleiding als 
onderdeel van een tweejarige master gericht op educatie en communicatie in het domein.

Het programma van deze lerarenopleiding is gebaseerd op de opleidingsdidactiek van het realistisch opleiden, met aandacht voor het aansluiten bij de concerns van studenten en het leren van ervaringen. Er wordt theorie aangereikt waarmee ervaringen geanalyseerd en beter begrepen kunnen worden, en de theorie krijgt betekenis door deze te verbinden met de ervaringen in de schoolpraktijk. Lerarenopleiders in deze opleiding verzorgen (vak)didactisch en pedagogisch onderwijs waarbij ze studenten stimuleren te reflecteren op hun ervaringen.

Lerarenopleiders begeleiden als mentor ook een aantal studenten individueel. Voor die begeleiding organiseren ze zelf een aantal begeleidingsgesprekken tijdens het opleidingsjaar, ook op verzoek van de studenten. Tenminste twee van die gesprekken staan formeel vast en hebben betrekking op het bespreken van het praktijkdossier, een portfolio waarin studenten hun kwaliteiten aantonen met behulp van bijvoorbeeld lesvoorbereidingen, video-opnames en reflecties.

\section{ONTWERP VAN DE STUDIES}

Om de ontwikkeling van studenten op verschillende momenten tijdens de lerarenopleiding te kunnen karakteriseren hebben we merendeels authentieke databronnen verzameld die ons in staat stelden te analyseren hoe studenten hun ontwikkeling tijdens de lerarenopleiding ervaren, ongeacht of ze de opleiding wel of niet afronden. We verzamelden:

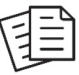

Leraarsprofielen: geschreven reflecties van studenten, bij aanvang van de lerarenopleiding, over de vraag "Wie denk je dat je bent als leraar?";

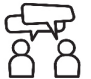

Begeleidingsgesprekken tussen studenten en lerarenopleiders, opgenomen met audio-recorders;

Interviews bij aanvang, in het midden en aan het eind van de opleiding met lerarenopleiders over de ontwikkeling van studenten en begeleidingsaanpakken.

We verzamelden de databronnen gedurende een studiejaar. Zie figuur 1 voor een overzicht van de dataverzameling. 


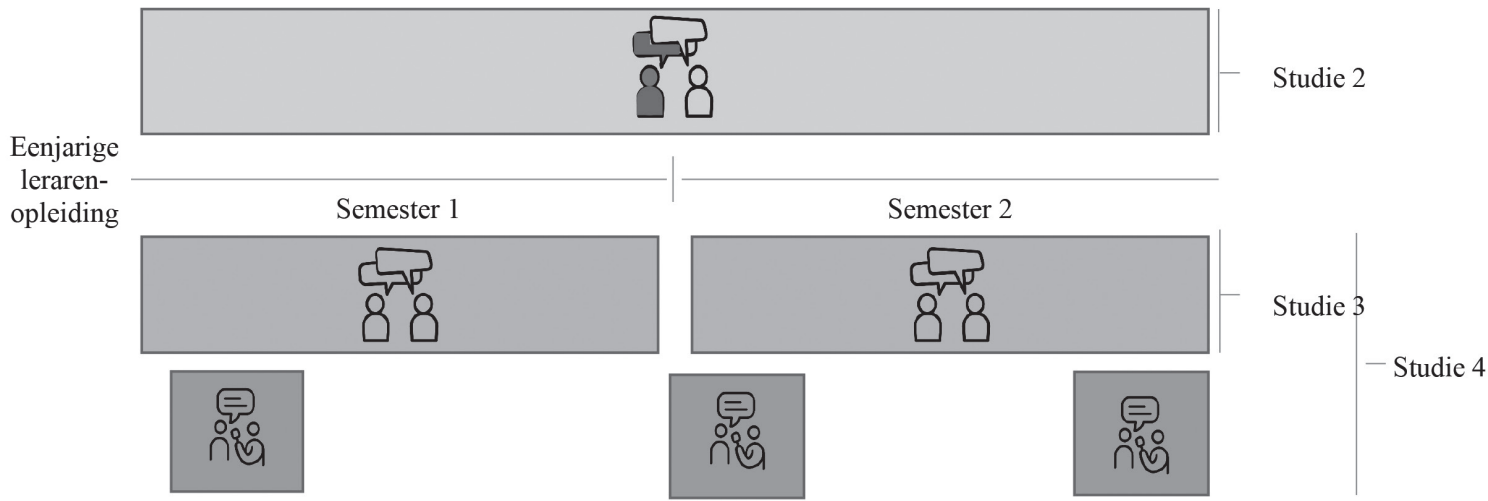

Figuur 1. Overzicht dataverzameling

\section{EMPIRISCHE STUDIES}

In de eerste studie, beschreven in hoofdstuk 2, onderzochten we hoe ervaringen van (dis)continuïteit ten aanzien van de ontwikkeling als leraar voorkomen bij verschillende studenten in de lerarenopleiding. Daarvoor richtten we ons op verschillen tussen de percepties en verwachtingen van studenten aan het begin van de lerarenopleiding. We onderzochten 35 leraarsprofielen om de volgende onderzoeksvraag te kunnen beantwoorden: "Hoe verschillen gerapporteerde zelfconcepten van studenten aan het begin van de lerarenleiding van elkaar in termen van kenmerken, percepties van het verleden, verwachtingen voor de toekomst en gevoelens van (dis)continuïteit?".

Studenten verschilden bij aanvang van de lerarenopleiding aanzienlijk van elkaar in de manier waarop ze zichzelf beschrijven als leraar en met welke kenmerken. We identificeerden vier typen percepties van het verleden en vier typen verwachtingen voor de toekomst in de leraarsprofielen. Deze percepties en verwachtingen vormen samen een raamwerk dat inzicht geeft in de mate waarin studenten continuïteit of discontinuïteit in ontwikkeling als leraar ervaren. We onderscheidden drie manieren van het ervaren van (dis)continuïteit, die illustratief zijn voor drie manieren waarop studenten zich met het beroep identificeren bij aanvang van de lerarenopleiding.

Veertien van de 35 profielen gaven een algemeen gevoel van continuïteit weer: een ervaring van consistentie in ontwikkeling als leraar gezien eerdere ervaringen en verwachtingen voor de toekomst. Deze profielen suggereerden een positieve houding ten opzichte van de ontwikkeling als leraar, wat over het algemeen als gunstig wordt gezien voor voortgang in ontwikkeling. Een algemeen gevoel van continuïteit kan echter ook risicovol zijn, bijvoorbeeld als studenten het nalaten om veranderingen te overwegen, ze een vals gevoel van onfeilbaarheid krijgen en/of ze 
hard en onverwacht geconfronteerd worden met inconsistentie in de ontwikkeling door nieuwe ervaringen tijdens de opleiding.

Dertien van de 35 leraarsprofielen lieten een gemengde ervaring van continuïteit en discontinuïteit zien: een gevoel van consistentie op basis van ervaringen uit het verleden en een gevoel van inconsistentie ten aanzien van de toekomstige ontwikkeling als leraar. Deze profielen illustreerden hoe studenten de ontwikkeling als leraar als een proces van verandering zien, met specifieke verbeterpunten. Eerdere ervaringen leken de problemen die men verwachtte in de toekomst te specificeren, ze gaven namelijk aanleiding tot specifieke zorgen bij het aangaan van nieuwe ervaringen in de onderwijspraktijk. Deze bevinding werpt een nieuw licht op de waarde van autobiografische reflecties tijdens de lerarenopleiding, aangezien deze dus ook kunnen leiden tot meer onzekerheid over toekomstige ontwikkeling.

Acht van de 35 leraarsprofielen gaven een ervaring van discontinuïteit weer: gevoelens van inconsistentie in ontwikkeling als leraar ten aanzien van zowel het verleden als de toekomst. Deze profielen zijn illustratief voor een beeld van de ontwikkeling van studenten in de lerarenopleiding als een uitdagend en veeleisend proces. Een algemeen gevoel van discontinuïteit kan leiden tot een selffulfilling prophecy: de verwachting van falen hindert ontwikkeling. Positief aan ervaring van discontinuïteit aan het begin van de opleiding kan juist zijn dat studenten zich bewust zijn van de uitdagingen die in de lerarenopleiding voor kunnen komen en voorbereid zijn op de noodzaak om deze uitdagingen tijdens de lerarenopleiding aan te gaan.

In de tweede studie, beschreven in hoofdstuk 3, onderzochten we de dynamiek van het proces van reflecteren op jezelf als leraar tijdens de lerarenopleiding met als doel om meer inzicht te krijgen in aanwijzingen voor het (on)succesvol verlopen van die ontwikkeling. We keken naar veranderingen in de manier waarop studenten (dis)continuïteit in ontwikkeling ervaren en verwachten. We bestudeerden de reflecties op het verleden en verwachtingen voor de toekomst zoals geuit door zes studenten in 25 begeleidingsgesprekken met hun lerarenopleider. De onderzoeksvraag was: Wanneer en met welk type percepties en verwachtingen verandert de initiële ervaring van (dis)continuïteit van studenten en de lerarenopleiding? De gedetailleerde analyse van de 25 begeleidingsgesprekken leverde een uitgebreid raamwerk op dat gebruikt kan worden om percepties van verleden en verwachtingen voor de toekomst bij studenten in de lerarenopleiding te kunnen herkennen

We vonden dat de ervaring van (dis)continuïteit op verschillende manieren verandert bij verschillende studenten en ook dat dit op verschillende momenten gebeurt. Het was niet mogelijk om een initieel gevoel van (dis)continuïteit te relateren aan een specifiek type ontwikkeling en/of het succesvol afronden van de lerarenopleiding. Slechts het ontwikkeltraject van één student uit deze studie vertoonde overeenkomsten met het ontwikkelpatroon dat vaker beschreven is in retrospectief onderzoek waarbij het te boven komen van ontgoocheling centraal staat. 0ok zagen we dat een student die enthousiast en met vertrouwen aan de lerarenopleiding begon, meer inzicht kreeg in (de eisen van) het beroep en daarop besloot om te stoppen met de opleiding, 
ondanks dat hij uitstekend functioneerde als leraar tijdens zijn stage.

De drie studenten die afstudeerden aan het eind van de opleiding lieten overwegend ervaringen van continuïteit zien in de laatste begeleidingsgesprekken. Het afronden van een ontwikkeltraject lijkt samen te vallen met het ervaren van consistentie in de ontwikkeling tot nu toe en vertrouwen in verdere ontwikkeling als professional. We zagen dat de drie studenten die onvoldoende continuïteit leken te ervaren stopten met de lerarenopleiding.

In de derde en in de vierde studie richtten we ons ook op de lerarenopleider als betrokkene bij het proces van reflecteren op de ontwikkeling als leraar door studenten, en richtten we ons specifiek op ervaringen van discontinuïteit. In de derde studie, waarover we rapporteren in hoofdstuk 4, onderzochten we de paradox die verbonden is aan het bespreken van discontinuïteit in ontwikkeling: het is zinnig problemen te analyseren om mogelijkheden voor ontwikkeling op kortere en langere termijn te verkennen, maar het is ook risicovol vanwege potentieel negatieve gevolgen voor de voortgang van die ontwikkeling. We bestudeerden de manier waarop lerarenopleiders en studenten ervaringen van discontinuïteit in begeleidingsgesprekken aan de orde stellen en bespreken en hoe dat doorgaande ontwikkeling van de student op kortere en langere termijn mogelijk maakt. We analyseerden daartoe 110 fragmenten uit 42 begeleidingsgesprekken. Het ging zowel om begeleidingsgesprekken in de eerste helft als in de tweede helft van de opleiding en om begeleidingsgesprekken met zowel een formeel als een informeel (niet beoordelend) karakter. De onderzoeksvraag was: "Hoe introduceren en verkennen studenten en lerarenopleiders discontinuïteit in ontwikkeling als leraar tijdens begeleidingsgesprekken in een eenjarige universitaire lerarenopleiding?"

op basis van de analyse van de 110 fragmenten konden we drie dialogische strategieën onderscheiden die door studenten en lerarenopleiders gebruikt worden om ervaringen van discontinuïteit te bespreken in de context van voortgaande ontwikkeling in de lerarenopleiding. Discontinuïteit was een gangbaar onderdeel van de begeleidingsgesprekken die we bestudeerden. Discontinuïteit werd zowel geïntroduceerd door studenten als door lerarenopleiders in verschillende typen gesprekken, zowel in de eerste en tweede helft van de opleiding als in informele en formele gesprekken. Studenten voelden zich veilig genoeg om discontinuïteit in te brengen, ook als de begeleidingsgesprekken een formeel, beoordelend karakter hadden. Het bespreken van soms complexe en persoonlijke onderwerpen is al met al een wezenlijk onderdeel van begeleidingsgesprekken in de lerarenopleiding, wat zou kunnen leiden tot gevoelens van onzekerheid en handelingsverlegenheid bij lerarenopleiders.

$\mathrm{Na}$ het introduceren van discontinuïteit bespraken lerarenopleiders en studenten samen de betekenis en richtten ze zich op het verkennen van mogelijkheden van voortgang in ontwikkeling. De dialogische strategieën die we identificeerden zijn 1) vertrouwen op ontwikkeling: accepteren dat er iets moet veranderen en vertrouwen dat dit zal lukken op basis van wat er al was en/of wat er komen zal, 2) compenseren vanuit het professionele zelfconcept: erkennen dat er een probleem of zwakke plek is en dat er andere, aanvullende kwaliteiten en vaardigheden zijn en 3 ) herwaarderen 
van de relevantie: heroverwegen van de discontinuïteit zelf in termen van bedreiging voor verdere ontwikkeling. Lerarenopleiders combineerden meestal de drie strategieën bij het bespreken van discontinuïteit.

Het bespreken van de discontinuïteit veranderde de ervaring van de student. Meestal veranderde de beleving van inconsistentie door het creëren van ruimte voor continuïteit naast de ervaring van discontinuïteit. Soms resulteerde het bespreken van discontinuïteit in het verdiepen of versterken van de ervaring van inconsistentie. Dit gebeurde als de student het probleem buiten zichzelf plaatste of als de student het probleem vergrootte.

Deze studie illustreert de dialogische aard van begeleidingsgesprekken in de lerarenopleiding, ook als het aankomt op reflecteren op twijfels over de ontwikkeling als leraar. De studie laat ook zien hoe inconsistentie in ontwikkeling als leraar besproken kan worden zonder dat er een oplossing voor het voorliggende probleem wordt aangedragen.

Omdat we in de derde studie zagen dat lerarenopleiders soms ook zelf twijfels over de ontwikkeling als leraar introduceren door de student te wijzen op de noodzaak tot veranderen, verkenden we in de vierde studie waarom en wanneer, en hoe lerarenopleiders hiertoe overgaan. Deze vierde studie is beschreven in hoofdstuk 5 . We verkenden het wijzen op de noodzaak tot veranderen door lerarenopleiders in het licht van de risico's en spanningen die kleven aan ervaringen van discontinuïteit voor de voortgang van ontwikkeling en in een context waarin uitgegaan wordt van aansluiten bij concerns van studenten en adaptieve begeleiding. We analyseerden 18 interviews en 37 fragmenten uit 42 begeleidingsgesprekken. De onderzoeksvraag was: "Waarom en wanneer, en hoe adresseren lerarenopleiders de noodzaak tot veranderen in begeleidingsgesprekken in een eenjarige universitaire lerarenopleiding?"

Lerarenopleiders wezen studenten op de noodzaak tot veranderen als ze meenden dat bepaalde eigenschappen van de student op dit moment niet goed pasten bij, of nog ontbraken voor, het beroep en als ze inschatten dat de student de verandering zou kunnen bewerkstelligen. Lerarenopleiders hadden verschillende overwegingen om over te gaan tot het wijzen op de noodzaak tot verandering. Deze overwegingen hadden betrekking op de waardering van de professionele standaarden, essentiële kenmerken van de student en de timing van het adresseren van de noodzaak tot veranderen.

We zagen dat het wijzen op de noodzaak tot veranderen gebeurde in verschillende typen gesprekken en op verschillende momenten in de opleiding. Soms wezen lerarenopleiders op de noodzaak tot veranderen op een sturende manier, door middel van mededelingen, met suggesties voor de aard van de verandering en met weinig reactie van de student. Vaker wezen lerarenopleiders op een meer genuanceerde manier op de noodzaak tot veranderen, door middel van interventies met aandacht voor het legitimeren van de interventie en het verder bespreken van de verandering met de student. In de interviews met de lerarenopleiders zagen we met betrekking tot overwegingen een vergelijkbare tweedeling. Soms lieten de lerarenopleiders geen twijfels zien over het aangeven dat verandering noodzakelijk was en/of over of de student in staat zou zijn om 
de verandering te bewerkstelligen. Vaker benoemden de lerarenopleiders genuanceerd hun overwegingen, reflecteerden ze op de noodzakelijkheid en haalbaarheid van de verandering en heroverwogen ze hun begeleidingsaanpak na verloop van tijd.

Deze studie toont dat het aangeven dat verandering nodig is in de ontwikkeling als leraar gedurende de lerarenopleiding beschreven kan worden als een complex proces waarbij verschillende actoren (ten minste de lerarenopleider en de student) en het moment in de opleiding op elkaar inspelen. Wijzen op de noodzaak tot veranderen doet een beroep op de verantwoordelijkheid en professionaliteit van de lerarenopleider.

De eerste twee studies van deze dissertatie laten zien dat de ontwikkeling van studenten in de lerarenopleiding gekarakteriseerd kan worden als idiosyncratisch en onvoorspelbaar. Dit vraagt om voortdurende aandacht voor veranderingen in de manier waarop studenten over zichzelf als leraar reflecteren. De derde en vierde studie laten zien dat discontinuïteit functioneel kan zijn in de ontwikkeling tijdens de lerarenopleiding. Om ervaringen van discontinuïteit productief te maken voor de ontwikkeling van de student als leraar, is het nodig om (de waarde van) dergelijke ervaringen en hieraan gekoppelde gevoelens van onzekerheid en twijfel in de ontwikkeling als leraar te erkennen.

\section{Reflecties op CONCEPten, OntWerp en CONTEXT}

De keuzes die we maakten bij het opzetten en ontwerpen van dit onderzoek kleuren de manier waarop de opbrengst van deze dissertatie benut kan worden voor verder onderzoek en de praktijk.

We bestudeerden de ontwikkeling van studenten in de lerarenopleiding als een proces van intrapersoonlijke betekenisgeving en keken naar de unieke constellatie van kenmerken die door de student als relevant voor het beroep wordt gezien. Anders dan bij het veelgebruikte concept professionele identiteit (van leraren) konden we hierdoor inzoomen op details en nuances die de studenten zelf belangrijk vinden en betrekken in hun reflecties. We konden ook de ervaringen bestuderen van voor en buiten de context van de lerarenopleiding die voor studenten relevant zijn.

Door ons te richten op ervaringen van discontinuïteit in relatie tot ervaringen van continuïteit creëerden we ruimte om te verkennen op welke manier de ontwikkeling van studenten in de lerarenopleiding een beladen proces is. We kregen zicht op pijnlijke, moeilijke maar ook hoopvolle, en krachtige aspecten die verbonden zijn aan de ontwikkeling als leraar. We kregen er ook meer inzicht in hoe ervaringen kunnen leiden tot verschillende emoties bij studenten. Door onze focus op ervaringen van discontinuïteit begrepen we beter hoe ontwrichtende ervaringen en onzekerheid functioneel zouden kunnen zijn in de ontwikkeling als professional.

Omdat we de begeleidingsgesprekken in de lerarenopleiding opvatten als dialogische conversaties, waarin beide betrokkenen van invloed zijn en op elkaar reageren, konden we nagaan hoe 
lerarenopleiders en studenten samen bijdragen aan betekenisgeving in de ontwikkeling als leraar.

Bij het uitvoeren van de studies investeerden we in het verzamelen van authentieke data om de dynamiek van de ontwikkeling van studenten in de lerarenopleiding van dichtbij te kunnen bestuderen. Hoewel tijdrovend en arbeidsintensief, stelde dit ons in staat om veranderingen in de ontwikkeling van studenten te beschrijven zonder verstorende effecten van het herwaarderen van de ontwikkeling in retrospectieve reflecties.

Het onderzoek in deze dissertatie werd uitgevoerd door een divers team voor wat betreft ervaring met de praktijk van de lerarenopleiding en onderwijswetenschappelijk onderzoek. Voor het verzamelen en analyseren van de grote verzameling unieke databronnen was het nuttig om zelf ook in de praktijk te staan en de taal en voorkomende spanningen rond de ontwikkeling van studenten in de lerarenopleiding van binnenuit te kennen. Deze betrokkenheid was ook uitdagend vanwege gevoelens van loyaliteit en het risico van vooringenomen interpretaties. Om negatieve gevolgen voor de studies te voorkomen voerden we verschillende betrouwbaarheidschecks uit, zoals het vaststellen van interbeoordelaarsbetrouwbaarheid en het uitvoeren van een audit-trail. Daarnaast zorgen uitgebreide en terugkerende reflecties op het conceptuele kader en tentatieve resultaten in het onderzoeksteam voor kwaliteitsbewaking.

\section{BEPERKINGEN EN VERDER ONDERZOEK}

De opzet en het ontwerp van dit onderzoek kent uiteraard ook zijn beperkingen en nodigt uit om te denken over vervolgonderzoek.

Door onze focus op het vocational self-concept en intrapersoonlijke reflecties was er geen ruimte om een beschrijving van kenmerken van studenten in de lerarenopleiding door anderen te betrekken in de analyse en/of een verbinding te maken met de prestaties als leraar van de student. Omdat we in deze studie vooral keken naar authentieke bronnen tijdens de ontwikkeling in de lerarenopleiding hebben we retrospectieve reflecties na afloop van de opleiding niet betrokken in het onderzoek. Vervolgonderzoek zou zich kunnen richten op de vraag of en hoe dergelijke reflecties van studenten en lerarenopleiders of stagebegeleiders overeenkomen en verschillen. We denken dat het ook goed is om te verkennen hoe verandering en stabiliteit in persoonlijke betekenisgeving tijdens de ontwikkeling als leraar zich verhoudt tot de beleving van die ontwikkeling later en de voortzetting van de ontwikkeling in de eerste jaren van de beroepsloopbaan, om begeleidingstrajecten in die periode te kunnen versterken.

In het onderzoek dat we hier hebben beschreven, lag de focus op ervaringen van discontinuïteit. Vervolgonderzoek zou zich ook kunnen richten op de betekenis van ervaringen van continuiteit in de ontwikkeling als leraar en in begeleidingsgesprekken. Daarbij is de balans tussen ervaringen van continuïteit en discontinuïteit interessant, bijvoorbeeld in relatie tot vraagstukken rond de ontwikkeling van veerkracht bij studenten in de lerarenopleiding en het opzetten van begeleidingstrajecten van onderwijsprofessionals die in transitie zijn. We zagen dat de studenten 
in onze studies zich vrij voelden om ervaringen van discontinuïteit aan te kaarten bij hun begeleider. Dit roept vragen op over hoe het de lerarenopleiders, die zowel begeleiden als beoordelen, is gelukt om hiervoor een veilige situatie te creëren.

om de opbrengst van het onderzoek in termen van aantallen en context uit te kunnen breiden, hopen we dat in vervolgonderzoek instrumenten en analyses (door)ontwikkeld worden die het mogelijk maken om vergelijkbare data op een minder arbeidsintensieve manier te verkrijgen. Dit maakt het makkelijker om grotere groepen studenten te bestuderen en om data te verzamelen binnen andere lerarenopleidingen, bijvoorbeeld in lerarenopleidingen voor primair onderwijs of opleidingen die werken vanuit andere opleidingsdidactische concepten.

\section{SUGGESTIES VOOR DE PRAKTIJK}

Deze dissertatie geeft een aantal aanknopingspunten voor de praktijk van de lerarenopleiding. Bovenal raden we lerarenopleiders aan om in hun onderwijs en begeleiding gebruik te maken van instrumenten en benaderingen die ruimte geven om onderwerpen als ervaringen van (dis)continuïteit in ontwikkeling te bespreken.

We zagen dat het schrijven van leraarsprofielen rijke beschrijvingen van relevante ervaringen, verwachtingen en kenmerken opleverde. Het raamwerk, dat in de studies van hoofdstuk twee en drie werd ontwikkeld, kan ingezet worden voor het analyseren en bespreken van dergelijke reflecties, ook om een breder perspectief op reflecties over jezelf als leraar te kunnen bieden. Omdat de manier van reflecteren over continuïteit en discontinuïteit verandert gedurende de opleiding en moeilijk te voorspellen is, raden we aan om met enige regelmaat aandacht te besteden aan percepties en verwachtingen van studenten in de lerarenopleiding.

Reflecties op kenmerken en gevoelens van continuïteit en discontinuïteit kunnen gevoed worden door de vragen die verbonden zijn aan de dialogische strategieën die gevonden werden in de studie van hoofdstuk 4. Deze vragen nodigen uit om na te denken over de balans tussen continuiteit en discontinuïteit in ontwikkeling en kunnen houvast bieden aan studenten en lerarenopleiders die te maken krijgen met ingewikkelde en persoonlijk problematiek.

Deze praktijksuggesties doen een beroep op de lerarenopleider als professional die bereid is om verantwoordelijkheid te nemen en aanspreekbaar te zijn in de complexe en dynamische begeleiding van studenten tijdens hun ontwikkeling als leraar. We vinden het belangrijk dat de professionaliteit van lerarenopleiders hierbij erkend en ondersteund wordt. Dit kan bijvoorbeeld door lerarenopleiders autonomie en ruimte te bieden bij het inrichten van hun begeleiding, waarbij er voldoende tijd is om de student en zijn of haar behoeftes te leren kennen. Om lerarenopleiders te kunnen ondersteunen bij het omgaan met handelingsverlegenheid of zorgen die op kunnen treden bij het begeleiden van de ontwikkeling van studenten met (heftige) twijfels over hun ontwikkeling als leraar, raden we lerarenopleidingen aan om tijd en ruimte te creëren voor professionele uitwisseling. 


\section{Curriculum Vitae}

Martine van Rijswijk was born in 1972 in Utrecht, the Netherlands. After completing secondary education (HAVO and VWO) she studied art history at Utrecht University. Subsequently, she studied in the teacher education program of Utrecht University (IVLOS). There, she discovered her love for teacher development, reflection and coaching.

She has been a teacher educator at Utrecht University since 2000. She has also worked as a trainer, with a focus on supporting student teachers' reflection, and was a member of the group that organized educational activities for teacher educators nationally and internationally ( $\mathrm{VvL}$ ). She was involved in several projects for VELON, the association for teacher educators in the Netherlands. Amongst others, she co-developed the new professional standard for teacher educators.

From 2012 she combined working as a part-time PHD-researcher with working as a teacher educator, member of the exam committee and, since 2017, as a coordinator of the courses Pedagogiek and Vakdidactiek. 


\section{Publications}

Van Rijswijk, M.M., Bronkhorst, L.H., van Tartwijk, J. đt Akkerman, S. F. (2019). Lerarenopleiders en studenten in gesprek over discontinuïteit in de ontwikkeling als leraar. Pedagogische Studiën, 96 (6), pp. 423-440.

Van Rijswijk, M.M., Bronkhorst, L.H., Akkerman, S. F. A van Tartwijk, J. (2018). Changes in sensed dis/continuity in the development of student teachers throughout teacher education. European Journal of Teacher Education, 41 (3), pp. 282-300.

Lunenberg, M., Berry, Amanda, van den Bos, Paul, Geursen, Janneke, Hagebeuk, Els, de Heer, A., Radstake, Jorien, van Rijswijk, M.M. \& Tuithof, J.I.G.M. (2018). Signposts, Profits, and Pitfalls in Teaching and Learning SelfStudy Research: A Conversation. In Jason K. Ritter, Mieke Lunenberg, Kathleen Pithouse-Morgan, Anastasia P. Samaras \& Eline Vanassche (Eds.), Teaching, Learning, and Enacting of Self-Study Methodology - Unraveling a Complex Interplay, pp. 163-174. Singapore: Springer.

Van Rijswijk, M.M., Bronkhorst, L.H., Akkerman, S. ¿t van Tartwijk, J.W.F. (2018). Supervision Dialogues in Teacher Education - Balancing Dis/continuities of the Vocational Self-Concept. Research on Teacher Identity, pp. 97-107. Cham: Springer.

De Heer, A., van Rijswijk, M.M. đt Tuithof, J.I.G.M. (2018). The researcher inside me - A quest for meaningful research in a shifting academic landscape. In Jason K. Ritter, Mieke Lunenberg, Kathleen Pithouse-Morgan, Anastasia P. Samaras A Eline Vanassche (Eds.), Teaching, learning and enacting of self-study methodology - Unraveling a complex interplay, pp. 149-162. Singapore: Springer.

Van Rijswijk, M.M., Akkerman, S. F., Schaap, H. ¿t van Tartwijk, J. (2016). Past perceptions and future expectations - Sensed dis/continuity at the start of teacher education. Teaching and Teacher Education, 58, pp. 99-108.

Van Rijswijk, M.M., Akkerman, S.F. đt Koster, B. (2013). Student teachers' internally persuasive borderland discourse and teacher identity. International Journal for Dialogical Science, 7 (1), pp. 43-60.

Bronkhorst, L.H., van Rijswijk, M.M., Meijer, P.C., Koster, B. đt Vermunt, J.D.H.M. (2013). University teachers' collateral transitions: Continuity and discontinuity between research and teaching. Infancia y Aprendizaje, 36 (3), pp. 293-308.

Van Rijswijk, M.M. ¿t Bronkhorst, L.H. (2013). Beelden van ontwikkeling: Identiteitsontwikkeling op het grensvlak van opleiden en onderzoek. Tijdschrift voor Lerarenopleiders, 34 (4), pp. 107-117.

Bronkhorst, L.H., van Rijswijk, M.M. A Suijker, J.C.B. (2012). Samenwerking in onderzoek naar de manier van leren van leraren in opleiding: De meerwaarde voor opleider en onderzoeker. Tijdschrift voor Lerarenopleiders, 33 (1), pp. 20-26.

Tigchelaar, A., Melief, K., van Rijswijk, M. đt Korthagen, F. (2010). Elementos de una posible estructura del aprendizaje realista en la formación inicial y permanente del profesorado. In K. Melief, 0. Esteve Ruescas at A. Alsina Castells (Eds.), Creando mi profesión: Una propuesta para el desarrollo profesional del profesorado, pp. 39-63. Barcelona: Ediciones Octaedro.

Tuithof, J.I.G.M., de Heer, A., van Rijswijk, M.M. A Bronkhorst, L.H. (2010). Schooladoptie: De betekenis van een vernieuwend en prikkelend project voor het opleiden van leraren. Tijdschrift voor Lerarenopleiders, 31 (3), pp. 33-39.

Van Tartwijk, J., van Rijswijk, M., Tuithof, H. It Driessen, E. W. (2008). Using an analogy in the introduction of a portfolio. Teaching and Teacher Education, 24 (4), pp. 927-938 
Van Tartwijk, J.W.F., van Rijswijk, M. đ Tuithof, H. (2005). De introductie van een portfolio aan de hand van een analogie. VELON : tijdschrift voor lerarenopleiders, 26 (3), pp. 24-30.

Oosterheert, I., Swennen, A. đt van Rijswijk, M. (2005). De ontwikkeling van leraren-in opleiding. In M. Commers, B. Oldeboom, M. van Rijswijk, M. Snoek, A. Swennen ¿t W. van der Wolk (Eds.), Leraren opleiden, een handreiking voor opleiders, pp. 31-45. Apeldoorn: Garant / VELON.

Van Rijswijk, M. A Oldeboom, B. (2005). Spiegel jezelf, leren van ervaringen door reflectie. In M. Gommers, B. Oldeboom, M. van Rijswijk, M. Snoek, A. Swennen \& W. van der Wolk (Eds.), Leraren opleiden, een handreiking voor opleiders, pp. 47-84. Apeldoorn: Garant / VELON.

Tigchelaar, A., Melief, K., van Rijswijk, M. đ Korthagen, F. (2005). Elemente eines möglichen Aufbaus reflexiven Lernens in der Leher ausbildung und Fortbildung. Seminar - Lehrerbildung und Schule, 11 (3), pp. 26-52. 


\section{Dankwoord}

"Dit is de leven,

En ik weet dat dit de leven is"

Sef - De leven $[A B C D]$

Larike Bronkhorst, Sanne Akkerman en Jan van Tartwijk: met en door jullie als begeleiders heb ik dit onderzoek af kunnen ronden. Ik startte het promotieonderzoek op met steun en begeleiding van Jan Vermunt, Harmen Schaap en Sanne. Dit waren de eerste stappen richting geloven dat onderzoek doen ook bij mij zou kunnen passen. Dank voor de duw in de rug!

Harmen, dank voor je zorg en betrokkenheid bij mijn ontwikkeling in een roerige periode in mijn leven, waarin werk even naar de achtergrond verdween. Je was een lijn naar de relevantie van werken in, en onderzoek doen naar, een lerarenopleiding.

Jan, als "baas" in de lerarenopleiding en als promotor, gaf je mij steeds het gevoel dat ik dit onderzoek zou kunnen volbrengen en dat ik interessante zaken aan de orde stelde. Het hielp me dat je op de juiste momenten vroeg of het allemaal nog te doen was en dat je mijn vrijdagmiddag cynisme zo nu en dan wilde incasseren.

Sanne, je was mijn inhoudelijk kompas bij dit onderzoek. Vol verbazing vertelde ik aanvankelijk thuis: zo leuk als ik het mentoraat in de lerarenopleiding vind, zo leuk vindt Sanne het schrijven van een artikel! Je hebt me uitgedaagd en gesteund en dankzij jou ontwikkelde ik liefde voor de kunst van het onderwijswetenschappelijk onderzoek.

Larike, wat fijn dat je bij ons onderzoeksteam bent gekomen! Je hebt het gevoel van samen onderzoek doen weten te bewaken en je hielp me navigeren tussen verschillende werelden, gedachtes en gevoelens. Jij zocht steeds met me mee en je erkent mijn ervaringen van continuïteit en discontinuïteit.

Sanne, Jan en Larike: voor mij was het uitvoeren van een onderzoek op het terrein van identiteitsontwikkeling als lerarenopleider en onderzoeker-in-opleiding boeiend en soms frustrerend. Reflecties op interventies, gesprekken, feedback en ontwikkeling waren er genoeg. Fijn dat jullie in die reflecties zo'n belangrijke rol speelden en dat ik op deze manier van jullie mocht leren. En vooral: dank voor de ruimte die jullie me gaven om het op mijn manier te doen.

Manon Kluijtmans, Paulien Meijer, Cok Bakker, Doret de Ruijter en Douwe Beijaard: ik ben blij dat jullie deel uit wilden maken van de leescommissie. Jullie gaven me op verschillende manieren inspiratie tijdens mijn promotietraject en ik vind het heel eervol dat jullie mijn proefschrift hebben beoordeeld. 
Dit onderzoek heb ik kunnen uitvoeren door de inzet van collega opleiders en hun studenten, die met vertrouwen toestonden dat ik gesprekken in de lerarenopleiding bestudeerde. Monica, Paul, Adrienne, Joke, Michel en 0tto: veel dank voor jullie werk en enthousiasme. Ik realiseer me dat ik door jullie open houding wat bij kan dragen aan inzicht in wat het vraagt om de ontwikkeling van studenten in de lerarenopleiding te begeleiden. Het onderzoek was soms zwaar, maar het bestuderen van de data bleef een feest en vervulde me steeds met trots. Esther, René en Marije: dank jullie wel voor het meedenken en ondersteuning bij het uitvoeren van mijn onderzoek!

Monica, Max, Els, Anna, Manon en Thea: dank voor het samen nadenken over onderzoek naar de identiteitsontwikkeling van professionals. Met en van jullie heb ik veel geleerd over mijn eigen weg zoeken en vinden in dit onderzoeksdomein.

Velen, binnen en buiten mijn werkomgeving, hielpen me om mijn ontwikkeling als onderzoeker door te zetten. Niet iedereen kan ik met naam en toenaam bedanken, maar weet dat ik me vaak gesteund voelde door betrokken vragen, relativerende opmerkingen en bemoedigende knikjes. Veel dank daarvoor!

Ari, Hanneke, Margriet, Lia, Gerrit Jan, Joke, Ineke, Karin, Jaap, Hanne, Hans, Karin, Felix, Joke, Jeroen, Tim, Marieke, Caroline, Janneke, Rosanne, Tamara, Ellie, Elise, Koen, Hanneke, Monika, Rosanne en vele, vele andere (oud)collega's uit lerarenopleiding, Educatie en Onderwijsadvies at Training: dank je wel voor jullie voor aandacht, professionaliteit en warmte. Het is fijn om in een omgeving te werken waar oog is voor elkaar en waardoor ik vaak een gevoel van thuis op het werk heb.

Bas, Jonne, Marloes, Luce, Steven, Esther, Mei en vele andere (oud)promovendi in alle soorten en maten op LV3 (en daar buiten): dank je wel voor het meeleven, het luisterend oor en de herkenning. Ik heb genoten van discussies en feestjes. Fijn dat jullie me hielpen onderzoeker te worden! Marieke, Hetty, Monica, Eva en Esther: wat fijn dat we samen in de fase van de laatste loodjes zaten, dank voor jullie openheid. Collega's van de leergang onderwijskundig leiderschap: dank jullie wel voor jullie belangstelling en ondersteuning in de laatste fase!

Jacqueline, Els, Marijn en Margreet, Amazones: dank jullie wel voor het samenwerken! Fijn om vloek, zucht, lach en traan te kunnen delen op de werkvloer. Bjorn en Els, dank jullie wel voor het elkaar in de gaten houden met en door intervisie.

Anke, Ko, Jeannette, Bob, Fred en Ria: veel dank voor de stevige basis die ik dankzij jullie ontwikkelde in het opleiden van leraren en het vertrouwen dat ik voelde toen ik als jonkie met jullie mocht samenwerken in OvL. Dank voor jullie kritische geesten en bemoedigende steun als ik die nodig had!

Marijke, Bruno en vele andere collega's die ik in VELON verband trof: dank jullie wel voor jullie enthousiasme en de saamhorigheid.

Ik prijs me gelukkig met werk, en een werkomgeving, waarbij ik me vaak als een vis in het water 
voel. Dat gevoel kan er zijn omdat er een sterke basis is van waaruit ik mijn werk kan doen. In de afgelopen jaren heb ik ervaren dat zo'n basis niet vanzelfsprekend is en ik voel me dan ook bevoorrecht met mensen om me heen die mij zien en waar ik op kan steunen.

Vrienden en vriendinnen van al lang, Jan, Ruth, Thirza, Sarah, Yael, Karen, Casper, Jacqueline, Sonja, Suus, Linda: dank jullie voor meeleven, relativering en het delen van veel mooie herinneringen.

Mede PVC-supporters: dank voor het samen blauwbekken, koffiedrinken en de gezelligheid. Een voetbaldag is (meestal) een vrolijke onderbreking van drukte van het werk. Maas Jan, Sahin, Fouad en Leonie: dank voor wat ik leerde als (assistent) teamleider. Ik hou me vaak jullie wijze lessen voor: het loopt wel los hoor, uiteindelijk!

Vrienden en vriendinnen van dichtbij, Jos, Renate, Rosanne, Jan Paul, Elles, Michel, Mariëlle en Hans: dank voor het letterlijk in de buurt zijn! Het was en is heel fijn te weten dat als ik het even niet meer weet ik altijd aan kan kloppen en jullie er voor me zijn.

Dansende vriendinnen, Renate, Marlou, Mariëlle en Karen: dank voor het feesten, dansen en lachen. Jullie zorgen voor broodnodige ontspanning op zijn tijd.

Vurige vriendinnen, Elles, Miranda, Marieke en Renate: dank voor het plezier en voor de wederzijdse waardering. Waardevol als je samen zo hard kan lachen en ook zorgen kan delen.

Paranimfen Bjorn en Marlou, dank je wel dat jullie mij terzijde willen staan! Bij jullie kan ik altijd terecht met zorgen, gemopper of lichte hysterie. Dank voor luisterende oren en aanmoedigingen, dank voor relativerende grappen en dank voor me soms beter kennen dan ik mezelf ken.

Familie Boel, en speciaal Pa en Ma, fijn dat ik ook bij jullie familie hoor. Het is waardevol te weten dat er altijd een achterban is waarop je terug op kan vallen. Machteld, Marcus, Janne, Daniël, Maaike en Matthias: dank jullie wel voor jullie vrolijkheid en energie. Er zijn maar weinigen die de kwalificatie tante Tientien mogen gebruiken van mij, maar jullie verdienen dat zeker!

Paula, Peter, Hanne en Lotte, wat fijn om te weten dat we er altijd voor elkaar zijn! Dank jullie wel voor het laten voelen dat goed soms goed genoeg is en dat jullie trots op me zijn. Dat helpt altijd.

Mam, dank je wel dat je me laat zien hoe ik een doorzetter kan zijn, dat vooruitkijken en zorgen in de ogen kijken krachtig is. Daar blijf ik van leren.

Papa, dank je wel dat jij altijd wist dat ik dit zou kunnen en dat je me dat met trots liet merken.

David, Alexander en Benjamin: dank jullie wel voor jullie mooie, lieve, stoere, grappige en standvastige aanmoediging en aandacht. Wat maken jullie van mij een rijk mens!

Christian: dank je wel voor wie je bent en voor hoe je mij ziet. We hebben veel om dankbaar voor te zijn. 


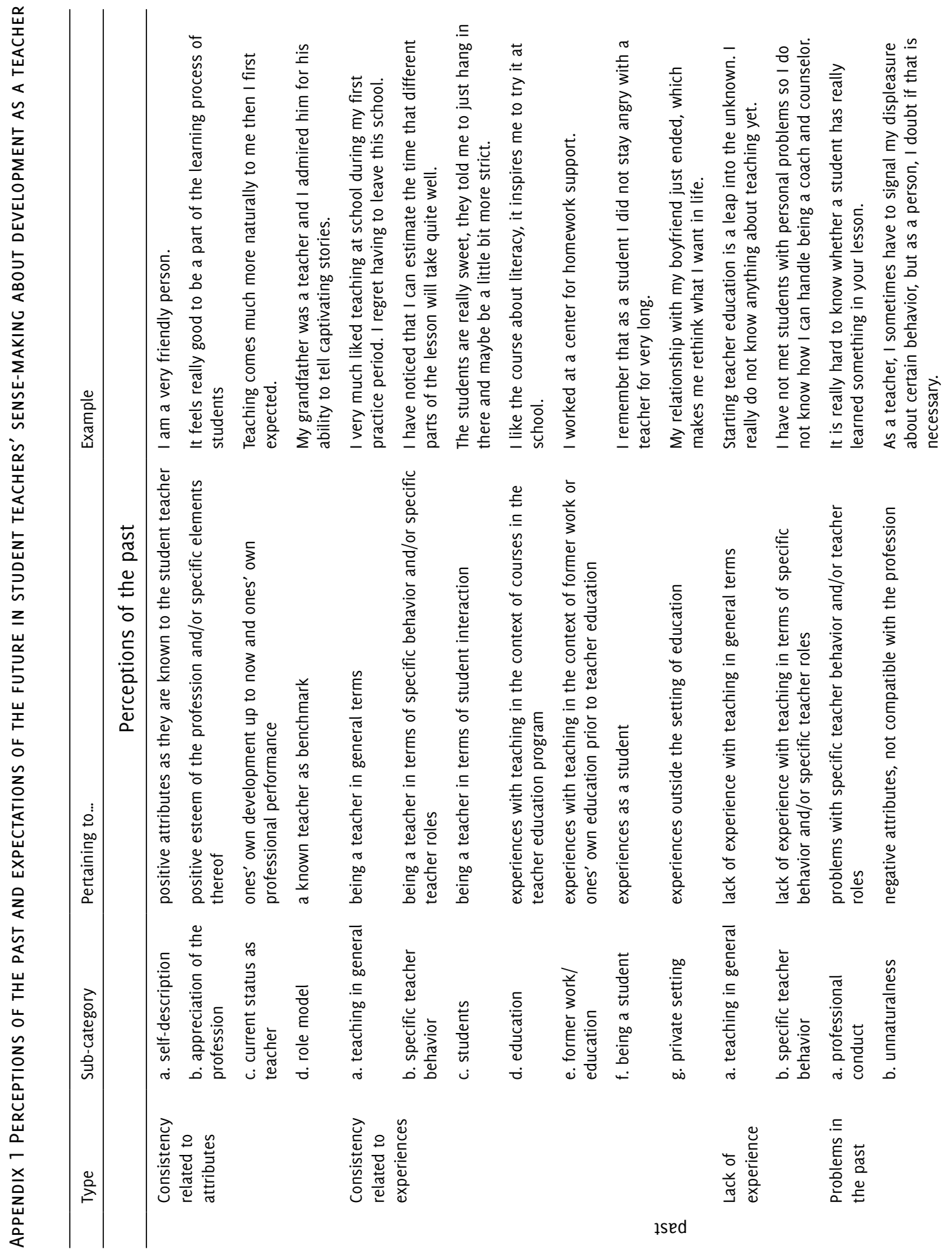




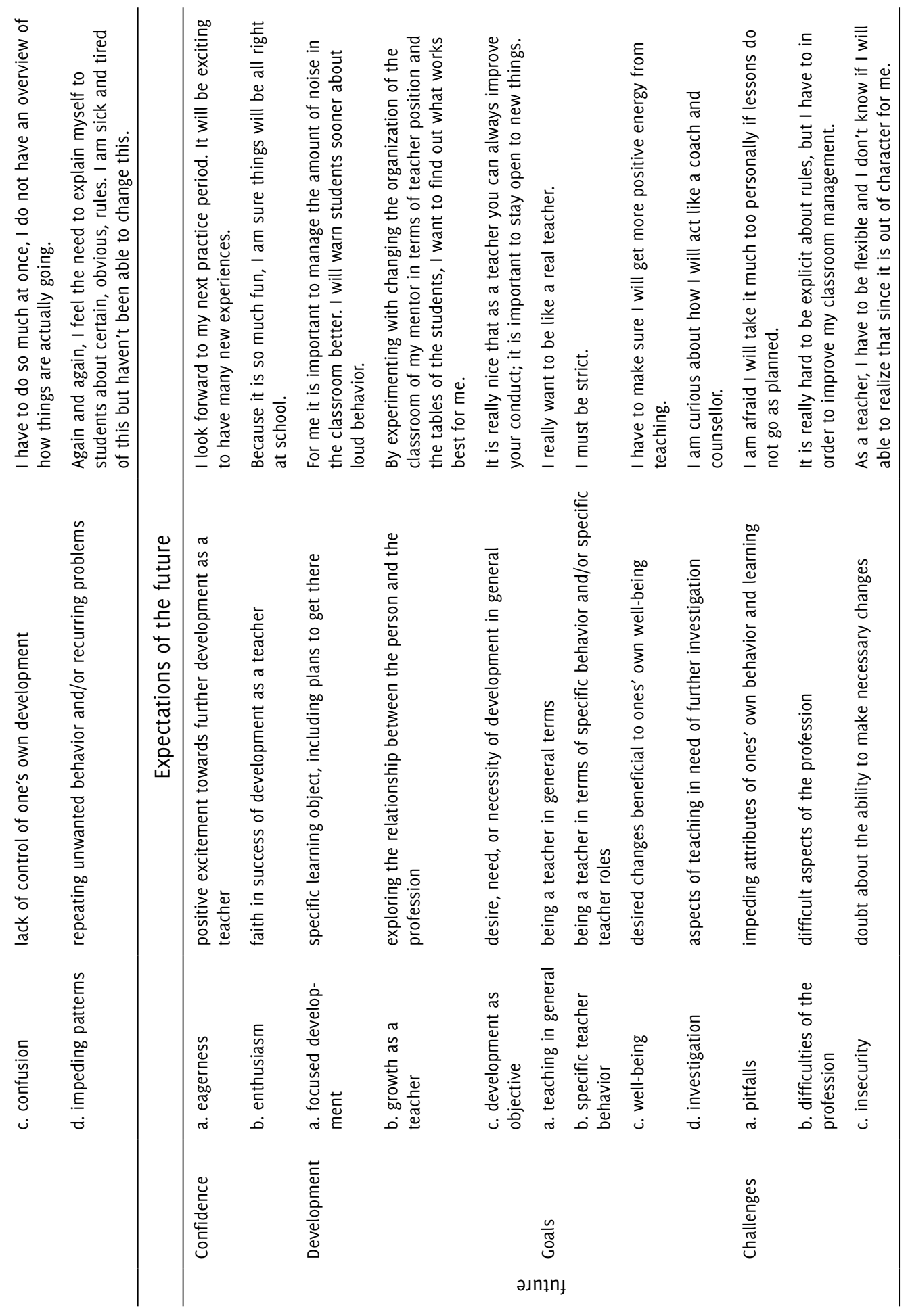





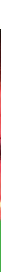

